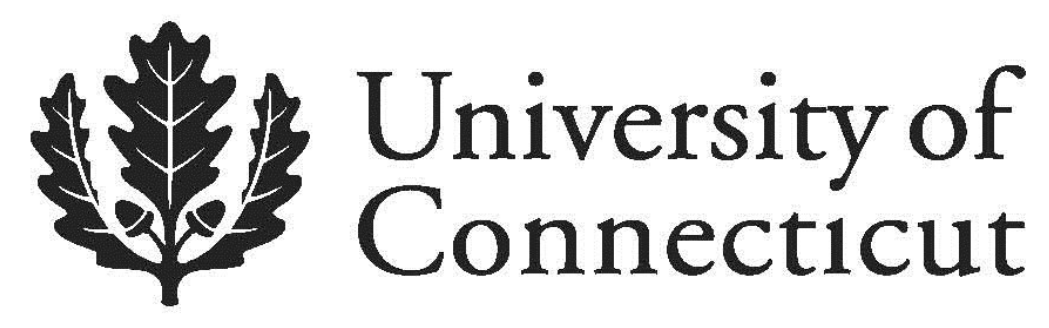

Department of Economics Working Paper Series

\title{
Change and Persistence in the Economic Status of Neighborhoods and Cities
}

Stuart S. Rosenthal

Syracuse University

Stephen L. Ross

University of Connecticut

Working Paper 2014-23

September 2014

365 Fairfield Way, Unit 1063

Storrs, CT 06269-1063

Phone: (860) 486-3022

Fax: (860) 486-4463

http://www.econ.uconn.edu/

This working paper is indexed on RePEc, http://repec.org 


\title{
Change and Persistence in the Economic Status of Neighborhoods and Cities
}

\author{
by \\ Stuart S. Rosenthal \\ Maxwell Advisory Board Professor of Economics \\ Department of Economics \\ Syracuse University \\ Phone: 315-443-3809 \\ Email: ssrosent@maxwell.syr.edu \\ Stephen L. Ross \\ Department of Economics \\ University of Connecticut \\ Storrs, CT \\ Phone: (860) 486-3533 \\ Email: stephen.1.ross@ucon.edu
}

September 22, 2014

Acknowledgements: We thank Matthew Turner, William Strange, Gilles Duranton, and Vernon Henderson for helpful comments. Nuno Mota provided excellent research assistance. The usual disclaimer applies. 


\begin{abstract}
This paper reviews recent literature that considers and explains the tendency for neighborhood and city-level economic status to rise and fall. A central message is that although many locations exhibit extreme persistence in economic status, change in economic status as measured by various indicators of per capita income is common. At the neighborhood level, we begin with a set of stylized facts, and then follow with discussion of static and dynamic drivers of neighborhood economic status. This is mirrored at the metropolitan level. Durable but slowly decaying housing, transportation infrastructure, and self-reinforcing spillovers, all influence local income dynamics, as do enduring natural advantages, amenities and government policy. Three recurring themes run throughout the paper: (i) Long sweeps of time are typically necessary to appreciate that change in economic status is common; (ii) history matters; and (iii) a combination of static and dynamic forces ensure that income dynamics can and do differ dramatically across locations but in ways that can be understood.
\end{abstract}

Key words: Neighborhood income dynamics; city income dynamics; durable housing; transportation infrastructure; spillovers; persistence, path dependence, and cycles.

JEL Codes: R0, R1, R2, R3, R4 


\section{Table of Contents}

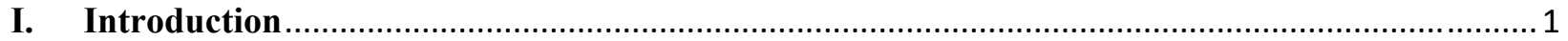

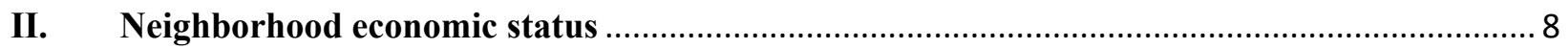

$2.1 \quad$ Four stylized facts about neighborhood economic status .......................................................... 8

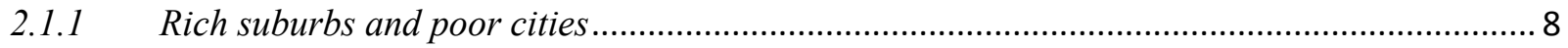

2.1.2 Change in neighborhood economic status is common ........................................................ 9

2.1.3 Mean reversion in neighborhood economic status is also common..................................... 10

2.1.4 Income segregation has increased in U.S. cities ................................................................. 13

2.2 Conceptual models of spatial variation in neighborhood economic status................................ 13

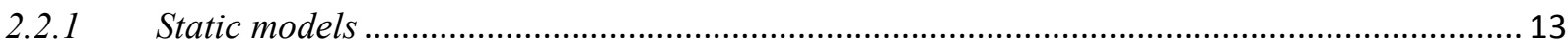

2.2.1.1 The "standard" model: Alonso (1964), Mills (1967), and Muth (1969) .............................. 13

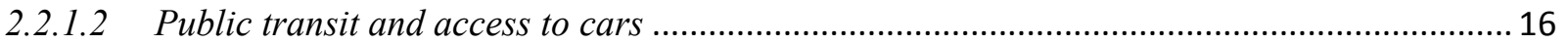

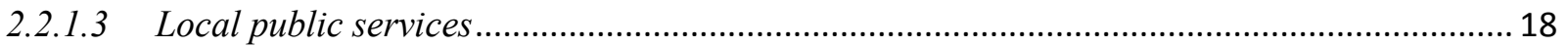

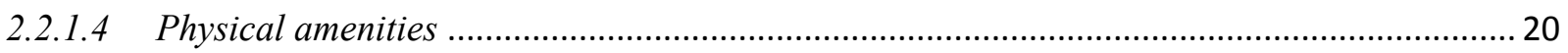

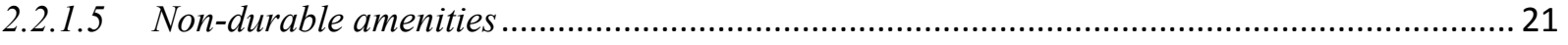

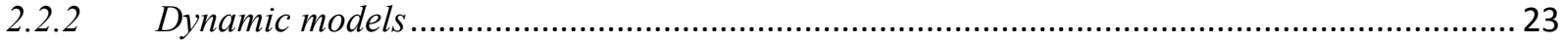

2.2.2.1 Durable housing, filtering and gentrification ................................................................ 23

2.2.2.2 Social dynamics, segregation and tipping, and homeownership ......................................... 25

$2.3 \quad$ Evidence of drivers of neighborhood economic status ............................................................. 33

$2.4 \quad$ The pace and timing of change in neighborhood economic status ........................................... 37

2.4.1 Home maintenance and depreciation of housing capital ..................................................... 38

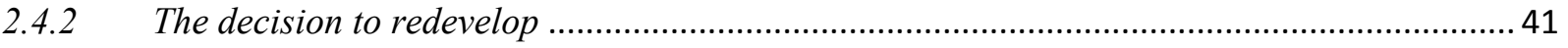

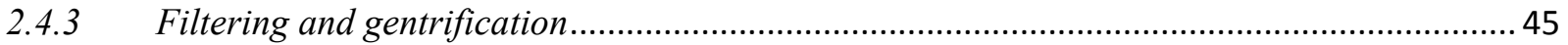

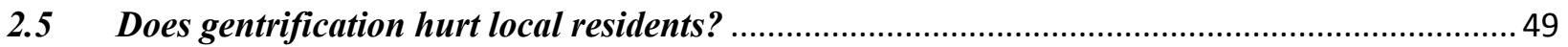

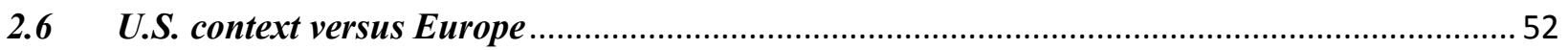

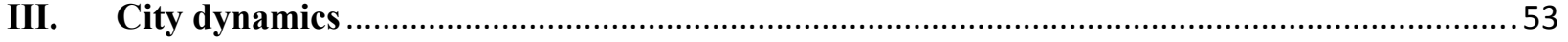

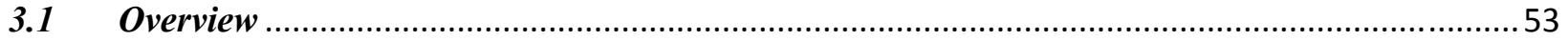

3.2 Three previous stylized facts and one new observation ............................................................... 54

3.2.1 Stable city size distributions that approximate the rank-size rule .......................................54

3.2.2 Slow movement of individual cities up and down the city size distribution ............................55

3.2.3 Fast changes in city industrial mix relative to total employment .........................................56 
3.2.4 Very fast movement of cities up and down in economic status based on income.

3.3 Drivers of persistence in metropolitan economic status .......................................................... 59

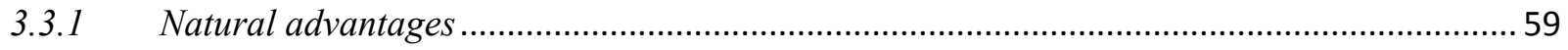

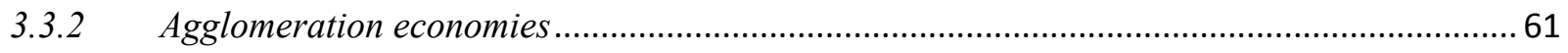

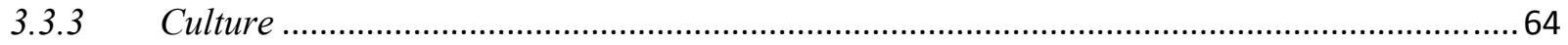

$3.4 \quad$ Drivers of change in metropolitan economic status .............................................................. 64

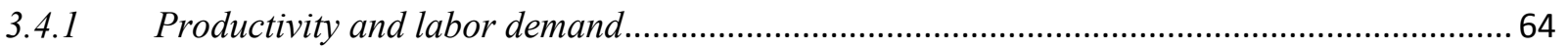

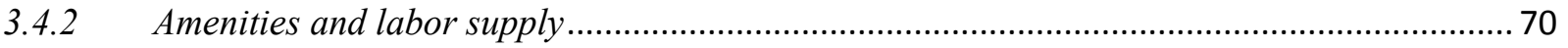

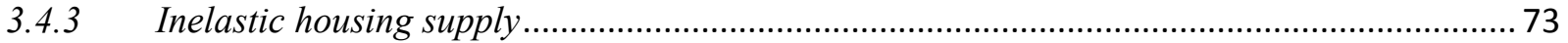

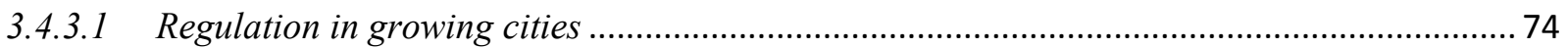

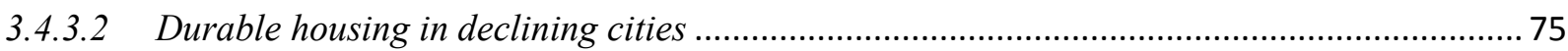

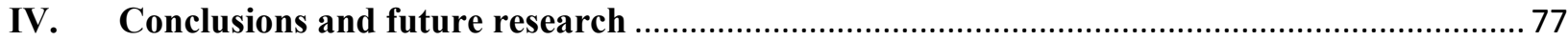

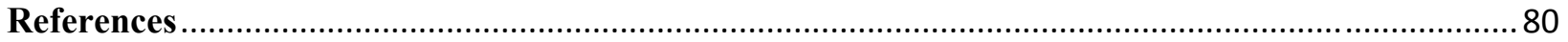

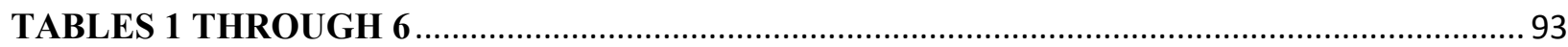

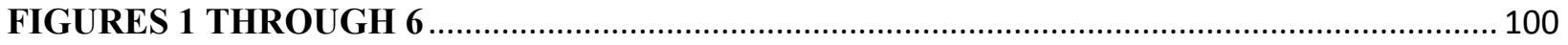

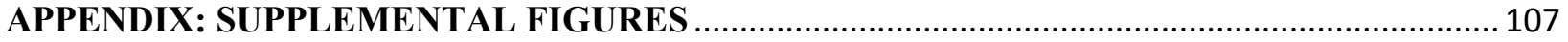




\section{Introduction}

At both the neighborhood and metropolitan levels, sharp differences in economic status are common. Within U.S. metropolitan areas, for example, between 2005 and 2009, the average difference in median income between the $75^{\text {th }}$ percentile census tract and the $25^{\text {th }}$ percentile census tract was 54.8 percent. ${ }^{1}$ Across U.S. metropolitan areas, the difference in MSA median income between the $75^{\text {th }}$ percentile MSA and the $25^{\text {th }}$ percentile MSA was 24.5 percent. $^{2}$ The extensive level of income inequality across locations implicit in these measures is well known and in many instances seemingly entrenched. It is hard to imagine Back Bay Boston, for example, with its famous brownstones losing its appeal to high income residents, or San Francisco with its natural amenities. ${ }^{3}$ Nevertheless, change in a location's economic status is common. Rosenthal (2008a), for example, shows that over half of all census tracts in the core areas of thirty-five U.S. cities were of markedly different economic status in 2000 relative to their status in 1950. The rise, fall, and rise again of Harlem over the last 100 years is emblematic of this change. At the metropolitan level, Glaeser and Gyourko (2005) emphasize that eleven of the fifteen largest U.S. cities in 1950 lost population by 2000; most dramatic among these, Detroit lost over half of its population!

A central goal of this chapter is to review recent literature that provides new insights into the extent and manner in which a location's economic status tends to change over time, both at the neighborhood and MSA level. When focusing on neighborhood change, much of our discussion will be set in a U.S. context as this has been the tendency in the literature.

\footnotetext{
${ }^{1}$ Authors' calculation based on the 366 largest CBSA (core based statistical areas) in the United States using pooled 1-percent samples from the 2005-2009 American Community Survey (ACS).

${ }^{2}$ MSA refers to metropolitan statistical area. The estimate above is based on the authors' calculation using the 1 percent sample of the 2010 American Community Survey (ACS).

${ }^{3}$ See the Back Bay Neighborhood Association website for a history of Back Bay which, until the landfill project begun in 1857, was a tidal marsh: http://www.nabbonline.com/about_us/back_bay_history.
} 
Nevertheless, the lessons learned from that literature apply to cities beyond the U.S. When focusing on metropolitan level change, the literature is more international as is our review. In most instances we will refer to various measures of per capita income to characterize local economic status, but in some instances we will refer to changes in population and employment. ${ }^{4}$

Throughout the chapter a recurring theme is that long sweeps of time are necessary to appreciate that change in a location's economic status is common. A related theme is that history matters and in some instances contributes to path dependency. A third message is that multiple forces affect neighborhood and MSA-level economic status so that income dynamics differ across locations. As a result, in some locations economic status exhibits extreme persistence while in other locations economic status is much more prone to random and systematic forces that prompt cycles of rise and fall.

Three mechanisms figure prominently in our discussion and often reinforce each other. These include the durability and slow decay of housing, the durability of transportation infrastructure, and self-reinforcing spillovers that have the potential to root ethnic/racial communities to a given neighborhood and seemingly footloose industries to a given location. In many instances, these mechanisms contribute to slow, relentless change that extends over decades. In other cases, economic forces build up until a tipping point is reached after which the pace of change can be dramatic.

At the neighborhood level, it is also important to recognize that income displays sharp, non-random spatial patterns. This is graphically apparent in Figure 1 which presents plots of neighborhood relative income as a function of distance from the city center for four metro areas in the U.S. over the 2005-2009 period. The plots include New York, (Panel 1), Los Angeles

\footnotetext{
${ }^{4}$ Our emphasis on per capita income is different from previous reviews of MSA-level productivity and growth which tend to focus on population and employment (e.g. Rosenthal and Strange (2004), Behrens and Robert-Nicoud (this volume), Combes and Gobillon (this volume), and Carlino and Kerr (this volume)).
} 
(Panel 2), Chicago (Panel 3), and Philadelphia (Panel 4). For each metro area, neighborhood relative income is measured based on census tract average income divided by the tract's MSA average income. In Los Angeles, relative income rises in a strikingly monotonic fashion with distance from the center. Relative income also trends upward with distance from the downtown in New York, Chicago, and Philadelphia, but in a much less monotonic fashion, a point that we will return to. Overall, these four cities are indicative of a widely documented stylized fact: U.S. central cities tend to be poor relative to the suburbs.

The broad spatial features in Figure 1 have been the focus of intense study since the late 1960s. Much less well appreciated is that a location's economic status is not static. This is evident in Figure 2 which displays summary measures drawn from Table 1 of Rosenthal (2008a). Four vertical bars are displayed in the figure, each of which is broken into four segments with 1950 census tract economic status increasing to the right and year-2000 economic status increasing vertically. For these purposes, status is measured by the ratio of a census tract's average income relative to its city.

Figure 2 indicates that regardless of whether a census tract was of low or high income status in 1950 (the first and fourth bars, respectively), over half of all census tracts in 1950 were of markedly different economic status relative to their respective cities in 2000. Moreover, Rosenthal (2008a) shows that this pattern holds regardless of whether the census tract is situated in a large or a small city. The decline of several of the largest U.S. cities as noted by Glaeser and Gyourko (2005) above is equally striking. These changes, however, require time to observe. Rosenthal reports that the average change in census tract income relative to its MSA is roughly 12 percent per decade (in absolute value). For the 10 largest cities in the U.S. in 1977, Duranton (2007) reports that the average change in population size rank over the following twenty years 
was just 1.2 from among 272 metropolitan areas (also in absolute value). Findeisen and Südekum (2008) document similar rates of change for German metropolitan areas. At this pace of change, if one were to adopt a time horizon of say just one decade it would be easy to overlook the enormously dynamic nature of neighborhoods and cities.

Nevertheless, that is often what policy makers and a vast academic literature on neighborhood and metropolitan productivity and growth have tended to do, consistent with our natural tendency to focus on the near term. Forty-five percent of all renters in the United States remain in their homes for less than two years while a similar fraction of owner-occupiers move in under nine years. In 2010, 14.1 percent of these moves were to a different state, 16.8 percent were to a different PUMA within state, and 66.3 percent were within the same PUMA. ${ }^{5}$ These sorts of mobility rates and relocation patterns help to explain the tendency to focus on the short term, at least when considering policies that affect the economic vitality of local communities. ${ }^{6}$

Two examples will help to frame our discussion as we review literature relevant to these ideas, Harlem and Detroit. With the extension of the New York subway system out to Harlem in 1904, local real estate developers expected a boom in housing demand and built homes in anticipation of incoming families. ${ }^{7}$ Much of that demand did not materialize because of concurrent improved access to downtown Manhattan from other locations. Local folklore has it that Phillip Payton, a real estate agent and entrepreneur, approached several Harlem landlords and convinced them to encourage black families to move to Harlem to occupy the new housing stock. By the 1920's Harlem had transformed into a thriving black community, rich in culture,

\footnotetext{
${ }^{5}$ Authors' calculations based on the 2010 American Community Survey. For renters 14.2 percent of moves are to a different state, 16.3 percent are to a different public use micro area (PUMA) within state, and 66.9 percent are within PUMA. For owner-occupiers the corresponding numbers are $13.8 \%, 18.5 \%$, and $64.3 \%$.

${ }^{6}$ Electoral politics also reinforce the tendency to focus on the near term as incumbents and challengers compete for votes from an electorate that discounts events in the future.

${ }^{7}$ See "History of Harlem Heritage Tours \& Cultural Center." Harlem Heritage Tours Cultural Center RSS. See also Vincent (2005). "Harlem." Continuum Encyclopedia of Popular Music of the World: Locations.
} 
jobs, and hope. That promise, however, was dealt a blow with the great depression of the 1930s, discrimination, and social upheaval. Harlem's population shrank in the late 1960s and 1970s as crime, riots, abandoned property and blight dominated the headlines instead of iconic sites like the Cotton Club and the Apollo Theater. By 1990, Harlem had become an impoverished black community living in aging and often decrepit housing. ${ }^{8}$ This too changed.

Where abandoned and rundown buildings were found in 1990 newly built homes now sell for over one million dollars and count Bill Clinton's business office as a neighbor. From 2000 to 2008 , Central Harlem's population rose from 109,000 to 126,000 . These changes have also coincided with the most profound change in the composition of Harlem's population in 100 years. Blacks in greater Harlem are no longer a majority but instead account for roughly 40 percent of the population, down from a high of roughly 64 percent in 1970. Central Harlem's black population share is said to have peaked at 98 percent in 1950 but stood at just 62 percent in 2008. ${ }^{9}$ These changes reflect both out-movement of blacks - Central Harlem's black population in 2008 had fallen to 77,000, a level not seen since the 1920s - along with in-movement of large numbers of Hispanic and non-Hispanic whites. ${ }^{10}$ We will argue that a variety of studies on neighborhood dynamics suggest that Harlem's rise and fall, and its transition from white to black and back again are reflective of many urban neighborhoods in the U.S. and elsewhere in the world. We believe these dynamics reflect the combined forces of access to transportation infrastructure, durable but slowly depreciating housing, and the self-reinforcing cultural effects of race and ethnicity. Importantly, a conclusion we draw from the literature is that the sort of changes experienced by Harlem are inevitable for many - but not all - urban communities.

\footnotetext{
8 "History of Harlem Heritage Tours \& Cultural Center." Harlem Heritage Tours Cultural Center RSS .

9 Payne (2010) "Is Harlem No Longer Black?" The Root, 8 Jan.

${ }^{10}$ Roberts (2010) "No Longer Majority Black, Harlem Is in Transition." The New York Times, 5 January.
} 
In 1950, Detroit was the fifth largest city in the United States with a population of roughly 1.85 million people, 45 percent of whom were white while the rest were almost exclusively black. By 2010, Detroit's population had fallen to just over 700,000 people and whites accounted for only 7.9 percent of the city's population. The city officially succumbed in July, 2013 when it filed for Chapter 9 bankruptcy, the largest municipal bankruptcy (by debt) in the history of the United States. Detroit's dramatic decline is emblematic of many declining U.S. rust belt towns that include Buffalo, Pittsburgh, Cleveland and other cities. Shrinking cities are also found outside of the U.S. rust belt as with Liverpool, England whose population in 2010 was down nearly fifty percent from its peak in the 1930s, and Torino, Italy which lost roughly 25 percent of its population between 1970 and $1990 .{ }^{11}$ Other cities have disappeared altogether, as with Memphis, Egypt which was once a leading city in the world. ${ }^{12}$ These cities remind us that metropolitan areas can shrink as well as grow.

As with our assessment of neighborhood dynamics, durable housing, transportation infrastructure, and fiscal policies played an important role in both the growth and demise of Detroit. Ease of transportation provided access to raw materials as well as distant markets and suppliers, enhancing trade, productivity and growth. Steel is an essential input for the auto industry and the raw materials necessary for steel production are found in vast quantities in areas close to the Great Lakes. This contributed to the emergence of Gary, Indiana and Pittsburgh,

\footnotetext{
${ }^{11}$ See, for example, Nurse (2008) in the University of Liverpool, University News, “The Liverpool View: Detroit's Lessons for Liverpool" at http://news.liv.ac.uk/2013/08/02/the-liverpool-view-detroits-lessons-for-liverpool/ . Power, Ploger, and Winkler (2008) also document and discuss population decline in seven European cities between 1970 and 1990, including Leipzig (-15\%), Bremen (-5\%), Sheffield (-8\%), Bilbao (-13\%), Torino (-25\%), and Saint Etienne (-20\%) (see Chart 6, page 11 of their report).

${ }^{12}$ Memphis was founded roughly 5,000 years ago adjacent to the southern end of the Nile delta (Prasad (1977)). In its heyday from around 3,000 B.C. to around 2,250 B.C., Memphis is thought to have been the largest city in the world, with a population that may have been as high as 50,000 people (Chandler (1987)). Nevertheless, where Memphis stood, today one finds scattered ruins and small villages (Waters (1895)).
} 
Pennsylvania as steel producing towns, which in turn contributed to the rise of nearby Detroit as "Motor City."

Racial strife, fiscal mismanagement, and especially the declining comparative advantage of Detroit as a world automobile center have since contributed to six decades of steady decline in Detroit's employment base. The same durable buildings that helped to support Detroit's growing population during its rise deepened and accelerated its fall as it declined. That is because reduced demand in conjunction with inelastic housing supply causes home prices to plummet which reinforce the shift towards a low-skilled, lower income population (e.g. Glaeser and Gyourko (2005)). Declining skill simultaneously lowers per capita income and reinforces the tendency for employers to flee the city. These shifts erode the local tax base and aggravate the city's growing fiscal crisis. In response, many declining U.S. rust belt cities including Buffalo, Cleveland, and especially Detroit have adopted policies of bulldozing underutilized and abandoned housing stock in an attempt to strengthen their local economies. It is in that spirit that Glaeser (2007) concludes that Buffalo should "shrink to greatness."

The history of rust belt towns in the U.S. suggest that cities can lose their comparative advantages as documented by Yoon (2013), after which durable housing stocks contribute to a sharp downward spiral. The idea that cities can shrink and even disappear, however, has been almost overlooked in the literature on urban dynamics and growth. It also contrasts with recent work by Davis and Weinstein (2002, 2008), Brakman, Garretsen, and Schramm (2004), and Glocker and Sturm (2013), all of who suggest that enduring locational natural advantages help to ensure that a city's economic status remains secure even following the devastation of war. The view that cities can not only rise but also fall also challenges recent literature which suggests that 
once built a city will endogenously grow and endure even after losing its initial comparative advantage, as with the obsolescence of canoe portage paths (e.g. Bleakley and Lin (2012)).

To explore these ideas, our chapter is organized in a manner that progresses from neighborhood-level to MSA-level geography. We begin by describing four stylized facts that pertain to the location of high- and low-income communities within individual cities. This is followed by a series of static and dynamic arguments that explain patterns documented in recent studies in addition to Harlem's experience highlighted earlier. An important conclusion is that while random shocks contribute to a community's economic status, in most instances neighborhood economic status follows from a mix of systematic static and dynamic economic forces. From there we review papers that consider change at the metropolitan level. Here too we outline four stylized facts and focus on whether a city's economic status relative to other metropolitan areas is fixed or whether it changes over time in a systematic fashion, and why. We conclude by highlighting areas that we believe are especially in need of further research.

\section{Neighborhood economic status}

\subsection{Four stylized facts about neighborhood economic status}

\subsubsection{Rich suburbs and poor cities}

A prominent feature of modern cities in the United States has been the tendency for suburban communities to have high levels of income relative to the central cities. Glaeser, Kahn, and Rappaport (2008), Brueckner and Rosenthal (2009) and others have confirmed this. We do so again here using pooled census tract data from the American Community Survey (ACS) from 2005-2009. Los Angeles provides a graphic example as shown in Panel 2 of Figure 1, with household income relative to the MSA (metropolitan statistical area) rising monotonically with 
distance (in miles) from the MSA center. ${ }^{13}$ The pattern for New York, which is shown in Panel 1 , is similarly upward sloping although with more of a saw-tooth shape to the plot. Given the striking patterns for Los Angeles and New York, and decades of concern about the concentration of poverty in the inner cities (e.g. Rosenthal (2008b)), it is easy to be lulled into thinking that suburban household incomes must nearly always be high relative to their MSA centers, both now and in the future. Nevertheless, one can point to instances where that is not the case, the most dramatic of which in the United States is Chicago. In Panel 3 of Figure 1, notice that for Chicago, central city income is high relative to the MSA, falls to a trough at roughly 5 to 10 miles from the city center, and then rises again. Philadelphia (shown in Panel 4 of Figure 1) also displays a pronounced v-shaped contour although its central city is still of relatively low-income status. Similar plots are provided in the Appendix for the forty-eight largest MSAs in the U.S. While it is clear that high-income suburban areas are the norm, it is also clear that there are other cities in addition to Chicago and Philadelphia where that is not the case as with Washington DC to name just one (see Panel 7 of Figure A-1). Nevertheless, although there are important exceptions, our first stylized fact is that in most metropolitan areas of the United States the suburbs are of higher income status while the central cities are relatively poor.

\subsubsection{Change in neighborhood economic status is common}

It is tempting to assume that a neighborhood's economic status as high or low income is largely fixed in place but that would not be correct. Rosenthal (2008a) calculates transition rates of neighborhoods between different levels of economic status using a balanced panel of census tracts for core areas of 35 cities that are followed on a consistent geographic basis from 1950 to

\footnotetext{
${ }^{13}$ In each of the panels of Figure 1, distance from the most densely populated census tract is plotted along the horizontal axis while the average ratio of census tract median income to the MSA median is on the vertical axis. Data for these plots are from the combined 2005-2009 American Community Survey.
} 
2000. Each census tract is treated as a separate neighborhood. Status is measured based on average household income in a neighborhood relative to average household income of all census tracts in the panel for the city and year in which the neighborhood is observed. Neighborhood geography is coded to year 2000 census tract boundaries for all years. Neighborhoods are further classified into four groups based on whether neighborhood relative income levels are in the first through fourth quartiles of relative income, referred to by Rosenthal (2008a) as low income, lower middle-income, upper middle-income and high-income, respectively.

A striking pattern emerges and is reproduced in Figure 2. For the 35 cities in the sample, only 34.21 percent of all low-income neighborhoods in 1950 were still of low-income status in 2000. For lower-middle income tracts, upper-middle income tracts, and high-income tracts the corresponding values are 26.42 percent, 26.94 percent, and 43.98 percent, respectively. Although there is a disproportionate tendency for low- and high-income tracts to remain as such, the overwhelming pattern is that most neighborhoods change economic status between 1950 and 2000, either up or down the economic ladder.

These patterns point to our second stylized fact: change in neighborhood economic status is common among urban neighborhoods in the United States. Yet most of our models and much urban policy seem to implicitly treat neighborhood economic status as stationary.

\subsubsection{Mean reversion in neighborhood economic status is also common}

With so much change in neighborhood economic status, a natural question is whether neighborhoods rise and fall in a systematic, cyclical pattern or whether individual neighborhood economic status follows a random walk. Table 1 reproduces estimates from Rosenthal (2008a)

(Table 3, page 5) that shed light on this question. The table reports regressions that characterize 
the degree to which change in neighborhood economic status is serially correlated. As above, neighborhood economic status $\left(y_{i t}\right)$ for neighborhood $i$ in period $t$, is measured as the ratio of average income in the neighborhood (census tract) relative to average income in its MSA. ${ }^{14}$ For 1900 and 1920 income in each voting Ward is based on the OCCSCORE measure available in IPUMs which provides an estimate of income that an individual would have earned in 1950 given their actual occupation in 1900 or 1920 (see www.ipums.org for details). Income after 1920 is based on actual reported individual income and for all years individual income is aggregated to the geographic unit used in the regression (e.g. 1900 voting Ward boundaries or census tracts).

The first two regressions focus only on Philadelphia County with data coded to year-1900 voting Ward geography. There were 39 such Wards in Philadelphia in 1900. The period length for the first regression is set to 50 years with $\log \left(\mathrm{y}_{2000} / y_{1950}\right)$ regressed on $\log \left(y_{1950} / y_{1900}\right)$. In the second regression the period length is set to 30 years with $\log \left(y_{1980} / y_{1950}\right)$ regressed on $\log \left(y_{1950} / y_{1920}\right)$. The third regression in the table also focuses on Philadelphia county but in this instance data are coded to year-2000 census tracts. In addition, census tracts are followed from 1950 to 2000 on a decade-by-decade basis with $\log \left(y_{t} / y_{\mathrm{t}-1}\right)$ regressed on $\log \left(y_{\mathrm{t}-1} / y_{\mathrm{t}-2}\right)$. The fourth and last regression in the table is similarly specified but includes census tracts for the core areas of 35 MSAs for which tracts were defined in 1950. This latter regression also includes county fixed effects.

Moving from left to right in Table 1 across the Philadelphia County regressions (in columns 1-3), notice that the coefficients on the lagged dependent variables are $-0.95,-0.45$, and

\footnotetext{
${ }^{14}$ To be precise, let $y_{i t}$ be the relative income of neighborhood $i(i=1, \ldots, \mathrm{I})$ in period $t$. In addition, $y_{i t}$ is defined to be $Y_{i t} / \bar{Y}_{t}$, where $Y_{i t}$ is the average level of income in tract $i$ in period $t$, while $\bar{Y}$ is the city-wide average level of income in period $t$. By construction, the expected value of $y$ over all neighborhoods in period t equals 1.
} 
-0.013 , respectively, with t-ratios of 6.2 and 3.2 and 0.24 . This indicates that for the typical neighborhood in Philadelphia, a neighborhood's relative economic status in 2000 is 95 percent back to where it began 100 years earlier in 1900. As the period length narrows in the second and third regressions, neighborhood cycles are less complete and the coefficients on the lagged dependent variables are reduced, falling to 1.3 percent for the 10 -year period length model. This latter estimate is close to the corresponding measure obtained for the 35 city balanced panel in the last regression. In that model, the coefficient on the lagged dependent variable is -5.6 percent (with a t-ratio of 11.27).

An implication of these results is that neighborhood income is stationary which can be tested using panel unit root tests. Consider the following equation,

$$
\log \left(y_{i t}\right)=\theta_{i, o}+\theta_{i, 1} \log \left(y_{i, t-1}\right)+e_{i t},
$$

where $\log \left(y_{i t}\right)$ is expressed as a function of a constant and its one period lag, and $i$ and $t$ denote the census tract and time period as before. If $\theta_{i, 1}<1, \log \left(y_{i t}\right)$ is stationary with finite variance and a stable long run mean. This would imply that neighborhood economic status displays a tendency for mean reversion. If instead $\theta_{1}$ equals 1 , then shocks to neighborhood economic status never damp out and neighborhood economic status would follow a random walk.

Using the same data as in column 4 of Table 1, Rosenthal (2008a) estimates panel unit root tests which clearly reject the null of a unit root in favor of the view that neighborhoods vary around a stable long run mean. ${ }^{15}$ These results lend support to the idea that Harlem's 100 year cycle of rise, fall, and renewal described in the Introduction is not unique and that urban neighborhoods tend to exhibit long running cycles in economic status and mean reversion.

\footnotetext{
${ }^{15}$ The two tests were those of Levin-Lin-Chu (2002) referred to as LLC, and a Fisher-type method developed by Maddala and $\mathrm{Wu}(1999)$.
} 


\subsubsection{Income segregation has increased in U.S. cities}

A series of studies provide evidence that income segregation has increased within U.S. metropolitan areas in recent decades. Massey and Fisher (2003) report evidence of regional income convergence between 1950 and 2000, they also find that inequality in income and poverty across census tracts increased between 1970 and 1990 while declining only slightly between 1990 and 2000. Taylor and Fry (2012) report an increase in census tract level income segregation between 1980 and 2010 which was especially pronounced among higher income households. Wheeler and LaJeunesse (2007) find that income segregation across census tracts within a given U.S. MSA increased substantially in the 1980s. Watson (2009) presents measures of within metropolitan income segregation over time based on income rank percentile as opposed to thresholds tied to real income levels. Watson also reports that within-MSA income inequality increased between 1970 and 2000 with most of the increase occurring between 1980 and 1990 .

\subsection{Conceptual models of spatial variation in neighborhood economic status}

The evidence above suggests that neighborhood economic status often exhibits pronounced systematic spatial and temporal patterns but does not explain why. This section offers a series of conceptual explanations that help to clarify the drivers of the patterns above.

\subsubsection{Static models}

2.2.1.1 The "standard” model: Alonso (1964), Mills (1967), and Muth (1969)

Early work by Alonso (1964), Mills (1967) and Muth (1969), hereafter AMM, provided the foundations for the first seemingly compelling explanation for why modern U.S. central cities tend to have low income relative to the suburbs. In its simplest form, all employment in a metropolitan area is concentrated in the central city (i.e. the metropolitan area is "monocentric") 
so that commuting costs increase with distance from the city center $(u)$ at rate $t$. Households have income $(y)$, and value housing $(h)$ and non-housing consumption $(x)$ for which the per unit prices are $P_{h}(u)$ and 1, respectively. With identical households, a spatial equilibrium would require that house prices fall with distance to the downtown to compensate for differences in commuting costs,

$$
\frac{\partial P_{h}(u)}{\partial u}=-\frac{t(y)}{h(y)}<0
$$

where unit commuting costs and housing demand vary with income. ${ }^{16}$ The impact of income on the slope of the house price function is then given by

$$
\frac{\partial^{2} P_{h}(u)}{\partial u \partial y}=c(y)\left[\varepsilon_{h, y}-\varepsilon_{t, y}\right]
$$

where $c(y)=\frac{t(y)}{y h(y)}>0$, and $\varepsilon_{h, y}$ and $\varepsilon_{t, y}$ are the income elasticities of demand for housing and of commuting cost, respectively.

Expression (3) yields the important result that if $\varepsilon_{h, y}>\varepsilon_{t, y}$ the house price function flattens with an increase in income while the opposite is true if $\varepsilon_{h, y}<\varepsilon_{t, y}$. Drawing on this principle, through most of the 1970s, 1980s, and 1990s, a common explanation offered for why U.S. central cities tend to be poor was that $\varepsilon_{h, y}>\varepsilon_{t, y}$. In that event, the house price functions for highand low-income households cross as in Figure 3, and high-income families outbid the poor for space in the suburbs while the poor outbid the rich for space in the central cities.

The AMM model, it seemed, offered an elegant explanation for the spatial pattern of high and low income neighborhoods and this became part of the standard discussion in many classes

\footnotetext{
manner that compensates households for longer commutes:

$$
y=P_{h}(u) h(y)+x(y)+t(y) u \rightarrow P_{h}(u)=\frac{y-x(y)}{h(y)}-\frac{t(y)}{h(y)} u
$$
}

${ }^{16}$ Expression (2) is obtained by rearranging the household budget constraint to ensure that house prices vary in a 
on urban economics. An early voice of dissent, however, was raised by Wheaton (1977) who questioned whether housing demand is actually more sensitive to income than are commuting costs. Wheaton's critique was largely overlooked until being revisited by Glaeser, Kahn and Rappaport (2008), or GKR, who provided compelling evidence that housing demand is far less sensitive to income as compared to commuting costs.

GKR emphasize that if households value commuting time in a manner that is proportional to the household head's hourly wage then the income elasticity of commuting costs will equal 1. Drawing on a sample of households from the American Housing Survey (AHS), GKR also estimate the income elasticity of demand for land among homeowners occupying single-family detached homes. The income elasticity of demand for land is roughly 8 percent when estimating by OLS and 25 percent when income is instrumented using education of the household head. ${ }^{17}$ Rosenthal (2014) recently estimated the income elasticity of demand for housing (not land) using all households other than those living in mobile homes. Based on OLS estimates, Rosenthal (2014) reports an income elasticity of 41 percent for owner-occupiers and 12 percent for renters. Together these and numerous similar estimates in the literature confirm that the income elasticities of demand for housing and land are well below 1.

Armed with their evidence, GKR argued that the AMM model and expression (3) above predict the opposite pattern from what is typically observed in the U.S.: specifically, higher income families should occupy the city centers, not the suburbs. A new explanation was needed for the spatial pattern of high- and lower-income communities in U.S. metropolitan areas.

\footnotetext{
${ }^{17}$ Housing demand is based on forward looking expectations of future income and for that reason is in principle more closely tied to permanent as opposed to current income. GKR instrument for income using education of the household head to allow for this distinction and obtain the anticipated result that income elasticity is higher relative OLS estimates that include current income as the primary control. GKR also recognize that education could potentially enter directly into the housing demand function and for that reason may not be a valid instrument. Nevertheless, the estimates obtained are far below 1 and reinforce the arguments above.
} 


\subsubsection{Public transit and access to cars}

In seeking to explain the discrepancy above, Glaeser, Kahn, and Rappaport (2008) emphasize that lower income families own fewer cars per adult and are more reliant on public transit for that reason. Moreover, public transit tends to be far more effective in densely developed central city areas where demand is high enough to substantively reduce average fixed costs and also allow for more frequent service. For these reasons, public transit opportunities will generally be more accessible in the central cities than in the suburbs and that should attract lower-income families to the center.

GKR document that public transit usage is generally notably lower as one moves away from the city center. The primary exception is that in metropolitan areas with subway systems public transit usage increases in the first few miles from the city center and then declines (see Figure 3 of GKR). We reconfirm the core features of these patterns here. As in Brueckner and Rosenthal (2009), each census tract is said to provide good or bad access to public transit ( 1 or 0 , respectively) depending on whether 10 percent or more of households in the census tract use public transit as their primary means of travel to work. Transit access is then averaged across tracts within a given distance band (e.g. 1 mile from the center, 1 to 2 miles from the center, ,..). For the four metro areas highlighted above (New York, Los Angeles, Chicago and Philadelphia), results are plotted as the solid lines in panels 1-4 of Figure 4 with distance from the city center on the horizontal access. Figure A-2 in Appendix A provides similar plots for the largest 48 metropolitan areas. In all cases, the plots are based on tract-level 2005-2009 pooled American Community Survey (ACS) data. The patterns in these figures reconfirm that reliance on public transit generally declines sharply with distance from the city center. 
Drawing on these ideas, GKR modify the standard AMM model to allow for the influence of public transit. They first confirm that car travel is faster than public transit, on average (see Table 3, page 12 of GKR), or $T_{P}>T_{C}$ where $T_{P}$ is travel time per mile by public transit and $T_{C}$ is travel time by car. If the poor use public transit and the rich drive cars, GKR then show that the poor will occupy the city center if,

$$
\varepsilon_{h, y}+\left[\frac{T_{P}-T_{C}}{T_{P}}\left(\frac{Y_{P o o r}}{Y_{\text {Rich }}-Y_{\text {Poor }}}+\varepsilon_{t, y}\right)\right]>\varepsilon_{t, y}
$$

where $\varepsilon_{h, y}$ is the income elasticity of demand for land in their discussion. Because the term in brackets is positive, this condition is more likely to be met than $\varepsilon_{h, y}>\varepsilon_{t, y}$ which is the standard model condition for the poor to occupy the city center. ${ }^{18}$

A further feature of the model above is that there are fixed costs associated with purchase of autos. Partly for that reason and partly because some rich prefer public transit (as in subway cities), GKR emphasize that alternative parameterizations of the model above can yield a variety of spatial patterns of high- and low-income neighborhoods. As an example, subway travel is faster than car transport in congested areas like Manhattan, downtown Chicago, and Paris. If higher income families prefer subway to auto travel in these cities, then the model above can readily explain why substantive portions of their downtown areas are high income. Alternatively, GKR further show that depending on the level of fixed costs associated with auto purchases, it is possible for a metropolitan area to display alternating bands of high and low income neighborhoods as one moves outward from the city center.

\footnotetext{
${ }^{18}$ GKR note that this expression analogous to equation (7) in LeRoy and Sonstelie (1983) who also emphasized the influence of transportation mode and travel speed.
} 


\subsubsection{Local public services}

As with transportation, the provision of local public services might provide a reason for why the poor live in cities and the rich live in suburbs, even though the rich face a substantially higher time cost for commuting. Epple and Romer (1991), Ross and Yinger (1999), and many other papers demonstrate that with a relatively inelastic supply of housing households will sort by income across jurisdictions. High income households will live in jurisdictions with high service levels that low income households will be unable to access because the rich outbid the poor for housing in such neighborhoods. A limitation of these local public finance models is that they do not incorporate space or commuting to employment centers. For this reason, while these models imply that the poor and the rich are segregated from each other they say little about where low-income communities are found.

DeBartolomé and Ross (2003) develop a model with an explicit spatial component in which, as in Glaeser, Kahn and Rappaport (2008), the rich have a higher time cost of commuting. Their model has two jurisdictions with a central city oriented around a central export node and an outer suburban ring. ${ }^{19}$ They prove that stable equilibria exist in which the poor comprise the majority in the central city and choose a low level of service provision that discourages the rich from locating in the center.

A natural question is what type of processes could lead to this equilibrium? DeBartolomé and Ross (2008) consider this question starting with a model in which all households locate in a single city with an exogenous border. Because of their lower time costs, the poor live closer to the urban fringe and commute further to the city center than the rich. As population grows, two

\footnotetext{
${ }^{19}$ See Epple, Gordon and Sieg (2010) for an empirical implementation of an income-sorting model with location specific amenities within political jurisdictions calibrated to data on Pittsburgh. Amenities in the paper implicitly include distance to employment centers and potential commute times. Hanushek and Yilmaz (2007) demonstrate that models of this type generate equilibrium implications that better fit observed sorting patterns.
} 
possibilities arise: either the poor move beyond the city boundary and form their own community with low service levels (which are unattractive to the rich), or rising housing prices in the city center cause the rich to form their own community in the suburbs. Simulations in DeBartolomé and Ross (2008) suggest that for a range of realistic parameter values the rich always develop their own jurisdiction in the suburbs before the poor spill over the city boundary. This leads to the DeBartolomé and Ross (2003) equilibrium in which the poor occupy the center. ${ }^{20}$

Peer effects have the potential to reinforce the sort of income segregation just described. Benabou (1993), for example, considers an urban model with two neighborhoods where the cost of obtaining skills decreases with the skill of neighborhood residents because of positive peer effects. If households sort across communities based on investment in skills then peer effects lead to much higher levels of skill inequality across neighborhoods and contribute to stratification of high and low income households into different communities. ${ }^{21}$ Glaeser, Sacerdote, and Scheinkman (1996) demonstrate that analogous social interactions can explain the very high variation in crime rates observed across cities. Calabrese, Epple, Romer and Sieg (2006) calibrate local public finance models of locational equilibrium to data in Massachusetts with and without peer effects. Adding peer effects to the model strengthens the relationship between jurisdiction income and both local government spending and housing prices. This increases the dispersion in jurisdiction quality which should increase the tendency for income segregation across communities.

\footnotetext{
${ }^{20}$ In related work, Bayer and McMillan (2012) simulate a general equilibrium model of residential location and show that lower commuting costs increase segregation across jurisdictions by income, education, and race.

${ }^{21}$ In Benabou's (1993) model, individuals choose to be high skill, low skill or out of the labor market. If individuals who choose high skills are able to segregate, the costs of acquiring skills in the lower skill community increase causing potentially low skill individuals to opt out of the labor market category. Benabou's analysis of the efficiency implications of peer-based sorting focuses primarily on the labor market outcomes. See DeBartolomé (1990) for an earlier, similar peer effects model, which examines the normative implications for efficiency in the production of skills or education services.
} 
More recently, a series of papers have examined the role of peer effects on sorting outcomes associated with education reforms. Epple and Ferrerya (2008) and Ferrerya (2009) calibrate models to match Detroit, Michigan at a time when an education finance reform had recently been implemented. They find that most of the effect of the reform is on housing prices rather than changes in sorting over demographics or school quality associated with demographicbased peer effects. The key intuition is that the reform did not change the ranking of communities on which sorting is based, and so while changes were capitalized into housing prices, the overall pattern of sorting across jurisdictions remained unchanged.

Ferrerya (2007) uses a similar model to examine the effect of a large scale voucher program in Chicago. In her model, income mixing occurs within neighborhoods because households have heterogeneous preferences for neighborhood locations and neighborhoods differ across multiple dimensions including school quality. She finds that school vouchers can reduce income segregation by weakening the link between a family's residential location choice and the quality of schooling opportunities for their children. ${ }^{22}$

\subsubsection{Physical amenities}

A different explanation for income stratification across communities is that higher income families are more able and willing to pay for opportunities to live near attractive physical amenities. Brueckner, Thisse, and Zenou (1999) appeal to this idea in explaining why Paris - the city of light - has a high income center. They emphasize that Paris has wonderful central city amenities including extensive cultural landmarks, such as the Louvre Museum, the Eiffel Tower,

\footnotetext{
${ }^{22}$ Epple and Romano $(1998,2008)$ and McMillan $(2005)$ also examine the effect of vouchers in education models with peers, but their models do not allow for sorting across schools located in specific neighborhoods. See Brunner (In press) for a detailed review of the literature on school choice and its effect on sorting and mobility, and Epple and Romano (2011) for a more general review of models of education production that involve peer effects.
} 
the Arc de Triumph, and more. Glaeser, Kahn and Rappaport (2008) also highlight these features of Paris at the end of their discussion. Amenities also seemingly explain the concentration of high-income households in center-city Vancouver, British Columbia which sits on a peninsula surrounded by magnificent scenery and other natural amenities. The location of such dramatic historic and/or natural amenities, however, is largely idiosyncratic. For that reason, Brueckner, Thisse, and Zenou suggest that amenity-based arguments help explain differences in economic status across communities but do not necessarily imply systematic spatial patterns of where high and lower income neighborhoods will be found within a given metropolitan area. In that sense, physical amenity-based arguments are more of an explanation for "exceptions" to systematic spatial patterns as opposed to characterizing what should be anticipated as the norm. ${ }^{23}$

\subsubsection{Non-durable amenities}

It should be noted that static amenities need not be physical attributes such as a scenic view or enduring monuments like the Arc de Triumph. Banzhaf and Walsh (2008) examine changes in pollution levels in very small geographic areas between 1990 and 2000. They find that population density increases when exposure to pollution declines and similar but weaker effects on neighborhood income. They attribute the weaker effects on income sorting to the fact that only large changes in pollution levels will change the relative ranking of neighborhoods and that in equilibrium it is the ranking of a location that should have the largest effect on income composition, echoing results from Epple and Ferrerya (2008) and Ferrerya (2009). ${ }^{24}$

\footnotetext{
${ }^{23}$ See also Lee and Lin (2013) for a recent addition to literature related to this theme.

${ }^{24}$ Bayer, McMillan and Rueben (2005) also document a strong role of amenities in explaining residential location patterns and further emphasize that amenity values tend to be capitalized into housing price premia.
} 
It is also worth emphasizing that many models of segregation entail sorting over nondurable amenities (in addition to fiscal services discussed above) that are endogenously determined by the socio-demographic attributes and behavior of whoever lives in the neighborhood. In boundary models like Courant and Yinger (1977) or in tipping models like Schelling $(1971,1978)$ households sort based on proximity to an individual's own group including race, ethnicity, or some other distinguishing socio-demographic factor. Building off these models, Bayer, McMillan and Rueben (2004) find that socio-demographic characteristics account for much of the segregation by race and ethnicity in the San Francisco Bay Area while income only plays a limited role in explaining segregation. ${ }^{25}$ Analogous results are reported in Bayer, Fang, and McMillan (2014) who show that black middle class neighborhoods are more likely to form in U.S. cities when there are a sufficiently large number of higher income blacks present. In the absence of such a critical mass, middle income blacks are more likely to either reside in middle income white communities or forego the higher levels of public services associated with those neighborhoods in favor of locations with greater black representation. ${ }^{26}$ Waldfogel (2008) provides evidence that endogenous spatial variation in the type of retail services available at the neighborhood level likely contributes to segregation by race and income. Using zipcode level data on restaurants, Waldfogel (2008) finds that fast food and other lower priced restaurants are more common in lower-income neighborhoods, and that restaurant type differs systematically with the racial and ethnic composition of a community. These

\footnotetext{
${ }^{25}$ In Bayer, McMillan and Rueben (2004), income is the most important driver of black segregation but at most explains only 10 percent of the observed level of segregation. Over 30 percent of Hispanic and Asian segregation is attributable to language. Another 20 percent of Hispanic segregation is attributed to lower levels educational attainment.

${ }^{26}$ Bayer, McMillan and Rueben (2005) and Bayer and McMillan (2005) also argue that there are economies of scale in neighborhood formation, and as a result high income blacks often face a trade-off between neighborhood amenities (e.g. school quality) and the desired level of African American presence in a community. In related work, Bayer and McMillan (2012) show that in the absence of differences in preferences for housing quality, income segregation would be notably reduced because of an increased tendency for high income blacks to select into lower income black neighborhoods.
} 
patterns are suggestive that restaurants and other local retail establishments cater to the tastes of their local communities. That in turn should reinforce the tendency for individuals to select into neighborhoods populated with others of their own type. To the extent that high and lower income families have different tastes for restaurant and other retail services, this mechanism should contribute to income segregation. ${ }^{27}$

\subsubsection{Dynamic models}

The literature described above goes a long way towards helping us understand why central cities tend to be poor relative to the suburbs. Nevertheless, while compelling, the arguments and literature above are inherently static in nature and do not do justice to rising income inequality across neighborhoods and the extensive level of redevelopment and gentrification that have swept through portions of many of the major cities in the U.S. The following models help to fill in the pieces of the puzzle.

\subsubsection{Durable housing, filtering and gentrification}

Two recent papers, Rosenthal (2008a) and Brueckner and Rosenthal (2009) offer an inherently dynamic view of what drives the spatiotemporal stratification of neighborhoods into high- and lower-income communities. Both papers emphasize that older homes in the U.S. tend to deteriorate and that higher income families prefer to live in younger housing which tends to be in better condition and more attractive. Moreover, because cities tend to develop and redevelop outwards over time, the age of homes within a given community tend to be relatively similar.

\footnotetext{
${ }^{27}$ Heterogeneity in preferences for the composition and/or level of local public services could also contribute to segregation. Alesina, Baqir and Easterly (1999) is an example of this. Their conceptual model implies that in equilibrium a neighborhood populated with multiple household types with different preferences for local public services tends to adopt lower public service levels. Empirical evidence in their paper confirms that ethnic fragmentation is negatively related to local spending on welfare support. An implication is that ethnic groups may sort into segregated neighborhoods in order to secure their preferred public service bundles.
} 
Together, these features imply long-running cycles in which a neighborhood's economic status rises and falls over a period of many decades. This occurs because housing is initially built for higher income families, decays and is passed down to lower income families, and is eventually redeveloped and occupied by a new generation of higher income households.

Brueckner and Rosenthal (2009) and Brueckner (2011, chapter 3) highlight implications of the correlation between the timing and location of development/redevelopment. In growing cities, housing at the urban/rural fringe tends to be newly developed and occupied by higher income families. Among older metropolitan areas, newly built housing will also be found in one or more rings at different distances from the center where redevelopment has recently occurred. ${ }^{28}$ Such locations are also populated with higher income families who seek out the newer housing. Moreover, as redevelopment bands gradually move outwards from the city center, the locations of high and low income neighborhoods shift, and this causes the relative economic status of the central cities and the suburbs to cycle up and down over extended periods of time.

Figure 5 displays the sort of housing stock age profile that might be anticipated in a growing city given the slow decay of housing capital and periodic redevelopment. Evidence in support of the qualitative features of the durable-housing model is provided in Figure 4. In the four panels described earlier (when discussing public transit access), plots are also provided of the frequency of new and old housing stock at different distance bands as one moves away from the city center. As before, the plots are based on census tract data from the pooled 2005-2009 American Community Survey (ACS). Similar plots are provided for all 48 of the largest U.S. MSAs in Figure A-2 of the appendix.

\footnotetext{
${ }^{28}$ See Braid (2001) for an earlier model in which the optimal redevelopment location moves outwards over time and the metropolitan age distribution of housing is non-monotonic over space. Notably in Braid (2001), developers are forward looking and consider the time path of population growth in redevelopment decisions. See also Arnott and Braid (1997) for a model of filtering with both redevelopment and maintenance.
} 
Consider Panels 3 and 4 of Figure 4 first, for Chicago and Philadelphia, respectively. For both MSAs though especially for Chicago, it is evident that close to the city center there has been considerable new construction of residential units as seen in the dashed-marked lines which plot the percent of housing stock built after 1990. Also apparent, the share of housing stock built prior to 1970 displays a marked upward trend as one moves away from the city center (as seen in the dotted lines). In both metro areas the concentration of older housing stock peaks roughly 10 to 20 miles from the center after which the incidence of newly built housing increasingly dominates. These patterns mirror the dramatic v-shaped plots for neighborhood economic status in Chicago and Philadelphia as displayed in Figure 1. Together, these patterns point to extensive recent redevelopment and gentrification that has occurred in areas close to the center of these metropolitan areas. $^{29}$

In contrast, for New York and Los Angeles (Panels 1 and 2) the plots suggest that central city redevelopment has been less pronounced than in Chicago and Philadelphia, allowing for exceptions such as Harlem and other such areas. Observe, for example, the greater relative presence of older homes (the dotted lines) closer to the city centers. These patterns are also echoed in the plots of neighborhood economic status in Figure 1: for New York, economic status varies little on average from the city center out to 20 miles after which it rises while for Los Angeles economic status increases monotonically with distance from the center.

\subsubsection{Social dynamics, segregation and tipping, and homeownership}

While Rosenthal (2008a) finds strong evidence of mean revision in neighborhood income, he also finds that socio-demographic variables have substantial power in explaining the

\footnotetext{
${ }^{29}$ Analogous patterns are also present in Boston, Miami, Minneapolis-St. Paul, Seattle, Baltimore, Denver, and Portland Oregon, as shown in Figures A-1 and A-2 of the appendix.
} 
rate at which neighborhoods transition up and down the income distribution even after conditioning on the age distribution of the housing stock, access to public housing, and other factors. Neighborhoods with high levels of positive demographic attributes, such as resident education levels, are much more likely to hold their position in the income distribution as the housing stock ages. Accordingly, in this section we review a set of papers that shed light on the role of social dynamics in driving change in neighborhood economic status. A theme throughout is that while these forces are important drivers of neighborhood change, as with physical amenities, they do not necessarily imply a systematic spatial pattern that would allow one to anticipate where high and low income communities will be found. A further distinction is that social dynamics tend to be self-reinforcing in a manner that contributes to the endogenous formation of high and low-income communities.

Two recent papers, O’Sullivan (2005) and Guerrieri, Hartley, and Hurst (2013), are examples of this. Both papers treat the presence of higher income families as itself an attractive force that draws additional high income families to a community. In O'Sullivan (2005), the presence of high income families is assumed to lower local crime rates while high income families are further assumed to have a higher willingness to pay for safe communities. These two assumptions ensure that the arrival of a set of high income families has a self-reinforcing effect that attracts additional higher income households causing a neighborhood to gentrify. O'Sullivan offers descriptive evidence that Portland, Oregon in the 1990s underwent just such a transformation. More generally, any change in neighborhood income will tend to be selfreinforcing if higher levels of neighborhood income contribute to improved levels of local 
amenities, as with school quality, local aesthetic features including gardens, trimmed lawns and clean streets, or improved word-of-mouth job networks. ${ }^{30}$

Guerrieri, Hartley, and Hurst (2013), hereafter GHH, take a more direct approach to these ideas by assuming that families directly value proximity to higher income households. This generates many of the same equilibrium outcomes as in O'Sullivan (2005). GHH further argue that following a city-wide positive demand shock, the growing population of high income households will increasingly seek housing in lower income communities adjacent to existing high income neighborhoods, thereby expanding the geographic extent of existing high income areas. This should also have the effect of raising house prices more in low-income communities that abut high-income enclaves, contributing to within city variation in house price growth. GHH test their model using quarterly Case-Shiller zipcode level repeat sales house price indexes from the late 1980 s to 2008 along with census tract data from the 1980, 1990, and 2000 census. Results support the model predictions. ${ }^{31}$

The above models of income segregation build on the long literature on racial segregation in housing including Schelling's $(1971,1978)$ well-known tipping models. Schelling's models are sometimes classified into two types: the spatial proximity model and the isolated neighborhood model. In the spatial proximity model, households are arrayed along a line (or a lattice) with mobile individuals selecting their optimal position on the line. Schelling (1971, 1978) assumes a simple preference function in which utility differs based on a step function over local racial composition. Households receive high levels of utility when the share of a

\footnotetext{
${ }^{30}$ Bond and Coulson (1989) develop a model that incorporates such income externalities into a model with aging housing stocks and filtering. They argue that departures of higher income families as homes age can lead to rapid downward transition of a neighborhood.

${ }^{31}$ It is worth noting that the Guerrieri, Hartley, and Hurst (2013) model implies a particular spatial form of gentrification in which existing higher income communities tend to grow into adjacent lower-income areas. This is in contrast to dynamic models such as Brueckner and Rosenthal (2009) where the spatiotemporal pattern of newly built housing drives the location of high income communities.
} 
household's own group in the immediate neighborhood is above a fixed threshold and low levels of utility when household group share is below the threshold. Households take turns moving along the line and choose location to maximize utility treating the current spatial distribution of household types as given. The classic result in these models is that even with very small differences in preferences for neighborhood racial composition, perfect segregation is the equilibrium outcome.

Recent studies (see Pancs and Vriend (2007), Zhang (2004, 2011), and O'Sullivan (2009)) have shown that these results are robust to more complicated preference functions. Even when individuals have relatively strong preferences for integration, for example, a myopic, best response allocation process of individuals across residential locations leads to segregation provided there is at least some difference across household types in preference for integration (e.g. whites prefer a slightly less integrated neighborhood than minorities). Pancs and Vriend (2007), for example, consider a model in which the utility maximizing level of integration is the same for two groups of households. A key feature of their model is that the rate at which utility declines with departures from the optimum level of integration is faster as own-group share falls below the optimum as compared to when own-group share rises above the optimum. This sort of asymmetry of preferences leads to perfect segregation even though the set of Nash Equilibria do not include perfect segregation. A fundamental feature of all of these models is that integrated neighborhoods tend to be unstable and prone to tipping towards a segregated outcome.

The intuition behind this result is relatively straightforward. Asymmetric preferences as just described will cause individuals belonging to a minority group to favor integrated communities with relatively high shares of minority households over integrated communities with lower minority shares. As minority households choose away from low minority-share 
integrated neighborhoods towards high minority-share integrated neighborhoods, integrated neighborhoods become increasingly segregated towards either minority or majority households.

In the isolated neighborhood model, Schelling $(1971,1978)$ still assumes that household preferences for neighborhood racial composition are based on a step function. However, in this case majority and minority households have heterogeneous preferences for integration such that the critical own-group neighborhood share (or step) at which utility changes is lower for more tolerant individuals and higher for individuals with a stronger taste for segregation. In this setup, integrated neighborhoods contain the most tolerant members of each group. Moreover, an increase in one group's representation within a neighborhood reduces the appeal of the neighborhood to the alternate group. This type of model typically yields a minimum of three equilibria for a single neighborhood: all majority (e.g. white in the U.S.), all minority, and integrated where the marginal-preference individual in each group is just indifferent between the integrated neighborhood and an outside option. Importantly, the middle, integrated neighborhood is a knife-edge equilibrium and unstable. This is because a very small increase in one group's population will cause the marginal individuals that belong to the alternate group to move away causing group composition within the neighborhood to shift towards an all-majority or all minority equilibrium. As with the spatial proximity model, this implies that integrated neighborhoods are prone to tipping and tend to be in transition towards segregated outcomes.

Card, Mas and Rothstein $(2008,2010)$, hereafter CMR, introduce a new model of tipping building on the isolated neighborhood model of Schelling. A distinguishing result from their model is that when neighborhoods tip they do so towards an all minority composition but not towards an all majority composition. They refer to this as one-sided tipping. 
In the CMR modeling framework, stable integrated neighborhoods emerge when whites (the majority group in their discussion) have a sufficiently strong taste for living in integrated communities. If, however, minority demand for housing in the integrated community rises above a critical value, the minority representation in the integrated neighborhood will become too high to be supported by white preferences for integration, and as a result whites flee the neighborhood and the community evolves to an all-minority, segregated outcome. The stronger white household tastes are for integration the higher the tipping point defined by neighborhood minority share. In this context, tipping can be prompted by a change in minority housing preferences (as driven by an increase in income, for example) and assuming that housing quality is higher in integrated neighborhoods as compared to all minority communities.

Using a panel of 1970-2000 census tracts from the U.S., CMR (2008) find strong evidence of tipping behavior in most cities and suburbs with tipping points between 5 and 20 percent minority household share (relative to majority white households). They also find that tipping points are lower in metropolitan areas where whites have more tolerant attitudes. Importantly, tipping appears to be one-sided as neighborhoods with minority shares above the tipping point for their metro area exhibit rising minority shares. In contrast, neighborhoods with minority shares below their tipping points exhibit relatively stable minority shares.

These sorts of tipping models make clear that when households choose neighborhoods in part based on the attributes of their neighbors (e.g. race, ethnicity, or income), small perturbations in migration patterns or preferences can destabilize integrated neighborhoods and lead to segregated communities. It is less clear, however, whether tipping will be one-sided or two-sided when households sort based on the income of their potential neighbors as this depends on the strength and nature of preferences for mixed income communities. 
A very different set of social interactions tend to be associated with homeownership and can have strong stabilizing effects on neighborhoods. Homeowners are financially invested in their communities in a manner that is not really matched by renters. Homeowners, therefore, have financial incentives to behave in ways that enhance local property values, whether by performing more maintenance on both the interior and exterior of their homes, gardening, participating in neighborhood watch groups, or by voting for local policies that will increase neighborhood appeal. Homeowners also tend to be less mobile than renters. These differences suggest that the presence of homeowners may reduce any tendency for neighborhood economic decline and thereby strengthen the current and future economic status of a community. ${ }^{32}$

Consistent with these ideas, using 1970-2000 census tract data for the U.S., Rosenthal (2008a) finds that higher homeownership rates reduce the likelihood that a neighborhood transitions down in economic status even after controlling for income, education, racial composition, and a host of other socioeconomic attributes of a community. Moreover, because homeownership is more prevalent in higher income neighborhoods, its presence helps to explain the greater tendency for higher income communities to retain their current economic status as shown in Figure 2 and discussed earlier. ${ }^{33}$

An increasingly rich literature has provided evidence of the many ways in which homeownership likely contributes to neighborhood stability. Important among these, the homevoter hypothesis (Fischel (2001)) suggests that homeowners are more likely to vote for local policies that enhance neighborhood quality and raise property values. Such behavior will tend to reinforce sorting outcomes described above and strengthen a community's economic status. Brunner, Sonstelie and Thayer (2001) using aggregate data and Brunner and Sonstelie

\footnotetext{
${ }^{32}$ See Ross (2011) for a short survey of this literature.

${ }^{33}$ The strong positive correlation between homeownership, income and education is overwhelming and has been well documented (e.g. Boehm and Schlottmann (2004), Haurin, Herbert and Rosenthal (2007)).
} 
(2003) using micro-based survey data, for example, provide evidence that homeowners in California are more likely to vote against school vouchers in jurisdictions where passage of the voucher referenda would reduce property values. Hilber and Mayer (2009) show that school spending increases when the land available for new development is limited, an implication of which is that housing supply is inelastic and that rising school quality will be capitalized into higher housing prices. Ahlfeldt and Maennig (2014) report that positive price effects of a proposed airport development plan in Berlin prompt greater voter support for the plan in locations populated with higher concentrations of homeowners. From this they infer that homeowners are more responsive than renters to positive capitalization effects, consistent with the home voter hypothesis. ${ }^{34,35}$

A very different perspective on the influence of homeownership on neighborhood economic status and change is offered by Boustan and Margo (2013). They provide evidence that white flight between 1940 and 1980 substantially increased black homeownership rates in U.S. central cities (they instrument for white flight using Baum-Snow's (2007) planned highway network measures). Boustan and Margo argue that this occurred in part because white flight contributed to lower central city home prices which would have facilitated purchase of homes by low wealth black families. Deng, Ross and Wachter (2003) and Dawkins (2005) also provide evidence that lower home prices contribute to minority homeownership. These studies point to a

\footnotetext{
${ }^{34}$ Dehring, Depken and Ward (2008) provide analogous evidence when considering the impact of a 2004 referendum on the development of a publically subsidized football stadium for the Dallas Cowboys in Arlington, Texas. As with Ahlfeldt and Maennig (2014), they first use hedonic methods to document spatial patterns of postannouncement but pre-referendum effects on local home prices. In a second stage, voting patterns are assessed in part as a function of anticipated changes in home prices. Dehring, Depken and Ward (2008) report positive effects of home price capitalization effects on support for the stadium but do not find differential effects of home price capitalization based precinct-level variation in homeownership rates (see Dehring et al (2008) page 164). This latter result differs from Ahlfreldt and Maennig and is suggestive of the absence of a homevoter effect.

${ }^{35}$ Homeowning residents may also support zoning ordinances that limit the density of development in an attempt exclude lower income residents and maintain a community's economic status. See Ross and Yinger (1999) for a discussion on the use of zoning to influence a jurisdiction's income and economic status.
} 
subtle but important implication of homeownership and the distribution of wealth for neighborhood income stratification and related dynamics. On the one hand, homeownership enhances a community's economic status and raises property values, but lower property values facilitate homeownership among low-wealth homebuyers. ${ }^{36}$ These arguments suggest that homeownership has both direct and indirect effects on a community's future economic status by affecting the type of families that have sufficient wealth to access the neighborhood.

\subsection{Evidence of drivers of neighborhood economic status}

From the discussion above it is clear that several factors drive static and dynamic spatial patterns of neighborhood economic status. The first of these is the standard AMM model that highlights tension between the time cost of commuting and the income elasticity of demand for housing. Properly parameterized, this model suggests that economic status is likely to decline with distance from employment centers as emphasized by Glaeser, Kahn and Rappaport (2008). The second mechanism is access to public transit which suggests the opposite, that the poor occupy the center. The third is the role of local public services which tend to be of higher quality (e.g. school quality) in higher income communities, thereby reinforcing the spatial implications of other mechanisms that are at work. The fourth is the slow deterioration of existing housing stock over time coupled with the correlation between the timing and location of development and redevelopment of housing stock. A fifth mechanism is the role of location-specific amenities that need not display a systematic spatial pattern but which nevertheless attract or deter households. Such amenities include physical features of an area like scenic views and proximity

\footnotetext{
${ }^{36}$ It is well appreciated that household wealth is a critical driver of homeownership (see, for example, Haurin, Herbert and Rosenthal (2007), Gabriel and Rosenthal (2005), Charles and Hurst (2002), or Ross and Yinger (Chapter 2, 2002), to name just a few references).
} 
to a lakefront, as well as amenities that arise endogenously like the racial/ethnic composition of a community, ethnic restaurants, and income itself.

Given the different implications of these mechanisms, it is not surprising that there is considerable variation in spatial patterns of neighborhood economic status among the largest 48 MSAs as shown in Figure A-1 in the appendix. ${ }^{37}$ This is especially evident from the sharp differences in spatial patterns of neighborhood economic status in New York, Los Angeles, Chicago, and Philadelphia in Figure 1 as discussed earlier. Overall, distance to the MSA center alone is a rather weak predictor of a neighborhood's economic status.

Brueckner and Rosenthal (2009) and Glaeser, Kahn, and Rappaport (2008) both run a series of regressions that help to confirm the effect of each mechanism discussed above on spatial variation in neighborhood economic status. Select results from the two papers are reproduced in Table 2 where estimates in columns 1 and 2 are drawn from Brueckner and Rosenthal (2009) and estimates in columns 3 and 4 are drawn from Glaeser, Kahn, and Rappaport (2008). It is worth noting that the dependent variable in columns 1 and 2 from Brueckner and Rosenthal (2009) is neighborhood relative income in 2000 calculated as in Figure 1 (and Figure A-1 in the appendix). The dependent variable in columns 3 and 4 from GKR is $\log$ of census tract median income in 2000 .

The first column in Table 2 includes only distance from the center as a control along with MSA fixed effects that capture time-invariant MSA-level amenities and related attributes. The familiar pattern is obtained with economic status rising with distance from the center.

Column 2 replaces MSA fixed effects with school district fixed effects that control for local level public services and amenities. Additional controls are also added for public transit

\footnotetext{
${ }^{37}$ It is worth noting that while urban poverty is especially concentrated in the central cities (e.g. Glaeser, Kahn and Rappaport (2008), Rosenthal (2008b)) there is considerable more spatial variation in neighborhood median income.
} 
access and the age distribution of the housing stock, all measured at the census tract level in 1980, twenty years prior to the dependent variable. These controls address either directly or indirectly all of the drivers of neighborhood economic status discussed above.

Results in column 2 confirm that access to public transit has a powerful attractive effect on lower-income families. This is evident from the highlight significant and negative coefficient on public transit. The magnitude of that coefficient implies that, all else equal, communities with good access to public transit have median income relative to the MSA that is 9.45 percentage points lower than communities for which public transit is not accessible.

Interpretation of the dwelling age variables is more subtle. Note first that the dwelling age distribution is broken into six categories based on the percentage of homes in the census tract that are 0 to 4 years old, 5 to 9 years old, 10 to 19,20 to 29,30 to 39 , and 40 or more years in age. The omitted dwelling age category is the percent of homes between age 30 and 40 years and all of the dwelling age variables are measured using 1980 data, 20 years prior to the dependent variable. The positive and significant coefficients on all of the included dwelling age categories implies a u-shaped pattern with respect to the influence of the 20-year lagged age distribution of the housing stock on current neighborhood economic status. That pattern is consistent with a scenario in which homes tend to depreciate over time, on average, and that older housing is eventually demolished and replaced with new dwellings. This is because few homes age 30-40 years in 1980 would have been demolished by 2000 with demolitions instead concentrated in homes that were over 40 years in age in 1980. The positive coefficient on homes over 40 years in age is therefore suggestive that older housing stocks are being replaced, which draws in higher income families. The positive coefficient on dwelling age segments under thirty 
years in age is suggestive that such homes offer more valuable service flows in 2000 than homes that were 30-40 years in age in 1980 .

Having controlled for the influence of public transit, local amenities, and the age of the housing stock, in principle the AMM model prediction should emerge that income falls with distance from the center. This is precisely what is obtained as indicated by the negative and highly significant coefficient on distance from the center. ${ }^{38}$ The magnitude of the estimated coefficient indicates that tract income relative to MSA income falls roughly 1 percentage point with every ten miles distance from the center.

Column 3 reports results from a restricted sample in GKR (2008) designed to control for the same confounding factors above that might otherwise mask the anticipated AMM pattern. Specifically, the regression is based on a sample of census tracts 5 to 15 miles from the city center drawn from 99 select MSAs for which public transit access is all but absent within this distance band. GKR refer to these census tracts as "Car zone" areas. They emphasize that since public transit is essentially not available in these areas households have no viable option except to rely on automobiles to travel to and from work (and for non-work trips). Since all households rely on car travel the influence of public transit on income sorting disappears. Although not discussed in GKR, it seems likely that these 99 metropolitan areas are smaller MSAs and for that reason, housing stock between 5 and 15 miles from the center will tend to be relatively similar in age. Their sampling strategy, therefore, likely also reduces the influence of the dwelling age on

\footnotetext{
${ }^{38}$ Brueckner and Rosenthal (2008) report two additional intermediate models with specifications sandwiched between those reproduced in columns 1 and 2 of Table 2. Replacing MSA fixed effects with school district fixed effects reduces the distance coefficient from 0.0018 (with a t-ratio of 9.08) to 0.00005 (with a t-ratio of 0.23 ). Adding the control for public transit changes the distance coefficient to 0.00011 (with a t-ratio of 0.45 ) while yielding a coefficient on public transit of -0.1525 (with a t-ratio of 18.06). Only when the age distribution of the housing stock is added to the regression - as reproduced in column 2 of Table 2 - does the distance coefficient become negative and significant.
} 
income sorting. The model also includes MSA fixed effects which help to control for MSA-level amenity effects.

The GKR (2008) model also recovers the AMM model prediction that neighborhood income should fall with distance from the center. As reported in column 3, with each mile from the center, median income in the census tract declines roughly 1.7 percent in the 5-10 mile distance band and 2 percent in the 10-15 mile band. Both estimates are also highly significant.

Summarizing, evidence from Glaeser, Kahn and Rappaport (2008) and Brueckner and Rosenthal (2009) confirms that public transit and aging housing stocks both attract lower income families, reducing a neighborhood's income and economic status, on average. Controlling for these factors and local amenities (through location fixed effects), both studies also provide evidence that supports a central prediction of the AMM model: neighborhood economic status falls with distance from the city center as would be expected given compelling evidence that the income elasticity of demand for housing is smaller than the income elasticity with respect to the time cost of commuting. Two further implications follow. First, it should come as no surprise that spatial patterns of income sorting differ across U.S. metropolitan areas even while the norm is for poor cities and rich suburbs. Second, the sorting mechanisms emphasized here include static drivers such as public transit access and dynamic drivers such as the slow deterioration of existing housing stock.

\subsection{The pace and timing of change in neighborhood economic status}

The discussion above makes clear that for many communities neighborhood economic status is dynamic rather than fixed. This section considers the pace at which communities rise and fall and sheds further light on drivers of the rate of change. We begin by discussing 
literature on home maintenance that affects the rate at which housing deteriorates over time. This leads naturally into discussions of the timing of demolition and redevelopment decisions and the rate at which neighborhoods and individual homes filter down and up the economic ladder.

\subsubsection{Home maintenance and depreciation of housing capital}

Home maintenance is an essential but understudied feature of housing supply that has a direct impact on the rate at which housing depreciates. Any homeowner who has replaced a leaky roof, installed a new furnace, or repaired rotted window frames knows this at an intimate level. Any discussion of the pace at which neighborhoods rise and fall must therefore recognize that maintenance decisions play a role.

Table 3 reports summary measures from the U.S. Bureau of Economic Analysis (BEA) that highlight the magnitude of investments in home maintenance. Values are provided for every other year from 2000 to 2012 for nominal expenditures on new construction and maintenance. Several patterns are especially relevant to our discussion of neighborhood dynamics.

Observe that maintenance expenditures are large, both in level terms, as compared to expenditures on new home construction, and as compared to GDP. This is evident in the first four rows which report expenditures on new construction and maintenance in dollar values and also as a percentage of GDP. Expenditures on new home construction are roughly 2.5 percent of GDP prior to the 2004-2006 housing boom, peak at roughly 3.4 percent of GDP in 2004-2006, and fall back to just under 1 percent of GDP in 2010. During this same period expenditures on home maintenance and improvements ranged between roughly 1 and 1.3 percent of GDP.

Also apparent in the middle rows of the table, roughly 90 percent of expenditures on new construction are for owner-occupied rather than rental units. It is well documented that owner- 
occupiers are of higher income status than renters. This pattern therefore echoes our earlier discussion that new construction disproportionately accommodates higher income households and is associated with higher income neighborhoods.

A final pattern in the table worth highlighting is that roughly three-quarters of expenditures on home maintenance and improvements are in the owner-occupied sector. This is notably less than the owner-occupied share of new construction, but still substantially above the overall U.S. homeownership rate which ranged between 65 and 69 percent over the 2000-2012 period. In part, these patterns arise because as homes age there is a net tendency for units to switch from owner-occupied to rental occupancy (see Rosenthal (2014)). We consider now the degree to which home maintenance slows depreciation of housing stock.

Harding, Rosenthal and Sirmans (2007) use 1985-2001 data from the American Housing Survey (AHS) to investigate the impact of home maintenance expenditures on the rate of house price inflation (quality adjusted) among owner-occupied homes. They document that reported home improvements and maintenance average just over 1 percent of house value on an annual basis, consistent with the large expenditure on home maintenance and improvements documented in Table 3. Harding, Rosenthal, and Sirmans (2007) then augment a standard repeat sales model (e.g. Case and Shiller (1987)) to include controls for age-related depreciation and maintenance expenditures in order to estimate the impact of these additional controls on house price depreciation rates. Their model takes on the following form,

$$
\ln \left(\frac{P_{t+\tau, i}}{P_{t, i}}\right)=\sum_{t=1}^{\tau_{i}} \gamma_{t} D_{t, i}+\alpha \log \left(\tau_{i}\right)+\tilde{b}_{1} \frac{\tilde{M}_{1 t o 3, i}}{P_{t, i}}+\tilde{b}_{3} \frac{\tilde{M}_{4 t o 6, i}}{P_{t, i}}+\tilde{b}_{3} \frac{\tilde{M}_{7 t o 18, i}}{P_{t, i}}+\omega_{t+\tau, i}
$$

where $P_{t}$ and $P_{t+\tau}$ are a home's sale price upon turning over at time $t$ and $t+\tau$. The standard repeat sales model includes only $\sum_{t=1}^{\tau_{i}} \gamma_{t} D_{t, i}$ for control measures with $D=1,0$, or -1 for the 
second sale date $t+\tau$, dates for which the home does not sell, and the first sale date $t$. That specification is obtained by differencing hedonic house price regressions between the two sale dates and imposing the assumption that all attributes of the home and their shadow prices remain fixed over time. In the augmented model in expression (5), depreciation associated with the passage of time is captured by $\alpha \log (\tau)$ while the $\tilde{M}$ terms capture the level of maintenance relative to period- $t$ house value 1 to 3 years in the past, 4 to 6 years in the past, and 7 to 18 years in the past. A limitation of the model is that depreciation must be entered non-linearly $(\operatorname{as} \log (\tau)$ in this instance) to avoid perfect collinearity with the inflation indexes $\sum_{t=1}^{\tau_{i}} \gamma_{t} D_{t, i}$. The gross-ofmaintenance rate at which homes depreciate is then given by $\alpha / \tau$.

Evaluating using sample median values for $\tau$, Harding, Rosenthal, and Sirmans report that the average annual gross-of-maintenance real rate of house price depreciation is roughly 3 percent. Expenditures on maintenance offset roughly 1 percentage point of that depreciation reducing the net-of-maintenance real rate at which homes depreciate to 1.94 percent per year ((see Table 4, page 212 of Harding, Rosenthal, and Sirmans (2007)). Together, these results and the summary measures in Table 3 confirm that expenditures on home maintenance are large and substantially slow the rate at which housing depreciates.

Gyourko and Saiz (2004) show that homeowners reduce maintenance expenditures by up to fifty percent if their home falls in value below construction cost, a result that has important implications for neighborhood dynamics. ${ }^{39}$ Consider for example a city in which home values have fallen below construction cost as would be typical of many declining areas such as Detroit that have experienced sharp declines in employment. In the face of declining house prices, the

\footnotetext{
${ }^{39}$ As with Harding, Rosenthal, and Sirmans (2007), they obtain this result using the American Housing Survey (AHS) panel.
} 
return on home maintenance will be far less than one dollar for every dollar invested. Moreover, in locations that have been subject to sharply falling home prices, many homeowners find themselves in a negative net equity position in which they owe their mortgage lender more than the market value of the home. Such families have financial incentives to default on their mortgage upon moving from their homes and, for that reason, have little incentive to maintain their home.

These implications of Gyourko and Saiz (2004) suggest that declining communities are likely to receive less investment in home maintenance. Reduced home maintenance in turn will accelerate depreciation of the housing stock, and contribute to neighborhood (and city-level) decline. Brueckner and Helsley (2011) develop a dynamic model that reinforces this view. They argue that market failures that draw households to suburban communities in search of more attractive homes depress central city home prices and undermine incentives to maintain central city housing. This contributes to decay of the central city housing stock and leads to further central city decline. Together, Gyourko and Saiz (2004) and Brueckner and Helsley (2011) suggest that there are important dynamic links between maintenance and neighborhood change although that relationship has mostly escaped attention in the literature. ${ }^{40}$

\subsubsection{The decision to redevelop}

The model in Brueckner and Rosenthal (2009) discussed earlier emphasizes that as housing ages it slowly deteriorates and is eventually demolished and redeveloped. As described above, this contributes to systematic cycles in neighborhood economic status as higher income

\footnotetext{
${ }^{40}$ Lee, Ries, and Somerville (2013) offer a completely different perspective on home maintenance. They argue that with incomplete information about house quality, home maintenance may be perceived by prospective buyers as a signal that housing quality is low. Under this argument, home maintenance reduces house value, ceteris paribus. An implication of this argument is that uncertainty about housing quality could accelerate deterioration of the stock by reducing incentives for maintenance.
} 
families are attracted to the newly built housing. This section considers a set of papers that evaluate the timing and nature of the decision to redevelop a home.

Rosenthal and Helsley (1994) develop and test a model that frames the decision to redevelop a parcel of land. In a perfect foresight setting, they argue that housing is redeveloped when the value of land in its vacant state exceeds the value of the property with the existing structure in place, and adjusted for demolition costs. Empirical evidence based on single family detached home sales in 1987 in Vancouver, British Columbia, supports the model structure. ${ }^{41}$

Rosenthal and Helsely (1994) separate home sales into two samples, those sold for redevelopment and those for which the existing structure is retained. Because demolition costs are small for single family detached homes, they argue that properties sold as teardowns can be treated as vacant land sales. Allowing for sample selection effects sale price regressions are then estimated using the two samples. A second stage structural probit model yields support for the view that homes are demolished when the site is more valuable as vacant land which allows for future development options as compared to retaining the current structure and use.

Dye and McMillen (2007) revisit the redevelopment question using data from seven municipalities in the Chicago metropolitan area. Between 1996 and 2003, the share of existing stock that was redeveloped ranged from a low of 2.11 percent (in Park Ridge) to a high of 9.4 percent (in Winnetka). The city of Chicago experienced a redevelopment rate of 2.9 percent. These high rates of redevelopment are consistent with the patterns in Figure 1, Panel 3 and Figure 4, Panel 3. As discussed earlier, those panels point to extensive redevelopment and gentrification in Chicago in recent years. Using these data, Dye and McMillen also find

\footnotetext{
${ }^{41}$ Vancouver is a particularly convenient location for such a study as it underwent a wave of redevelopment during this period with nearly 8 percent of single family homes sales in 1987 having been sold for redevelopment.
} 
compelling support for the principle that the price of teardown properties is approximately equal to the value of vacant land. ${ }^{42}$

Three recent papers more clearly cast the decision to redevelop or partially modify a structure as a call option held by the owner of the property. That option gives the owner the right but not the obligation to modify the structure, either completely as in the case of demolition and redevelopment, or partly as in the case of home improvements. Modeling property ownership in this manner has several advantages as it allows one to draw on standard implications of option theory. In a largely theoretical paper, Guthrie (2010), for example argues that new house prices can exceed development costs even in the absence of restrictive zoning that limits development. They emphasize that in competitive land markets, uncertainty encourages land investors to delay development of vacant parcels of land. ${ }^{43}$ In Guthrie's model competition erodes the value of the development call option but does not reduce option value to zero (analogous to Bulan, Mayer, and Somerville (2009)). Guthrie further argues that when housing demand is very price elastic and interest rates are low, growing cities with heterogeneous quality vacant land should exhibit relatively high ratios of home price to development costs (including land and construction cost). Guthrie offers this as an alternative explanation for high price-to-cost ratios that have previously been attributed to restrictive zoning (e.g. Glaeser, Gyourko and Saks (2005a, 2005b)) and topographic features that restrict land supply and development opportunities (e.g. Saiz (2010)).

Clapp and Salavei (2010) argue that as a structure ages and deteriorates, the value of the option to modify the structure increases. Clapp and Salavei (2010) emphasize that increasing

\footnotetext{
${ }^{42}$ Dye and McMillen (2007) use demolition permits to classify homes as those sold as teardowns and those for which the existing structure was retained. They also carefully model and test for possible misclassification. Results indicate that misclassification occurs but only for a small share of homes and not enough to affect their results. These findings suggest that demolition permits are an effective way of classifying homes sold for demolition. ${ }^{43}$ Capozza and Helsley (1990) also discuss the manner in which uncertainty in the face of irreversible development increases the option value on undeveloped land and delays development. It is worth noting, however, that under alternate conditions uncertainty can actually accelerate development, as in Bar-Ilan and Strange (1996) who consider the impact of lags between the time when an investor begins a project and when it is completed.
} 
option value associated with older properties should increase property value, ceteris paribus. McMillen and O'Sullivan (2013) emphasize that as the time to redevelopment approaches, the value of existing structure attributes (e.g. bedrooms, size, etc.) should decline. At the point of redevelopment, as emphasized by Rosenthal and Helsley (1994) and Dye and McMillen (2007), existing structural attributes should have zero value.

Clapp and Salavei (2010) test the implications of their model using home sales between 1995 and 2007 in Greenwich, Connecticut. They construct alternative measures of the potential obsolescence of the existing structure which should be positively related to the value of the option to modify or redevelop the home. Their preferred measure is the town's assessed value of the structure divided by the assessed value of the lot as if cleared of the structure. The intuition behind this measure is that structure and land are complementary goods. Families who are willing to pay a large amount for their location and other lot-specific attributes (e.g. square footage) will typically also want to occupy a valuable structure on the site. A low structure-tolot value ratio, therefore, is characteristic of a home with a potentially dilapidated or obsolete structure that is ripe for renovation or redevelopment. Hedonic regressions of sale prices confirm that, controlling for many other attributes, low structure-to-value ratios increase sale price.

Clapp and Salavei (2010) also experiment with an alternative measure of structure obsolescence based on floor space of the home in question divided by floor space of recently built nearby homes. The intuition behind this measure is that newly built structures provide interior space that meets current preferences and demand. Existing homes of markedly different size are likely to be obsolete. This was graphically apparent in Vancouver B.C. in the late 1980s and 1990s. Small but relatively young homes were frequently demolished and invariably 
replaced with much larger homes (e.g. Rosenthal and Helsley (1994)). Using this alternate measure Clapp and Salavei (2010) obtain results that are largely similar to those from their preferred measure.

An implication of these results is that the effect of house age on property value is more complicated and nonlinear than typically allowed for in traditional specifications of hedonic models that do not control for the value of the option to modify the structure. Clapp and Slavei (2010) interact their measures of structure obsolescence with age of the home and obtain evidence consistent with this view. McMillen and O'Sullivan (2013) extend these ideas by emphasizing that at the time of sale there is uncertainty as to whether a home will soon be renovated or redeveloped. This differs from Rosenthal and Helsley (1994) and Dye and McMillen (2007) who assume that a home's teardown status is known with certainty at the time of sale. McMillen and O'Sullivan (2013) allow for their more general view by estimating a hazard model of time to demolition following a sale. They then estimate separate hedonic models of sale price for homes likely to be redeveloped within two years of sale and those that are less likely to be redeveloped. Results confirm that uncertainty delays the decision to redevelop as would be expected from standard option theory. In addition, structural attributes including especially interior space have much less effect on transactions price for homes destined for demolition and redevelopment within two years. ${ }^{44}$

\subsubsection{Filtering and gentrification}

Home maintenance and the decision to redevelop a property clearly affect the pace and timing of change in neighborhood economic status. Here we summarize results from two recent

\footnotetext{
${ }^{44}$ See also Brooks and Lutz (2012) who argue that challenges with land assembly can create frictions that delay urban redevelopment.
} 
papers that offer evidence on the rate at which change occurs while shedding light on additional drivers of change.

Rosenthal (2008a) measures the change in neighborhood economic status on a decadeby-decade basis. As discussed earlier, economic status is measured as the average income in a census tract divided by average income across tracts in the MSA. For the balanced panel of census tracts drawn from the 35 cities previously described, the absolute value of the change in tract relative income ranges from a high of 14.9 percent from 1950 to 1960 to a low of 11.5 percent from 1970 to 1980 . Similar values are obtained for a balanced panel of census tracts drawn from 331 metropolitan areas and followed from 1970 to 2000 . For this sample the absolute value of the change in tract relative income averages 12.2 percent from 1970 to 1980 , 13.1 percent 1980 to 1990 , and 12.4 percent 1990 to 2000 .

Rosenthal (2014) takes a more micro view by considering the rate at which individual homes filter down and up the economic ladder. Drawing on the American Housing Survey (AHS) panel which follows homes - not people - over time, Rosenthal observes when homes turn over. The standard repeat sales model is then adapted to consider the change in real income of newly arriving occupants across turnover dates. More specifically, consider two successive turnovers when a home is age $t$ and $t+\tau$ years, respectively. For each of these turnovers, income of the arriving occupant is written as

$$
\begin{aligned}
& Y_{t}=e^{\gamma_{t}} f\left(\mathbf{X}_{t} ; \boldsymbol{\beta}_{t}\right), \\
& Y_{t+\tau}=e^{\gamma_{t+\tau}} f\left(\mathbf{X}_{t+\tau} ; \boldsymbol{\beta}_{t+\tau}\right) .
\end{aligned}
$$

where $f(\mathbf{X} ; \boldsymbol{\beta})$ is an unknown and potentially non-linear function of the structural and neighborhood characteristics of the home $(\mathbf{X})$ and their shadow prices $(\boldsymbol{\beta})$. If $\mathbf{X}$ and $\boldsymbol{\beta}$ are time 
invariant, taking logs and rearranging gives the log change in arriving occupant income between turnovers,

$$
\log \left(\frac{Y_{t+\tau}}{Y_{t}}\right)=\gamma_{t+\tau}-\gamma_{t}+\omega_{t+\tau},
$$

where $\omega$ is a disturbance term and $f(\mathbf{X} ; \boldsymbol{\beta})$ differences away. For a sample of properties $(i=1$, $\ldots, n)$ that experience turnovers at various ages, an estimable version of (7) is,

$$
\log \left(\frac{Y_{t+\tau, i}}{Y_{t, i}}\right)=\sum_{t=1}^{\tau_{i}} \gamma_{t} D_{t, i}+\omega_{t, i} \quad \text { for home } i=1, \ldots, n
$$

where $D_{t}$ equals $-1,0$ or 1 depending on whether a given property of age $t$ turns over for the first time, does not turn over, or turns over for the second time, respectively.

Rosenthal (2014) estimates expression (8) separately for rental and owner-occupied units. Results confirm that housing filters down with house age, on average, and more rapidly when the home is young. For rental units, the real income of an arriving occupant at a 50 year old home is roughly 70 percent below that of the arriving occupant of a newly built unit, ceteris paribus. For owner-occupied housing the difference is smaller, just 30 percent. On the whole, these estimates are large enough to account for the stylized fact that except for newly built subsidized units, lower income families typically live in older homes.

To help explain the micro-foundations of these rates of change, Rosenthal (2014) next considers the following simple housing demand function:

$$
\log \left(h_{t, i}\right)=\theta_{Y} \log \left(Y_{t, i}\right)+\theta_{q} \log \left(q_{t, i}\right) .
$$

where housing $(h)$ is treated as a package of homogenous quality adjusted units, rent per unit of housing on a quality adjusted basis is given by $q$, and the parameters $\theta_{Y}$ and $\theta_{q}$ are the income and price elasticities of demand for housing, respectively. Rearranging (9), differencing across 
turnover dates, and imposing a constant annual rate of depreciation $d$ (i.e. $\left.\log \left(h_{t+\tau, i} / h_{t, i}\right)=d \tau_{i}\right)$

yields an alternate expression for $\log \left(Y_{t+\tau, i} / Y_{t, i}\right)$,

$$
\log \left(\frac{Y_{t+\tau, i}}{Y_{t, i}}\right)=\frac{d}{\theta_{Y}} \tau_{i}-\frac{\theta_{q}}{\theta_{Y}} \log \left(\frac{q_{t+\tau, i}}{q_{t, i}}\right)+\omega_{t, i}
$$

Expression (10) makes clear that filtering rates depend on the rate at which housing depreciates $(d)$, the income and price elasticities of demand for housing $\left(\theta_{Y}\right.$ and $\left.\theta_{q}\right)$, and the rate of house price inflation $\left(\log \left(q_{t+\tau} / q_{t}\right)\right)$. As would be expected, house price inflation slows the rate at which homes filter since $-\theta_{q} / \theta_{Y}>0$ given downward sloping demand $\left(\theta_{q}<0\right)$ and that the income elasticity of demand is positive $\left(\theta_{Y}>0\right)$. Because house price inflation differs across locations, filtering rates should as well. Moreover, if real house prices do not change as has been the long run norm for most areas of the United States (see Table 6 of Rosenthal (2014), homes filter at a rate given by $d / \theta_{Y}$. As noted earlier, Glaeser, Kahn, and Rappaport (2008), Rosenthal (2014), and other studies confirm that $\theta_{Y}$ is well below 1. From expression (10), this amplifies the rate at which homes filter down for any given rate at which housing depreciates.

Rosenthal (2014) estimates (10) for rental and owner-occupied homes separately. House price inflation is measured using the Federal Housing Finance Association (www.fhfa.gov) repeat sale price index either as a direct proxy for the change in $q$ or as an instrument treating the change in real rent (for rental units) and price (for owner-occupied units) as endogenous controls. While estimates differ modestly with alternative specifications (e.g. OLS, 2SLS, house fixed effects), results mostly indicate that rental units filter down at a real annual rate of roughly 2.5 percent while owner-occupied filter down at a real annual rate of roughly 0.5 percent. $^{45}$

\footnotetext{
${ }^{45}$ Expression (10) also allows one to estimate model-based measures of filtering rates by dividing separately estimated rates of depreciation $(d)$ by separately estimated values for the income elasticity of demand for housing. Rosenthal (2014) performs this exercise and obtains additional, qualitative support for the idea that filtering rates increase with the rate at which homes depreciate and more so as the income elasticity of demand falls below 1.
} 
Summarizing, evidence suggests that neighborhoods change in economic status at a rate of roughly 12 percent per decade. Over a fifty year period, newly built rental homes experience a roughly 70 percent decline in occupant real income while newly built owner-occupied units experience a 30 percent decline. Although mobile households might not recognize that their communities are in slow transition to a different status, the rates of change described above confirm that neighborhood economic status is dynamic and goes through long running periods of rise and fall for most urban communities.

\subsection{Does gentrification hurt local residents?}

Gentrification: "The buying and renovation of houses in deteriorated urban neighborhoods, especially by middle-income professionals, thus improving property values but often displacing low-income families"

\section{The Random House College Dictionary, Revised Edition, Random House (1981)}

Gentrification is controversial and often associated with negative connotations. The definition above explains why. Gentrification implies an asymmetry as higher income families choose to move into a community while lower-income households are at risk of being forced out because of rising property values and rents. This section reviews a small set of recent papers that consider who wins and who loses from gentrification, and whether lower income families are necessarily hurt.

Freeman (2005) uses individual-level data from the Panel Survey of Income Dynamics (PSID) to compare mobility rates of individuals residing in gentrifying communities to individuals in communities of similar economic status that do not gentrify. Freeman reports that mobility rates are similar for the two groups and from this concludes that gentrification does not disproportionately prompt out-movement of low-income families. McKinnish, Walsh, and White (2010) conduct a complementary analysis using confidential long form data from the 1990 
and 2000 U.S. Census. They evaluate who moves out of gentrifying neighborhoods, who among existing residents remains in the community, and who moves in from other locations. Based on a detailed assessment of individual and census tract-level data, McKinnish, Walsh and White conclude that predominantly black low-income communities that gentrify attract middle class black households. In contrast, gentrifying communities with limited numbers of black families exhibit high rates of out-migration among black high school graduates.

Vigdor (2010) is the only study we are aware of that applies core economic principles to evaluate whether existing residents of gentrifying communities are hurt or benefit from the rising status of their neighborhood. Central to Vigdor's work is a sorting model in which households differ in their taste for neighborhood quality where neighborhood quality is exogenously given. In Vigdor's model, households with the weakest taste for neighborhood quality sort into the lowest quality community in equilibrium. Households with the next strongest taste for neighborhood quality occupy second-tier quality neighborhoods, and so on up the quality ladder. In this setting, Vigdor shows that an exogenous decrease in quality in a given neighborhood lowers utility levels for all households in communities of equal or higher quality. This follows because of competition for access to given communities and the equilibrium adjustment of house prices.

Vigdor (2010) explores empirical implications of his model using a special feature of the American Housing Survey (AHS). Following homes over time, he carefully tracks the change in a set of indicators of neighborhood distress based on features within 300 feet of the housing unit. These include the number of abandoned buildings, bars on windows, streets in disrepair, and trash in the streets. Also included in the AHS is a qualitative variable in which respondents rate 
their satisfaction with their neighborhood on a 1-10 scale where 10 is the best. The AHS also allows one to observe changes in housing rents for rental units at the individual unit level.

Controlling for a variety of other factors, results indicate that improving neighborhoods signaled by a reduction in abandoned buildings and the like exhibit rising rents as would be expected. The question then is whether the willingness to pay for existing neighborhood improvements exceeds the increase in market rents. Such evidence would suggest that gentrification enhances welfare for current residents while the opposite would be true if rent increases exceed willingness to pay. Based on a series of analyses and robustness checks, Vigdor reports that most renters are willing to pay between 1 and 3 percent of their annual income for a one standard deviation increase in neighborhood quality while the change in rent from improved neighborhood quality is much less. From this assessment, Vigdor concludes that, at least for many renters, improved neighborhood quality arising from gentrification enhances welfare.

From a qualitative perspective, Vigdor's analysis reminds us that rent increases are a poor proxy for the welfare effects of gentrification on existing residents who may themselves benefit from improved neighborhood amenities. Indeed, the possibility that gentrification may be good for local residents has been raised in various popular press reports, an example of which is a recent article in New York Magazine, (see Davidson (2014), “Is Gentrification All Bad?”). Nevertheless, controversy remains as is evident in a New York Times article in 2008 by Williams (2008)), "Harlem Area is Blighted, State Agency Declares.” 


\subsection{U.S. context versus Europe}

In the Introduction we noted that most of the literature on neighborhood dynamics has been written in a U.S. context and for that reason our review reflects this. Here we pause to briefly consider the possible influence of two prominent contextual features of U.S. cities on neighborhood income dynamics and in comparison to cities found in Europe.

U.S. cities are young compared to most European cities. Partly for that reason, few U.S. cities have the sort of historic downtowns that are characteristic of cities like Madrid, Barcelona, Paris, Basel, Rome, or Vienna, not to mention truly ancient cities like Jerusalem in the Middle East. In many of these places, a protected historic center provides a unique urban amenity that may attract higher income families and has the potential to slow the tendency for filtering and related cycles in economic status. The paper by Brueckner, Thisse and Zenou (1999) on Paris provides evidence of this. In that sense, historic city centers may have much the same dampening effect on neighborhood change as attractive physical amenities that have recently been studied by Lee and Lin (2013). Partly for that reason, neighborhood income dynamics may be more pronounced in the U.S. relative to Europe but this remains an open question.

A second feature of the U.S. that may have also amplified neighborhood income stratification and related dynamics is its history of racial tension and the Great Migration. As described in Cutler, Glaeser and Vigdor (1999), between 1890 and 1970, the U.S. experienced a massive flow of predominantly poor African-Americans from the rural south to cities throughout the country, especially in the south and in the industrial northeast and Midwest. That migration gave African-Americans access to higher paying manufacturing jobs and contributed to prosperous African-American neighborhoods, such as Harlem as described in the Introduction. However, post-World War II, the great migration was accompanied by equally dramatic 
suburbanization of both white households (Boustan (2010)), Baum-Snow (2007)) and manufacturing (Glaeser and Kahn (2001)). By the 1970's U.S. manufacturing was in sharp decline and migration from the rural south had slowed to a trickle leaving highly segregated central cities with declining economic fortunes and population. It is certain that the massive migration of lower income, southern rural blacks into U.S. cities increased racial segregation in U.S. cities. It seems likely that this also contributed to income segregation and amplified cycling of neighborhood economic status over the long sweeps of time described earlier. However, this is also an open question.

\section{City dynamics}

\subsection{Overview}

This section reviews a particular slice of literature on city dynamics. As with the previous section our focus is on the extent and conditions under which a location's economic status relative to other locations is entrenched or changes over time in a systematic or nonsystematic fashion. An important conclusion from this section is that when metropolitan area status is measured based on population size, as has been the case in most of the agglomeration literature, MSA status appears to be extremely stable. However, when status is measured based on direct indicators of economic activity and especially per capita income, MSA economic status is far more dynamic than has generally been recognized.

As with the previous section on neighborhoods, we begin with four stylized facts, the first three of which are taken from the literature while the fourth is new to this review. We then discuss various recent papers that help to explain and interpret the stylized facts while drawing out implications for MSA-level dynamics. 


\subsection{Three previous stylized facts and one new observation}

\subsubsection{Stable city size distributions that approximate the rank-size rule}

Eaton and Eckstein (1997) examine changes in relative city sizes for 40 long-established cities in Japan between 1876 and 1990, and 39 cities in France between 1925 and 1985. They find that most cities exhibit parallel population growth. Moreover, the city size distributions are consistent with the rank-size rule and Lorenz curves confirm that the size distributions of French and Japanese cities remain stable over time. Sharma (2003) examines the size distribution of cities in India over a roughly 100 year period. She reports short run deviations from long-run parallel growth paths but those deviations tend to fade after less than a decade. Her results also confirm that city size distributions tend to be stable.

Probably the most dramatic evidence of stable spatial distributions of population comes from Davis and Weinstein (2002). Drawing on current, historical and archeological data for Japan, they evaluate the extent to which the spatial distribution of population across 39 regions throughout Japan adheres to the rank-size rule at different points in time over an 8,000 year history. For each period they estimate,

$$
\log (\text { Population rank })=\text { Constant }-b \cdot \log (\text { Population Size })
$$

where a coefficient for $b$ of -1 implies that the $\mathrm{n}^{\text {th }}$ largest location is $1 / \mathrm{n}$ the size of the most populous area, in which case Zipf's Law and the rank-size rule are said to hold.

Table 4 reproduces estimates of $b$ from Table 1 of Davis and Weinstein (2002, page 1273) for twelve periods from $-6000 \mathrm{BC}$ to 1998 . The patterns are stunning with Zipf coefficients close to -1 in nearly all periods. These and other estimates in the literature confirm the first stylized fact, that the spatial distribution of population within a country tends to be extremely stable over long sweeps of time and approximate the rank-size rule. This feature of 
economic growth has been appreciated for some time now in the literature. See, for example, Gabaix and Ioannides (2004).

\subsubsection{Slow movement of individual cities up and down the city size distribution}

Returning to Eaton and Eckstein (1997), for both Japan (1876-1990) and France (19251985), they divide the cities in their samples into six relative size categories based on a fixed reference point. In both samples, Eaton and Eckstein (1997) find that there is relatively little tendency for cities to transition to a different size category over the sample horizon. In Japan, 0 to 22 percent of cities transition to a different size category depending on the initial category to which a city is assigned. In France, the corresponding range is 10 to 31 percent. Analogous results are obtained by Black and Henderson (2003) for 282 U.S. metropolitan areas between 1900 and 1990 (and five city size categories). As highlighted in the Introduction, Duranton (2007) documents that of the ten largest metropolitan areas in the United States in 1977, the average change in rank in the MSA rank-size distribution over the following twenty years was just 1.2. Moreover, only two of these ten MSAs, Cleveland and San Francisco, experienced a change in rank beyond one position in the MSA size distribution.

Broadly speaking, these and other studies in the literature provide evidence in support of a second stylized fact: cities tend to move only very slowly up and down the city population size distribution. Together, these first two stylized facts could suggest that the economic status of individual MSAs hardly changes even over extended periods of time. The next two stylized facts suggest that such an interpretation would not be correct. 


\subsubsection{Fast changes in city industrial mix relative to total employment}

In an important departure from earlier literature on urban dynamics, Duranton (2007) focuses on the pace at which the mix of local economic activity changes over time. He shows that metropolitan areas in both France and the U.S. exhibit comparatively rapid changes in their industrial mix over time in comparison to population size. In a follow up study, Findeisen and Südekum (2008) document similar patterns for West Germany.

In both Duranton (2007) and Findeisen and Südekum (2008), industry churning across MSA's is measured by comparing the degree to which employment shares in individual industries within a given metropolitan area change over time. Churn is thus measured as

$$
\text { Churn }_{c}=\frac{1}{25}\left(\sum_{t=1977}^{2001} \sum_{z=1}^{n} \frac{|e(z, c, t+1)-e(z, c, t)|}{e(c, t)}\right) \text { for } c=1, \ldots, 326
$$

where $e$ is the level of employment in industry $z$ in city $c$, at time $t$. In Findeisen and Südekum Churn is measured using 25 years of data from 1977-2001 for 326 MSAs in West Germany. Similar magnitude samples were used by Duranton (2007) for the U.S. and France. In both studies, values for Churn were then compared to the yearly average aggregate change in each MSA's total employment and also the average annual change in each industry's share of national employment.

Table 5 reproduces estimates of Churn from Table 1 of Findesen and Südekum (2008). The estimates include measures for the U.S. and France taken from Duranton (2007) and also for West Germany as calculated by Findeisen and Südekum (2008). Two patterns are especially striking. First, the average value of Churn across MSAs is remarkably similar for West Germany, the US, and France. Second, the industrial mix within a given MSA changes at nearly twice the rate necessary to accommodate change in the MSA's aggregate level employment. 
These patterns indicate that the industrial mix within individual MSAs tends to change rather quickly in comparison to changes in the MSA's total level of employment, our third stylized fact.

\subsubsection{Very fast movement of cities up and down in economic status based on income}

The comparatively fast change in an MSA's industrial mix is suggestive that MSA economic status may be subject to much more change over time than implied by stable MSA population size distributions as documented in the first two stylized facts. This section introduces a fourth stylized fact that reinforces that view.

In Figure 6 we display two Lorenz curves that summarize inequality across U.S. metropolitan areas in $2000 .^{46}$ The solid line is based on differences in population across MSAs, treating total population across all metropolitan areas in the U.S. as the normalizing factor. The dashed line is calculated in an analogous manner and is new to the literature. This line reports inequality in median income across MSAs treating the sum of median income across all metropolitan areas as the normalizing factor (with each MSA given equal weight). The MSA population size distribution displays a familiar highly skewed pattern that clearly dwarfs the degree of inequality in median income across metropolitan areas.

It should come as no surprise that the distribution of median income across MSAs is much flatter than its population analogue. Glaeser and Mare (2001) report that nominal average wage rates in 1990 were roughly 30 percent higher in MSAs over 1 million people as compared to rural areas outside of MSAs. That is a small difference compared to the difference in population density between such areas. Moreover, the urban wage premium falls dramatically after controlling for worker attributes. In a review of earlier literature, Rosenthal and Strange (2004) report that doubling city size increases wage by 3 to 5 percent controlling for worker

\footnotetext{
${ }^{46}$ The Lorenz cures are based on the authors' calculations using public use micro data from the 2000 Decennial Censuses as obtained from www.ipums.org.
} 
attributes (consistent with estimates in Rosenthal and Strange (2008)). More recent literature reviewed by Combes and Gobillon (this volume) suggests an even smaller urban wage premium, possibly as low as 1 to 3 percent. This does not, however, mean that differences in income distributions across MSAs are fixed.

Using the public use micro data sample of the Decennial Censuses (see www.ipums.org), we examine changes in an MSA's economic status between 1980 and 2010 using a balanced panel of 219 MSAs in the United States. For these purposes, an MSA's economic status is measured based on its rank among the other metropolitan areas when comparing income at a given point in the within-MSA income distribution. Results are reported in Table 6 based on several different measures of MSA income. Reading across the columns, these include $10^{\text {th }}$ percentile income, $25^{\text {th }}$ percentile income, $50^{\text {th }}$ percentile income, $75^{\text {th }}$ percentile income, and $90^{\text {th }}$ percentile income. For each column, the distribution of the 1980-2010 change in rank among the 219 MSAs is reported going down the rows, from the $10^{\text {th }}$ percentile to the $90^{\text {th }}$ percentile. By construction, the mean change in rank must always be zero as shown in the third row. The median change in rank (in the fourth row) is always close to zero and suggestive of an approximately symmetric distribution. This accounts for the negative values in the first two rows (for the $10^{\text {th }}$ and $25^{\text {th }}$ percentiles) and the positive values in the last two rows (for the $75^{\text {th }}$ and $90^{\text {th }}$ percentiles). For reference, the final column in the table reports analogous measures based on 1980-2010 change in MSA population rank.

The patterns in Table 6 indicate much larger changes in MSA economic rank based on the different measures of income as compared to population. As an example, at the $25^{\text {th }}$ percentile as indicated in the second row, MSA population rank falls 10 positions. In contrast, rank based on income falls roughly 30-35 positions depending on the income measure used. 
This suggests a new fourth stylized fact: based on various measures of per capita income, metropolitan areas move very fast up and down in economic status relative to other MSAs, and especially in comparison to population rank.

\subsection{Drivers of persistence in metropolitan economic status}

In this section we highlight three drivers of persistence in metropolitan-level economic status. These are natural advantages of the location, self-reinforcing effects of agglomeration and economic activity, and the enduring effects of culture. Each is discussed below.

\subsubsection{Natural advantages}

Some of the most striking evidence of extreme persistence is in a series of papers that examine the effects of allied bombings in Japan and Germany during WWII on the long-run population of cities in these two countries. As noted earlier, Davis and Weinstein (2002) examine the distribution of population across regions throughout Japan going back 8000 years. From the stone-age period to $1200 \mathrm{AD}$ the correlation between past and current (based on 1998) region-level population is roughly 0.5 to 0.6 with higher correlations after $1200 \mathrm{AD}$. These patterns indicate that areas that were important thousands of years ago remain so today.

Davis and Weinstein (2002) also report that the correlation between city level population in Japan between 1998 and 1920 is 0.94 . In some respects, these patterns are even more striking than the 8000 year correlations since many of the Japanese cities were heavily bombed during WWII. ${ }^{47}$ The post-war patterns indicate that despite widespread destruction during the war, that damage had little long term impact on the spatial distribution of population in Japan as the

\footnotetext{
${ }^{47}$ In the 66 Japanese cities covered in the United States Strategic Bombing Survey, estimates indicated that over half of all structures were destroyed and that some cities lost as much as 50 percent of their population during the war.
} 
country rebuilt and recovered. Two especially prominent examples of this sort of extreme tendency towards mean reversion are Hiroshima and Nagasaki which were devastated by the nuclear detonations. Davis and Weinstein (2002) show that although both cities suffered dramatic loss in population during the war, Nagasaki returned to its long run population growth path by 1960 while Hiroshima returned to its long run population growth path by 1975 (see Davis and Weinstein (2002), Figure 2, page 1282).

In a subsequent paper, Davis and Weinstein (2008) further show that the industrial mix of economic activity within individual metropolitan areas in Japan also displays considerable mean reversion and long-run resilience to damage incurred during WWII. The loss of manufacturing and other industry specific employment during World War II was followed by substantially faster growth in war-damaged industries and a strong tendency for individual cities to return to their former, pre-war industrial composition. Based on these patterns, Davis and Weinstein (2008) conclude that location fundamentals - i.e. natural advantages - play an important role in determining the distribution of population and industrial mix over space.

Brakman, Garretsen and Schramm (2004) conduct a similar exercise for housing stock in German metropolitan areas prior to and following World War II. In West Germany, they find that cities that lost the most housing stock during Allied bombings displayed the fastest post-war growth in housing stock. Mirroring much of Japan, West German metropolitan areas returned to their previous long-run trends by the 1960s. In contrast, in East Germany, post-war spatial patterns of growth in housing stock were mostly unrelated to the level of wartime damage. Brakman, Garretsen and Schramm (2004) suggest that central planning and limited property rights in post-war East Germany may account for the East-West difference in post-war recovery patterns. However, they also caution that their sample of East German cities is relatively small 
and that idiosyncratic features of the split between East and West Germany may confound interpretation of post-war patterns of development.

Recent work by Glocker and Sturm (2013) sheds further light on these patterns by examining pre-war German cities that became part of Poland after the war. Efforts by West Germany to rebuild its cities following the war cannot be the driving factor behind growth in these formally German cities. Similarly, a tendency for displaced population to return to their former and now destroyed cities in order to renew previous social networks would not seem a likely driver of growth in formally German metropolitan areas. The same is true for any sense of patriotic duty that might foster a desire to rebuild an area that was destroyed. Indeed, the change in border for formerly German cities incorporated into post-war Poland invalidated previous property rights and prevented the return of displaced pre-war population. Nevertheless, Glocker and Sturm (2013) also find that bombed cities fully recover their pre-war population shares. On balance, therefore, the evidence for Germany is consistent with Davis and Weinstein's (2002, 2008) findings for Japan. In both countries cities regained their pre-war relative status in population rank and in a manner that suggests an important role of location fundamental advantages in shaping the spatial distribution of economic activity. ${ }^{48}$

\subsubsection{Agglomeration economies}

A completely different argument for extreme persistence of a city's economic status is based on self-reinforcing spillovers from agglomeration. Imagine a featureless plain and that economic activity is dropped first at site A instead of site B. If agglomeration fosters productivity spillovers then site A gains an immediate productivity advantage over site B that is

\footnotetext{
${ }^{48}$ Consistent with the above literature, Acemoglu, Johnson and Robinson (2005) argue that the rise of Western Europe after 1500 was disproportionately driven by growth among countries adjacent to the Atlantic Ocean.
} 
self-reinforcing unless or until congestion costs slow site A's growth (as in Cuberes (2011), for example). Under these conditions, site A will forever be a larger and likely higher per capita income city than site B because of greater productivity even though the events that initiated development at site A may no longer be relevant.

Bleakley and Lin (2012) make creative use of data on historical patterns of development that allows them to look for evidence of the sort of persistence just described. They examine development patterns adjacent to canoe portage paths that once provided economically important routes around rapids and water falls along natural fall lines that occur at the edge of the Appalachian escarpment in the eastern United States. These portage paths were once an important trade route that contributed to local concentrations of population and equipment in order to facilitate overland transportation of goods. As such, portage paths prompted development of various small towns along the Appalachian mountain chain. However, portage paths lost their economic relevance with the advent of rail transportation and have no intrinsic commercial value today except for recreation.

In the absence of self-reinforcing agglomeration economies, we should not see unusual concentrations of population and economic activity adjacent to portage paths today. Bleakley and Lin (2012) find the opposite and document that portage path locations have significantly higher employment density today. They examine several potential mechanisms for this result including the influence of railroads, education, industrial composition, and the early use of water power. Only the early use of water power survives the inclusion of controls for other historical factors. Portage cities appear to have adopted water power earlier than other locations along the same river shed and so obtained an advantage that leads to future population growth. More 
generally, the patterns in Bleakley and Lin (2012) support the view that agglomeration economies can contribute to extreme persistence in a city's economic status.

In an analogous set of papers, Jedwab and Moradi (2014) and Jedwab, Kerby and Moradi (2014) examine the impact of colonial railroads in Africa as a whole, as well as in Ghana and Kenya. Both papers show that access to colonial railroads implies higher post-colonial population levels even though colonial railroads quickly fell into disrepair and disuse throughout Africa following independence from colonial rule. In Africa as a whole and in Ghana, there is no evidence that this impact operates through roads that were built along original railroad paths. Instead, population patterns in 2000 are entirely explained by urbanization in 1960 when colonial rule was still the norm.

The connection between year 2000 and colonial era population patterns is robust to a variety of identification strategies including the use of straight line distance from major ports to historical capitals as an instrument for railroads. In Kenya, the authors show that access to colonial railroads increases present day population, urbanization, access to public services, and decreases poverty. The authors argue that the railroads were built for geopolitical purposes on the continent and had little to do with local economic factors within Kenya. Further, no population effects are found for placebo lines based on branch lines that were planned, but not built. Like Bleakley and Lin (2012), these papers suggest that obsolete transportation networks have an enduring effect on current spatial patterns of economic activity, consistent with the view that localized shocks to growth have long-term effects. ${ }^{49}$

\footnotetext{
${ }^{49}$ Also consistent with a self-reinforcing role for agglomeration economies, Hanlon and Miscio (2013) find that the interruption of the cotton trade caused by the U.S. Civil War had a significant negative impact on employment in English towns tied to the textile industry for many decades after the end of the war. Wahl (2013) finds that GDP is higher at locations at or close to the site of a Medieval-period trade center even after instrumenting for trade center status with controls for geography, climate, and the historical presence of Christian populations.
} 


\subsubsection{Culture}

A different mechanism that can contribute to extreme persistence in economic development at the regional level is culture. Tabellini (2010) shows that economic growth between 1995 and 2000 within European sub-regions is related to cultural factors after controlling for country fixed effects, school enrollment in the 1960's, and urbanization in 1850 as past indicators of economic development. The influence of culture also persists when Tabellini uses historical variables to instrument for culture, including literacy in 1880 and political institutions between 1600 and 1850. In another recent example, Falck, Heblich, Lameli and Südekum (2012) examine linguistic data from 1879-1888 in German schools. They show that region-level migration decisions are heavily influenced by linguistic similarity even after controlling for geographic features, travel distance, religious boundaries, historical industrial structure, and jurisdiction borders. As with portage paths in the U.S. and colonial railroads in Africa, literacy rates, political institutions, and linguistic differences from over 100 years ago are capable of fostering extreme persistence in spatial patterns of economic activity.

\subsection{Drivers of change in metropolitan economic status}

In this section we discuss drivers of change in metropolitan-level economic status. These include productivity shocks that affect labor demand as well as amenities that affect labor supply. We also highlight the role of housing supply which, when inelastic, has potential to contribute to and in some instance amplify metropolitan area per capita income dynamics.

\subsubsection{Productivity and labor demand}

There has been a strong and well-placed tendency in the literature to equate city growth in population and employment with rising productivity and economic status. Much of that 
literature has been reviewed elsewhere (e.g. Duranton and Puga (2004), Rosenthal and Strange (2004), Behrens and Robert-Nicoud (this volume), Combes and Gobillon (this volume), and Carlino and Kerr (this volume)). In this section we highlight a particular slice of recent additions to that literature that have direct implications for the stylized facts outlined above.

An old literature, beginning with Losch (1954) and Christaller (1966), often referred to as Central Place Theory, outlines a largely static model of a hierarchy of cities within a system of cities framework. In its simplest form, non-export industries differ in their internal economies of scale and also with respect to per capita demand for their services. ${ }^{50}$ Allowing for travel costs, industries with deep internal economies of scale and low per capita demand typically thrive only in large metropolitan areas with large numbers of nearby customers. An example would be specialized medical facilities. Industries with low internal economies of scale and high per capita demand thrive in metropolitan areas of all sizes, as with gas stations.

An implication of the central place theory model is that large metropolitan areas are not simply scaled up versions of small cities but instead have more diverse economies. That diversity has dynamic implications in that it can contribute to cross-fertilization of ideas, innovation, and growth as emphasized by Jacobs $(1969,1984)$ and explored in various papers in the literature on agglomeration economies (see Rosenthal and Strange (2004), for a review). Duranton and Puga (2001), for example, develop an explicitly dynamic model in which large diverse cities serve as incubators and nurture newly created industries. An implication is that industries benefit disproportionately from large-city locations when they are young and are more likely to relocate to more specialized locations as the industry matures. Consistent with this view, Duranton and Puga (2001) report that 72 percent of French plant relocations entail moves from diverse to more specialized locations. In especially innovative sectors of the economy

\footnotetext{
${ }^{50}$ See O’Sullivan (2003), Chapter 5, pp. 92-118, for a discussion of this model.
} 
these sorts of relocations are even more extreme: 93 percent for research and development and 82 percent for pharmacology.

Duranton (2007) develops a conceptual model that builds off of this earlier work and which generates predictions that fit the first three stylized facts described above. He modifies Grossman and Helpman's (1991) model of innovation and growth by adding cross-industry spillovers in a manner that allows for innovations within and across cities. In Grossman and Helpman (1991), research firms compete within each industry to develop new technology for a given industry. Whichever firm succeeds becomes the next technology leader in the industry and only that firm can profitably operate in the industry. In Duranton (2007), a firm in one industry may generate a discovery that makes it the technology leader in a different industry. Further, research firms in an industry can only operate in the city in which the technology leader for that industry is located. In this way, cross-industry spillovers allow cities to both gain and lose industries over time.

Duranton shows that his model leads to comparatively rapid churning of the industrial composition within individual cities, consistent with the third stylized fact above. He also shows that with multiple industries present in each city, individual cities tend to experience slow economic decline or growth as the number of industries present in the city changes over time, consistent with the second stylized fact above. Finally, using parameter values calibrated to fit the model to data for the U.S. and France, simulations largely replicate the existing size distribution of metropolitan areas in those countries and approximate Zipf's law. Analogous results are obtained by Findeisen and Suedekum (2008) for Germany. ${ }^{51}$

\footnotetext{
${ }^{51}$ See Gabaix and Ioannides (2004) and Desmet and Henderson (this volume) for in-depth discussions of Zipf's Law and the size distribution of cities. Outside of the economics literature, there is also recognition that historydependent stochastic processes of the sort modeled by Duranton (2007) yield Zipf's law rank distributions of outcomes for many natural and social systems (see Corominas-Murtra, Hanel, and Thurner (2014), for example).
} 
An implication of Duranton's (2007) model that is not fully developed in his paper or in Findeisen and Suedekum (2008) is that the evolution of individual city size should be a mean reverting process. ${ }^{52}$ A simple derivation of the expected change in city size conditional on a city's initial period size confirms this result. As in Duranton (2007), there are $m$ cities in the system, each of which has one first-nature industry that cannot move. In addition there are $n$ mobile (not first-nature) industries spread throughout the system of cities. All industries are of equal size (employment) so that a city's size is completely determined by the number of mobile industries present plus its one first-nature industry. All individual industries - both first-nature and mobile industries - generate own-industry innovations with probability $D$ and cross-industry innovations in any industry with probability $C$, with $D>C$. Importantly, in a given period, it is never possible for a given industry to receive more than one innovation. Instead, a given industry receives either zero or one innovation.

Consider now a city $p$ in period $t$ with $\eta_{p t}$ mobile industries. To determine the expected size of $p$ in $t+1$ conditional on its period- $t$ size we first calculate the probability that a given mobile (not first-nature) industry $q$ will be present in the city in $t+1$. Summing probabilities over all mobile industries $q=1, \ldots, n$, gives,

$$
E\left[\eta_{p(t+1)} \mid \eta_{p t}\right]=\sum_{q=1}^{n} \operatorname{Prob}\left(\text { industry } q \text { in city } p \text { in } t+1 \mid \eta_{p t}\right) \text {. }
$$

Next, divide this summation into two parts as shown in expression (12b) below. The first summation reflects the expected contribution of city $p$ 's initial set of $\eta_{p t}$ mobile industries to the number of mobile industries present in $p$ in the subsequent period. For a given industry $q$, this equals the probability that no industry anywhere in the system of cities develops an innovation in $q$ between periods plus the probability that an innovation in $q$ does occur but is generated by one

\footnotetext{
${ }^{52}$ For macro-econometric evidence on convergence across states and regions in the U.S., see Holmes, Otero and Panagiotidis (2013), Mello (2011) and Choi (2004).
} 
of the industries already present in $p$. Summing over all $\eta_{p t}$ mobile industries in $p$ then gives the expected number of mobile industries in $t$ that are still present in $t+1$. The second summation in (12b) reflects the expected contribution of the $n-\eta_{p t}$ mobile industries not in $p$ at time $t$ to the number of industries present in $p$ at time $t+1$ :

$$
\begin{aligned}
& E\left(\eta_{p t+1} \mid \eta_{p t}\right)= \\
& \sum_{q=1}^{\eta_{p t}}(\operatorname{Prob}(\text { no innovation in } q)+\operatorname{Prob}(\text { innovation in } q \text { generated in } p))+ \\
& \left.\sum_{q=\eta_{p t}+1}^{n} \text { Prob(innovation in } q \text { generated in } p \mid q \text { not in } p \text { at } t\right)
\end{aligned}
$$

Using the notation above, the probability of no innovation in one of $p$ 's initial mobile industries (the first term in the first summation in (12b)) can be written as $1-D-(n+m-1) C$, where $n+m$ - 1 are the number of industries in the system apart from the own-industry including both mobile and first-nature industries. The probability of an innovation in a specific one of $p$ 's initial mobile industries from within $p$ is given by $D+\eta_{p t} C$ (the second term in the first summation in (12b)). The probability of an innovation in a mobile industry not initially in $p$ but which is generated from within $p$ is given by $\left(\eta_{p t}+1\right) C$ (the second summation in $(12 b)$ ).

Substituting these expressions into (12b), the expected number of mobile industries in city $p$ in $t$ +1 can be written as:

$$
\begin{aligned}
& E\left(\eta_{p t+1} \mid \eta_{p t}\right)= \\
& {\left[\sum_{q=1}^{\eta_{p t}}(1-D-(n+m-1) C)+\left(D+\eta_{p t} C\right)\right]+\left[\sum_{j=\eta_{p t}+1}^{n}\left(\eta_{p t}+1\right) C\right] .}
\end{aligned}
$$

Subtracting $\eta_{p t}$ from (12c) gives the expected change in city size between periods which, upon collecting terms simplifies to, ${ }^{53}$

$$
E\left(\eta_{p t+1} \mid \eta_{p t}\right)-\eta_{p t}=\left(-\eta_{p t} m+n\right) C
$$

\footnotetext{
${ }^{53}$ Expression (12c) simplifies to: $\left(\eta_{p t+1} \mid \eta_{p t}\right)=\eta_{p t}+\eta_{p t}\left(-(n+m-1)+\eta_{p t}\right) C+\left(n-\eta_{p t}\right)\left(\eta_{p t}+1\right) C$.
} 
Expression (12d) indicates that there is a unique steady state $\eta^{*}=n / m$ at which the expected change in city size between periods is zero. This steady state is "stable" because when city size is below that level expression (12d) indicates that the city is expected to grow while the reverse is true when city size is above the steady state. It should be noted, however, that this result requires that $C$ be a constant. If instead $C$ was sensitive to the number of industries in the city, possibly because of external scale economies in research and innovation, then $C$ would be a non-linear function of city size. In this instance, multiple steady states could exist.

Interestingly, Duranton and Puga (2001) postulate such a model in their Nursery City paper where young, innovating industries benefit from being in large cities with a diverse mix of industries. Further, if $C$ varies with the type of innovating industry, then $C$ varies with the mix of industries present in the city and depends on the city's economic and industrial history. This likely increases the potential for multiple steady states and reduces the potential for mean reversion.

For these reasons, the Duranton (2007) model has very different implications for long-run population growth trends across cities as compared to the model in Eaton and Eckstein (1997) which predicts parallel growth across cities. Empirically, Findeisen and Südekum (2008) do find some evidence of mean reversion in total employment among growing German metropolitan areas, a pattern that is inconsistent with parallel growth. Nevertheless, Eaton and Eckstein (1997), Black and Henderson (2003), and Sharma (2003) all report patterns roughly consistent with long run parallel growth for metropolitan areas in Japan, the U.S. and India, respectively, as do Desmet and Rappaport (2013) for U.S. counties after the 1940s. ${ }^{54}$

\footnotetext{
${ }^{54}$ Cuberes (2011) develops a model of sequential city growth that also ultimately implies parallel growth. In the Cuberes model, capital initially flows to the largest city which offers greater returns because of productivity spillovers associated with agglomeration. As excess returns in the largest city diminish, capital flows to the next largest city, and so on down the line towards smaller, newer locations. In any given period, growth is concentrated
} 
It is also interesting to note that industrial churning and change in MSA-level per capita income are both rapid in comparison to MSA-level change in population. Resolution of this difference requires going beyond Duranton's (2007) conceptual model which implies that MSAlevel per capita income is constant across metro areas and over time given the assumption that all industries are alike. For per capita income to vary with city size there must be a correlation between the quality and quantity of industries within a given city. Such correlations are implied by Eaton and Eckstein (1997) and much of the literature on agglomeration economies which tends to argue that larger cities are more productive, an implication of which is that per capita income and city size should move together. Returning to the patterns in Table 6 (our fourth stylized fact), evidence that MSA per capita income changes more rapidly than population and seemingly more rapidly than industrial mix is suggestive that something is going on in metropolitan areas beyond what has been recognized in the literature.

\subsubsection{Amenities and labor supply}

This section considers a very different driver of change in MSA-level per capita income and related economic status. Local amenities and the perceived quality of life have a direct effect on household utility and the desire of families to live and work in a given metropolitan area. This affects MSA-level labor supply, equilibrium wages, and the economic status of the metropolitan area. A substantial literature on urban quality of life has emphasized these points, including Roback (1982), Blomquist et al (1988), Gyourko and Tracy (1991), Gyourko, Kahn,

among a small number of cities that grow in size relative to other cities in the system. Using data from numerous countries, Cuberes provides empirical support for his model. An implication of Cuberes' framework is that with sufficient passage of time, all cities within a country will have achieved their steady state relative population size and should exhibit parallel growth rates thereafter. 
and Tracy (1999), Chen and Rosenthal (2008), and Albouy (2008, 2009). ${ }^{55}$ A central tenant of the quality of life literature is that real wages adjust across metropolitan areas to compensate mobile workers for differences in MSA-level amenities. We focus here on recent additions to this literature that have especially direct implications for changes in MSA-level economic status as reflected in indicators of nominal per capita income.

The evidence that households are drawn to high amenity cities is compelling. Glaeser, Kolko and Saiz (2001), for example, find that high amenity cities have grown faster in population than low amenity cities and that urban rent has risen faster than urban wages suggesting a growing premium for residing in attractive locations. Chen and Rosenthal (2008) document that retirees are especially likely to migrate towards high-amenity locations that are not necessarily attractive to business (as with Tampa Bay but not San Francisco) as such locations provide high quality of life at lower costs. Nevertheless, these patterns by themselves do not ensure that high amenity cities and especially larger cities exhibit high levels of per capita income.

Glaeser, Kolko and Saiz (2001) and Quigley (1998) both argue that city size is extremely important for facilitating consumption, consistent with the diversity of activity implied by central place theory as described at the outset of the previous section. High-end restaurants, theater, and various other cultural amenities typically require large numbers of patrons to bring down average cost and for that reason thrive best in larger metropolitan areas with their larger populations. To the extent that such cultural amenities appeal to higher income families this draws higher skilled, higher income workers to larger cities. Various studies, however, also make clear that the link between city size and the quality of consumption opportunities is not restricted to just higher income households.

\footnotetext{
${ }^{55}$ Gyourko, Kahn, and Tracy (1999) review much of the early literature in this area.
} 
As discussed earlier, Waldfogel (2008) shows that diversity of restaurant options increases with the size of the local population including the presence of both high- and lowercost venues. Similarly, Waldfogel (2003) demonstrates that the diversity of radio broadcast programs increases with the number and size of the different target audiences. Because minority communities tend to be larger in larger cities, such locations also offer a greater variety of radio broadcast programs including programs that cater to individual ethnic and racial groups such as black, white, Hispanic, and others. George and Waldfogel (2003) obtain analogous results for newspapers and related readership. These and other studies make clear that larger metropolitan areas offer a more diverse, and often a more appealing mix of consumption opportunities, but not necessarily in a manner that would raise or lower indicators of per capita income in the area.

Reinforcing this view, Eeckhout, Pinheiro and Schmidheiny (2014) develop a model of spatial sorting with skill complementarity in production. In their model, large metropolitan areas boost the productivity of both highly skilled and very low skilled workers in what they refer to as "Extreme Skill Complementarity." This occurs because low skill service workers provide valuable services that free high-skilled individuals to devote more time to market work. Empirically, Eeckhout, Pinheiro, and Schmidheiny find that both the highest and the lowest skilled workers are overrepresented among the largest U.S. cities, and that both groups enjoy a skill-adjusted city size wage premium. ${ }^{56}$ The endogenous growth of both high- and low-skilled populations in larger metropolitan areas contributes to the diversity of consumption opportunities across the economic spectrum, and further obscures any a priori tendency for large-city amenities to elevate per capita income and the city's economic status.

\footnotetext{
${ }^{56}$ See Baum-Snow and Pavan (2012) for evidence of an alternative empirical pattern. They find that between 1979 and 2007 the largest cities in the U.S. had the largest growth in wage inequality. They attribute a substantial portion of the relative increase in large-city wage inequality to changes in the price for unobservable skills and lower relative wages for the lowest skill workers.
} 
The conclusion above is based implicitly on an assumption that high amenity metropolitan areas are not in limited supply. Gyourko, Mayer, and Sinai (2013) consider a set of "Superstar" cities with exceptionally attractive amenities for which that is not the case. San Francisco and Vancouver, B.C. with their dramatic natural beauty are examples as is New York which has no match in North America for its depth of cultural amenities including Broadway Theater and the like. Gyourko, Mayer, and Sinai argue that as national income rises, demand for residential opportunities in Superstar cities like San Francisco increases causing housing prices to shoot up. The increase in home prices discourages entry of low-income families into such areas and contributes to a high-income equilibrium. Gyourko, Mayer, and Sinai (2013) provide empirical support for their model. They show that as the number of high income households in the U.S. grows, housing prices in high amenity cities grow faster than in other cities and both average income and the upper tail of the income distribution in Superstar cities increases relative to other metropolitan areas.

As national incomes rise over time, an implication of the Superstar city model is that there could be a greater divergence in per capita income between high- and low-amenity metropolitan areas. Eeckhout, Pinheiro and Schmidheiny (2014), however, remind us that highand low-skilled individuals often complement each other, and for that reason, a growing population of higher income individuals does not necessarily mean that lower income households will be excluded from high-amenity metropolitan areas.

\subsubsection{Inelastic housing supply}

For growing cities with elastic housing supply developers will expand the housing stock to meet demand. Under such conditions, housing supply would not have any long term effects 
on MSA economic status and related dynamics. If instead, however, zoning limits new construction, then new housing supply will be inelastic and rising demand for the location is likely to be associated with rising house prices. If a metropolitan area is shrinking, the durability of the housing stock also causes housing supply to be highly inelastic in the face of declining demand. We explore implications of each of these scenarios for metropolitan income dynamics below.

\subsubsection{Regulation in growing cities}

An important set of recent studies demonstrates that regulation in growing, densely developed cities has reduced housing construction and caused housing rents and prices to rise. Glaeser and Ward (2009) show that land use regulations in Massachusetts are associated with reduced levels of new construction activity and higher housing prices. They also show that the effect of regulation on prices operates entirely through reductions in population density. Glaeser, Gyourko and Saks (2005a, 2005b) show that housing prices are much higher than production costs in large, growing metropolitan areas like New York and argue that land use regulations are the natural explanation for this difference. For a sample of 44 U.S. metropolitan areas, Mayer and Somerville (2000) report that land use regulations are associated with lower levels of new construction and lower housing supply price elasticities. In California, Quigley and Raphael (2005) find that growth restrictions in heavily regulated cities lead to higher rents and housing prices, significantly reduced construction activity, and near zero housing supply elasticities.

As a group, these studies suggest that housing regulations in growing cities can cause the supply of new housing to be extremely inelastic. In such locations, rising demand for residential opportunities should push price up. The effect of housing regulations on a metropolitan area's 
level of per capita income, however, is not completely obvious as this will depend on the impetus for rising demand and also the degree to which housing regulations are associated with enhanced amenities that are favored by the rich. A prominent set of European cities, for example, have unusually attractive historic centers that are filled with cultural amenities, including Paris (as discussed by Brueckner, Thisse and Zenou (1999)), Barcelona, Seville, Amsterdam, Vienna, and more. To the extent that such amenities are of sufficient scale to attract higher income households to the metro area, related regulations that restrict density and preserve important cultural sites have potential to elevate a city to superstar status with the associated rising income profile discussed by Gyourko, Mayer, and Sinai (2013). On the other hand, if regulations and related increases in housing costs are not matched by enhanced local amenities, then zoning could discourage migration into a metropolitan area. In this instance, labor supply could be reduced with potentially adverse effects on a city's per capita income and economic status. ${ }^{57}$

\subsubsection{Durable housing in declining cities}

As emphasized in the Introduction, the U.S. rust belt led by Detroit is a graphic reminder that cities can shrink. ${ }^{58}$ Glaeser and Gyourko (2005) emphasize that in such instances, the durability of housing stock ensures that supply is highly inelastic which contributes to sharp declines in house prices in the face of declining demand. As price falls below construction cost new construction stops which further reduces employment and demand, resulting in still lower home values. The resulting low home prices serve as a net attractor of low-skilled, low-income families and other households not closely tied to the workforce (e.g. retirees). As the skill level

\footnotetext{
${ }^{57}$ In related work, Saks (2008) shows that as regulation levels increase, positive demand shocks have a reduced impact on employment growth but an enhanced positive impact on wage.

${ }^{58}$ It is worth noting that patterns reported in Black and Henderson (2003) indicate that the presence of major declining cities in the U.S. is a relatively recent phenomena.
} 
in the city drops it becomes even less attractive to business owners in search of skilled labor, encouraging still more businesses to leave the town. Durable housing, therefore, accelerates and deepens economic decline in shrinking cities.

Glaeser and Gyourko (2005) follow U.S. MSAs over the 1970-2000 period and report a series of different patterns that are all consistent with the model just described. Among other things, they document that low skill workers are attracted to the low housing prices in declining cities. An implication is that the durable nature of housing contributes to decline in per capita income and economic status in shrinking cities. ${ }^{59}$ Options for how to turn the downward spiral around are limited. Nevertheless, in recognition that the housing stock becomes a liability in declining cities, numerous U.S. rust belt cities have begun to bulldoze housing stock. The goal in such policies is to shrink the supply of housing, boost prices, and break the city's downward spiral. Indeed, in 2009, Mayor Dave Bing in Detroit proposed bulldozing up to one-quarter of Detroit's housing stock! ${ }^{60}$

Research discussed in earlier sections suggests that metropolitan areas typically exhibit parallel long run growth trends, relatively static population ranks, and moderate churning of industrial composition. Our own analysis in Table 6 suggests comparatively rapid change in the economic status of a metropolitan area as measured by various indicators of per capita income. For all four of the stylized facts outlined at the start of this section, however, it is not clear that

\footnotetext{
${ }^{59}$ Extending these arguments, Broxterman and Yezer (2014) note that if the income elasticity of housing demand is less than one then high skill/high earnings potential workers will tend to sort into high rent, high wage cities and low skill workers will sort into low rent, low wage cities. The documented low income elasticity of demand for housing, therefore, contributes to net migration of high-skilled individuals away from declining metropolitan areas and reinforces the decline in such locations. Yoon (2013) also suggests that high-skilled workers in formerly thriving cities like Detroit were more likely to have invested in skills that are readily marketable in other cities and which facilitate their out-migration during the city's decline. Low-skilled workers, in contrast, were relatively more likely to have developed industry-specific skills that are more tied to a given city and less marketable elsewhere. Yoon argues that these differences reinforce decline in places such as Detroit.

${ }^{60}$ See, for example, Snyder's (2010) article in Business Insider, "The Mayor of Detroit's Radical Plan to Bulldoze One Quarter of the City" at http://www.businessinsider.com/the-mayor-of-detroits-radical-plan-to-bulldoze-onequarter-of-the-city-2010-3.
} 
those patterns would hold equally for declining versus growing regions. In part, that is because the Glaeser-Gyourko model of durable housing makes clear that history should matter much more for declining metropolitan areas as compared to growing areas.

\section{Conclusions and future research}

A theme throughout this review is that the location of high and low-income communities at both the neighborhood and metropolitan level arises from a blend of static and dynamic forces. In some instances, systematic cycling of a community's economic status should be anticipated. In other cases change is driven more by random shocks that have potential to live on for extended periods of time. In still other instances, spatial patterns of development display incredible persistence.

The rise, fall, and renewal of Harlem is a reminder that communities can undergo dramatic change in economic status. The remarkable decline of Detroit also reminds us that just because a city is strong today it will not necessarily always be so. In both cases long periods of time are typically necessary to appreciate that a location's economic status may well be radically different in the future.

There remain numerous opportunities for further research on neighborhood and metropolitan income dynamics. Most obvious to us, at the neighborhood level, there is a dearth of research on neighborhood income dynamics outside of a U.S. context, including older European cities as well as emerging Asian giants. We also need to know more about whether gentrification hurts or helps existing residents since local opposition to gentrification and neighborhood change is so often tied to this issue. At the metropolitan level, there is need for further research on the nature and consequences of declining metropolitan areas. Although rising 
world population ensures that most cities will grow, shrinking cities are found in many places beyond the U.S. rust belt including former manufacturing hubs in Europe, parts of Russia, and the former Soviet States (see, for example, Power, Ploger, and Winkler (2008), Berlinger (2012), and the UN-Habitat's (2013) report "State of the World's Cities"). Research is also needed to help explain why metropolitan-level measures of per capita income exhibit more rapid change over time relative to industry churning and MSA population. Will growing superstar cities retain both low- and high-skilled labor, and how will markets and/or government provide housing opportunities for lower income families in such locations?

Finally, our review makes a distinction between neighborhood and metropolitan level income dynamics, mostly treating the two as independent events. Although this is a meaningful distinction, MSA-level events can nevertheless affect neighborhood sorting and vice versa. In a recent lecture, Epple (2012), for example, argued that decline in the Pittsburgh metropolitan area disproportionately hurt central city school districts and their communities. This occurs because declining metro-level population along with durable housing causes suburban house prices to fall which draws central city residents to the suburbs in search of better schools and related amenities. The resulting hollowing out of a central city seems likely to be especially severe in declining metropolitan areas (see, for example, Schmitt (2010), "Without a Plan, Sprawl Will Continue to Hollow Out Cleveland Region"). In the opposite direction, Benabou (1996) develops a model in which neighborhood-level segregation of households by skill and financial resources has potential to undermine education production and human capital accumulation, depressing economic growth at the city level. Fernandez and Rogerson (1998) similarly argue that elimination of local funding disparities through school finance reform will yield large welfare gains that extend beyond immediate school districts. Related work on neighborhood 
based word-of-mouth job networks provides a further explanation for why the nature of household sorting at the neighborhood level can affect the quality of employer-employee job matches and labor productivity at the metropolitan level (e.g. Damm (2014), Hellerstein, Kutzbach and Neumark (2014), Topa and Zenou (this volume)). Although these and other studies imply links between neighborhood and metropolitan level income dynamics, this also remains an area for further research. 


\section{References}

Ahlfeldt, Gabriel M. and Wolfgang Maennig (2014). "Homevoters vs. Leasevoters: A Spatial Analysis of Airport Effects". Working Paper.

Acemoglu, Daron, Simon Johnson, and James Robinson (2005). "The Rise of Europe: Atlantic Trade, Institutional Change, and Economic Growth.” American Economic Review 95(3), 546-579.

Albouy, David (2009). “The Unequal Geographic Burden of Federal Taxation”. Journal of Political Economy 117(4), 635-667.

Albouy, David (2008). “Are Big Cities Bad Places to Live? Estimating Quality of Life across Metropolitan Areas.” National Bureau of Economic Research, NBER Working Paper No. 14472, November.

Alesina, Alberto, Reza Baqir, and William Easterly (1999). "Public Goods and Ethnic Divisions". Quarterly Journal of Economics 114(4), 1243-1284.

Alonso, William (1964). Location and Land Use. Cambridge: Harvard University Press.

Arnott, Richard J. and Ralph M. Braid (1997). "A filtering model with steady-state housing". Regional Science and Urban Economics 27(4-5), 515-46.

Banzhaf, H. Spencer and Randall P. Walsh (2008). "Do People Vote with Their Feet? An Empirical Test of Tiebout's Mechanism”. American Economic Review 98(3), 843-863.

Bar-Ilan, Avner and William C. Strange (1996). "Urban Development with Lags". Journal of Urban Economics 39(10), 87-113.

Baum-Snow, Nathaniel (2007). "Did Highways Cause Suburbanization?" Quarterly Journal of Economics 122(2), 775-805.

Baum-Snow, Nathaniel and Ronni Pavan (2012). "Understanding the City Size Wage Gap". Review of Economic Studies 79(1), 88-127.

Bayer, Patrick, Hangming Fang, and Robert McMillan (2014). "Separate When Equal? Racial Inequality and Residential Segregation". Journal of Urban Economics 82, 32-48.

Bayer, Patrick, and Robert McMillan (2005). "Racial Sorting and Neighborhood Quality". National Bureau of Economic Research, NBER Working Paper 11813, December.

Bayer, Patrick and Robert McMillan (2012). “Tiebout Sorting and Neighborhood Stratification”. Journal of Public Economics 96(11), 1129-1143. 
Bayer, Patrick, Robert McMillan, and Kim Rueben (2004). "What drives racial segregation? New evidence using Census microdata”. Journal of Urban Economics 56(3), 514-535.

Bayer, Patrick, Robert McMillan, and Kim Rueben (2005). "Residential Segregation in General Equilibrium". National Bureau of Economic Research, NBER Working Paper No. 11095, January.

Beherns, Kristian and Frederic Robert-Nicoud (this volume), "Agglomeration Theory" in Handbook of Regional and Urban Economics,_Vol 5, Gilles Duranton, J. Vernon Henderson, and William C. Strange eds.

Benabou, Roland (1993). "Workings of a City: Location, Education, and Production". Quarterly Journal of Economics 108(3), 619-652.

Benabou, Roland (1996). "Heterogeneity, Stratification, and Growth: Macroeconomic Implications of Community Structure and School Finance." American Economic Review 86(3), 584-609.

Berlinger, Joshua (2012). "The 28 Fastest-Shrinking Cities in the World." Business Insider, October 22, http://www.businessinsider.com/cities-that-are-shrinking-2012-10? op=1 .

Black, Duncan, and J. Vernon Henderson (2003). "Urban Evolution in the USA". Journal of Economic Geography 3(4): 343-72.

Bleakley, Hoyt, and Jeffrey Lin (2012). "Portage and Path Dependence". Quarterly Journal of Economics 127, 587-644.

Blomquist, Glenn, Mark Berger, and J. Hoehn (1988). "New estimates of the quality of life in urban areas". American Economic Review 78, 89-107.

Boehm, Thomas P. and Alan M. Schlottmann (2004). "The dynamics of race, income, and homeownership". Journal of Urban Economics 55(1), 113-130.

Bond, Eric W. and Coulson, N. Edward. (1989). "Externalities, Filtering, and Neighborhood Change". Journal of Urban Economics 26(2), 231-49.

Boustan, Leah P. (2010). "Was postwar suburbanization 'white flight'? Evidence from the black migration". Quarterly Journal of Economics 125 (1), 417-443.

Boustan, Leah P. and Robert A. Margo (2013). "A Silver Lining to White Flight? White Suburbanization and African-American Homeownership, 1940-1980". Journal of Urban Economics 74(1), 71-80.

Braid, Ralph M. (2001). "Spatial Growth and Redevelopment with Perfect Foresight and Durable Housing". Journal of Urban Economics 49(3), 425-52. 
Brakman, Steven, Harry Garretsen, and Marc Schramm (2004). "The Strategic Bombing of German Cities during World War II and its Impact on City Growth". Journal of Economic Geography 4, 201-218.

Brooks, Leah and Byron Lutz (2012). "From Today's City to Tomorrow's City: An Empirical Investigation of Urban Land Assembly". Federal Reserve Board of Governors, Working Paper, November.

Broxterman, Daniel A. and Anthony M. Yezer (2014). "City Size and Skill Intensity: Is it all Housing Cost?” Social Science Research Network Working Paper, SSRN-id2408179.

Brueckner, Jan (2011). Lectures on Urban Economics. Cambridge: The MIT Press.

Brueckner, Jan and Robert Helsley (2011). "Sprawl and Blight". Journal of Urban Economics 69 (1), 205-13.

Brueckner, Jan and Stuart S. Rosenthal (2009). "Gentrification and Neighborhood Cycles: Will America's Future Downtowns Be Rich?” Review of Economics and Statistics 91(4), 725743.

Brueckner, Jan, Jacques-F. Thisse, and Yves Zenou (1999). "Why is central Paris rich and downtown Detroit poor? An amenity-based theory". European Economic Review 43, 91107.

Bulan, Laarni, Christopher Mayer, and C. Tsuriel Somerville (2009). "Irreversible investment, real options, and competition: Evidence from real estate development". Journal of Urban Economics 65(3), 237-251.

Brunner, Eric, and John Sonstelie (2003). "Homeowners, property values, and the political economy of the school voucher". Journal of Urban Economics 54, 239-257.

Brunner, Eric, John Sonstelie, and Mark Thayer (2001). "Capitalization and the voucher: An analysis of precinct returns from California's Proposition 174". Journal of Urban Economics 50, 517-536.

Calabrese, Stephen, Dennis Epple, Thomas Romer, and Holger Sieg (2006). "Local public good provision: Voting, peer effects, and mobility". Journal of Public Economics 90(6), 959-981.

Capozza, Dennis R. and Robert W. Helsley (1990). "The Stochastic City”. Journal of Urban Economics 28(2), 187-203.

Card, David, Alexandre Mas, and Jesse Rothstein (2008). "Tipping and the Dynamics of Segregation". Quarterly Journal of Economics 123(1), 177-218.

Card, David, Alexandre Mas, and Jesse Rothstein (2010). "Are Mixed Neighborhoods Always Unstable? Two-Sided and One-Sided Tipping" in Neighborhood and Life Changes: How 
Place Matters in Modern American? H. Newburger, E.L Birch, S.M. Wacther eds. University of Pennsylvania Press.

Carlino, Gerald A. and William Kerr (this volume). "Agglomeration and Innovation" in Handbook of Regional and Urban Economics, _Vol 5, Gilles Duranton, J. Vernon Henderson, and William C. Strange eds.

Case, Karl E. and Robert J. Shiller (1987). "Prices of single family homes since 1970; New indexes for four cities". New England Economic Review, Sep/Oct, 45-56.

Chandler, Tertius (1987). Four Thousand Years of Urban Growth: An Historical Census. Lewiston, NY: The Edwin Mellen Press.

Charles, Kerwin K. and Erik Hurst (2002). "The Transition to Home Ownership and the BlackWhite Wealth Gap". Review of Economics and Statistics 84(2), 281-297.

Chen, Yong and Stuart S. Rosenthal (2008). "Local Amenities and Life Cycle Migration: Do People Move for Jobs or Fun?” Journal of Urban Economics 65(3), 519-537.

Christaller, Walter (1966). Central Places in Southern Germany, translated by Carlisle W. Baskin, Englewood Cliffs, N.J., Prentice Hall, Inc.

Choi, C Y. (2004). "A Reexamination of Output Convergence in the U.S. States: Toward Which Level(s) are they Converging?” Journal of Regional Science 44(4), 713-741.

Clapp, John M. and Katsiaryna Salavei (2010). "Hedonic pricing with redevelopment options: A new approach to estimating depreciation effects". Journal of Urban Economics 67(3), 362377.

Combes, Pierre-Philippe and Laurent Gobillon (this volume). "The Empirics of Aglomeration," in Handbook of Regional and Urban Economics,_Vol 5, Gilles Duranton, J. Vernon Henderson, and William C. Strange eds.

Corominas-Murtra, Bernat, Rudolf Hanel, and Stefan Thurner (2014). “Understanding Zipf's Law with Playing Dice: History-Dependent Stochastic Processes with Collapsing SampleSpace Have Power-Law Rank Distributions," arXiv: 1407.2775v2, 12 July 2014, Cornell University Library.

Courant, Paul N. and John Yinger (1977). “On models of racial prejudice and urban residential structure”. Journal of Urban Economics 4(3), 272-291.

Cuberes, David (2011). “Sequential City Growth: Empirical Evidence”. Journal of Urban Economics 69(2), 229-239.

Cutler, David, Glaeser, Edward, Vigdor, Jacob (1999). "The rise and decline of the American ghetto". Journal of Political Economy 107 (3), 455-506. 
Damm, Anna (2014). "Neighborhood Quality and Labor Market Outcomes: Evidence from Quasi-Random Neighborhood Assignment of Immigrants". Journal of Urban Economics 79, 139-166.

Davidson, Justin (2014). “Is Gentrification All Bad?” New York Magazine, February 2, 2014. http://nymag.com/news/features/gentrification-2014-2/

Davis, Donald R. and David E. Weinstein (2002). "Bones, Bombs, and Breakpoints: The Geography of Economic Activity”. American Economic Review 92(5), 1269-1289.

Davis, Donald R. and David E. Weinstein (2008). "A Search for Multiple Equilibria in Urban Industrial Structure”. Journal of Regional Science 48(1), 29-65.

Dawkins, Casey J. (2005). "Racial gaps in the transition to first-time homeownership: The role of residential location”. Journal of Urban Economics 58(3), 537-554.

DeBartolomé, Charles A.M. (1990). "Equilibrium and Inefficiency in a Community Model with Peer Group Effects". Journal of Political Economy 98(1), 110-133.

DeBartolomé, Charles A.M., and Stephen L. Ross (2003). "Equilibria with Local Governments and Commuting: Income Sorting vs Income Mixing”. Journal of Urban Economics 54(1), 120 .

DeBartolomé, Charles A.M., and Stephen L. Ross (2008). "The Race to the Suburb: The Location of the Poor in a Metropolitan Area". University of Connecticut, Department of Economics Working Paper, May.

Dehring, Caroline A., Craig A. Depken II, and Michael R. Ward (2008). "A direct test of the homevoter hypothesis". Journal of Urban Economics 64, 155-170.

Deng, Yongheng, Stephen L. Ross, and Susan M. Wachter (2003). "Racial differences in homeownership: the effect of residential location". Regional Science and Urban Economics 33(5), 517-556.

Desmet, Klaus and Vernon Henderson (this volume), "Cities and Development" in Handbook of Regional and Urban Economics, _Vol 5, Gilles Duranton, J. Vernon Henderson, and William C. Strange eds..

Desmet, Klaus and Jordan Rappaport (2013). "The Settlement of the United States, 1800 to 2000: The Long Transition Towards Gibrat's Law”. Federal Reserve Bank of Kansas City, Research Working Paper 13-02, September.

Duranton, Gilles (2007). "Urban Evolutions: The Fast, the Slow, and the Still”. American Economic Review 97(1), 197-221. 
Duranton, Gilles and Diego Puga (2001). "Nursery Cities: Urban Diversity, Process Innovation, and the Life Cycle of Products". American Economic Review 91(5), 1454-1477.

Duranton, Gilles and Diego Puga (2004), "Micro-foundations of urban agglomeration economies," in the Handbook of Urban and Regional Economics, Volume 4, pg. 2063-2117, Elsevier, eds. Vernon Henderson and Jacques Thisse.

Dye, Richard F. and Daniel P. McMillen (2007). "Teardowns and land values in the Chicago metropolitan area". Journal of Urban Economics 61(1), 45-63.

Eaton, Jonathan and Zvi Eckstein (1997). "Cities and growth: Theory and evidence from France and Japan”. Regional Science and Urban Economics 27(4). 443-447.

Eeckhout, Jan, Roberto Pinheiro, and Kurt Schmidheiny (2014). "Spatial Sorting”. Journal of Political Economy 122(3), 554-620 .

Epple, Dennis (2012). "School Choice and Urban School Districts". Distinguished Lecture in Economics at the University of Connecticut (April 12).

Epple, Dennis, Maria M. Ferreyra (2008). "School finance reform: Assessing general equilibrium effects". Journal of Public Economics 92(5), 1326-1351.

Epple, Dennis, Brett Gordon, and Holger Sieg (2010). “A New Approach to Estimating the Production Function for Housing”. American Economic Review 100(3), 905-924.

Epple, Dennis and Richard E. Romano (1998). "Competition between Private and Public Schools, Vouchers, and Peer-Group Effects”. American Economic Review 88(1), 33-62.

Epple, Dennis and Richard E. Romano (2008). "Educational Vouchers and Cream Skimming". International Economic Review 49(4), 1395-1435.

Epple, Dennis and Richard E. Romano (2011). "Chapter 20: Peer Effects in Education: A Survey of the Theory and Evidence" in Handbook of Social Economics, Jess Benhabib, Alberto Bisin and Matthew O. Jackson 1053-1163.

Epple, Dennis and Thomas Romer (1991). "Mobility and Redistribution". Journal of Political Economy, 99(4), 828-858.

Falck, Oliver, Stephan Heblich, Alfred Lameli, and Jens Südekum (2012). "Dialects, cultural identity, and economic exchange". Journal of Urban Economics 72(2), 225-239.

Fernandez, Raquel and Richard Rogerson (1998). "Income Distribution and Public Education: A Dynamic Quantitative Evaluation of School Finance Reform." American Economic Review 88, 813-833. 
Ferreyra, Maria M. (2007). "Estimating the Effects of Private School Vouchers in Multidistrict Economies". American Economic Review 97(3), 789-817.

Ferreyra, Maria M. (2009). “An Empirical Framework for Large-Scale Policy Analysis, with an Application to SchoolFinance Reform in Michigan". American Economic Journal: Economic Policy 1(1), 147-180.

Findeisen, Sebastian and Jens Südekum (2008). "Industry churning and the evolution of cities: Evidence for Germany”. Journal of Urban Economics 64(2), 326-339.

Fischel, F.A. (2001). The Homevoter Hypothesis. Cambridge: Harvard University Press.

Freeman Lance (2005). "Displacement or Succession? Residential Mobility in Gentrifying Neighborhoods". Urban Affairs Review 40(4), 463-491.

Gabaix, Xavier and Yannis M. Ioannides (2004), "The Evolution of City Size Distrtibutions" in Handbook of Regional and Urban Economics, Vol 4, J. Vernon Henderson and JacquesFrancois Thisse eds., Chapter 53, 2,341-2,378.

Gabriel, Stuart A. and Stuart S. Rosenthal (2005). "Homeownership in the 1980s and 1990s: Aggregate trends and racial gaps". Journal of Urban Economics 57(1), 101-127.

George, Lisa and Joel Waldfogel (2003), "Who Affects Whom in Daily Newspaper Markets?" Journal of Political Economy 111(4), 765-784.

Glaeser, Edward L. (2007), “Can Buffalo Ever Come Back?” City Journal, Autumn.

Glaeser, Edward L. and Joseph Gyourko (2005). “Urban Decline and Durable Housing”. Journal of Political Economy 113(2), 345-375.

Glaeser, Edward L., Joseph Gyourko, and Raven E. Saks (2005a). "Why Is Manhattan So Expensive? Regulation and the Rise in Housing Prices" Journal of Law and Economics XLVIII, 331-369.

Glaeser, Edward L., Joseph Gyourko, and Raven E. Saks (2005b). "Why Have Housing Prices Gone Up?” American Economic Review 95(2), 329-333.

Glaeser, Edward L., Matthew E. Kahn, and Jordan Rappaport (2008). "Why Do the Poor Live in Cities? The Role of Public Transportation". Journal of Urban Economics 63(1), 1-24.

Glaeser, Edward L. and Matthew Kahn (2001). "Decentralized Employment and the Transformation of the American City". Brookings-Wharton Papers on Urban Affairs 163.

Glaeser, Edward L., Jed Kolko, and Albert Saiz (2001). "Consumer City". Journal Economic Geography 1(1), 27-50. 
Glaeser, Edward L., and David C. Mare (2001), "Cities and Skills". Journal of Labor Economics 19(2), 316-342.

Glaeser, Edward L., Bruce Sacerdote, and Jose A. Scheinkman (1996). "Crime and Social Interactions". Quarterly Journal of Economics 111(2), 507-548.

Glaeser, Edward L. and Bryce A. Ward (2009). "The causes and consequences of land use regulation: Evidence from Greater Boston”. Journal of Urban Economics 65(3), 265-278.

Glocker, Daniela and Daniel M. Sturm (2013). "War-Time Destruction and the Persistence of Economic Activity”. London School of Economics Working Paper, London, November.

Grossman, Gene M. and Elhanan Helpman (1991). "Quality Ladders in the Theory of Growth". Review of Economic Studies 58(1), 43-61.

Guerrieri, Veronica, Daniel Hartley, and Erik Hurst (2013). "Endogenous Gentrification and Housing Price Dynamics". Journal of Public Economics 100, 45-60.

Guthrie, Graeme (2010). "House prices, development costs, and the value of waiting". Journal of Urban Economics 68(1), 56-71.

Gyourko, Joseph, Matthew Kahn, and Joseph Tracy (1999). "Quality of Life and Environmental Comparisons," in the Handbook of Urban and Regional Economics, Volume 3, pg. 14141443, Elsevier, eds. Edwin S. Mills and Paul Cheshire.

Gyourko, Joseph, Christopher Mayer, and Todd Sinai (2013). "Superstar Cities". American Economic Journal: Economic Policy 5(4), 167-199.

Gyourko, Joseph and Albert Saiz (2004). "Reinvestment in the housing stock: the role of construction costs and the supply side". Journal of Urban Economics 55(2), 238-256.

Gyourko, Joseph and Joseph Tracy (1991). "The Structure of Local Public Finance and the Quality of Life". Journal of Political Economy" 99, 774-806.

Hanlon, W. Walker and Antonio Miscio (2013). "Agglomeration: A Dynamic Approach". UCLA Economics Department, Working Paper, December.

Hanushek, Eric and Kuzey Yilmaz (2007). "The Complementarity of Tiebout and Alonso". Journal of Housing Economics 16(2), 243-61.

Harding, John, Stuart S. Rosenthal, and C. F. Sirmans (2007). "Depreciation of Housing Capital, Maintenance, and House Price Inflation: Estimates from a Repeat Sales Model". Journal of Urban Economics 61(2), 193-217. 
Haurin, Donald R., Christopher E. Herbert, and Stuart S. Rosenthal (2007). "Homeownership Gaps Among Low-Income and Minority Households". Cityscape: A Journal of Policy Development and Research 9(2), 5-52.

Hellerstein, Judith, Mark Kutzbach, and David Neumark (2014). "Do Labor Market Networks Have an Important Spatial Dimension?” Journal of Urban Economics 79, 39-58.

"History of Harlem Heritage Tours \& Cultural Center". Harlem Heritage Tours Cultural Center RSS. $<$ http://www.harlemheritage.com/history-of-harlem/ $>$.

Hilber, Christian and Christopher Mayer (2009). "Why do households without children support local public schools? Linking house price capitalization to school spending". Journal of Urban Economics 65, 1, 74-90.

Holmes, Mark J., Jesus Otero, and Theodore Panagiotidis (2013). "A Note on the Extent of U.S. Regional Income Convergence”. Macroeconomic Dynamics 17(1), 1-28.

Jacobs, Jane (1969). The Economy of Cities. New York: Vintage.

Jacobs, Jane (1984). Cities and the Wealth of Nations: Principles of Economic Life. New York: Vintage.

Jedwab, Remi, Edward Kerby, and Alexander Moradi (2014). "History, Path Dependence and Development: Evidence from Colonial Railroads, Settlers and Cities in Kenya". Centre for the Study of African Economies, University of Oxford, CSAE Working Paper Series 201404, January.

Jedwab, Remi and Alexander Moradi (2014). "Transportation Technology and Economic Change: The Impact of Colonial Railroads on City Growth in Africa". The George Washington University, Institute for International Economic Policy, Working Papers 201403, January.

Lee, Sanghoon, John Ries, and C. Tsuriel Somerville (2013). "Repairs Under Imperfect Information”. Journal of Urban Economics 73(1), 43-56.

Lee, Sanghoo and Jeffrey Lin (2013). "Natural Amenities, Neighborhood Dynamics, and Persistence in the Spatial Distribution of Income". Federal Reserve Bank of Philadelphia Working Paper 13-48.

LeRoy, Stephen F. and Jon Sonstelie (1983). "Paradise Lost and Regained: Transportation Innovation, Income, and Residential Location". Journal of Urban Economics 13(1), 67-89.

Levin, Andrew, Chien-Fu Lin, and Chia-Shang Chu (2002). "Unit root test in panel data: Asymptotic and finite sample properties". Journal of Econometrics 108(1), 1-25.

Losch, Augus (1954). The Economics of Location, New Haven, Yale University Press. 
Maddala, G.S. and Shaowen Wu (1999). "A comparative study of unit root tests with panel data and a new simple test". Oxford Bulletin and Economics and Statistics 61(S1), 631-652.

Massey, Douglas S. and Mary J. Fischer (2003). "The Geography of Inequality in the United States, 1950-2000”. Brookings-Wharton Papers on Urban Affairs 1-40.

Mayer, Christopher J. and C. Tsuriel Somerville (2000). "Land use regulation and new construction". Regional Science and Urban Economics 30(6), 639-662.

McKinnish, Terra, Randall Walsh, and T. Kirk White (2010). "Who gentrifies low-income neighborhoods?” Journal of Urban Economics 67(1), 180-193.

McMillan, Robert (2005). "Erratum to Competition, incentives, and public school productivity". Journal of Public Economics 89, 1133-1154.

McMillen, Daniel and Arthur O'Sullivan (2013). “Option value and the price of teardown properties". Journal of Urban Economics 74(1), 71-82.

Mello, Marcelo (2011). "Stochastic Convergence Across U.S. States". Macroeconomic Dynamics 15(2), 160-183.

Mills, Edwin S. (1967). “An Aggregative Model of Resource Allocation in a Metropolitan Area”. American Economic Review 57, 197-210.

Muth, Richard F. (1969). Cities and Housing. Chicago: University of Chicago Press.

Nurse, Alex (2008). “The Liverpool View: Detroit's Lessons for Liverpool” University of Liverpool, University News, http://news.liv.ac.uk/2013/08/02/the-liverpool-view-detroitslessons-for-liverpool/.

O’Sullivan, Arthur (2003). Urban Economics, McGraw-Hill Copmanies, Inc.

O’Sullivan, Arthur (2005). "Gentrification and Crime”. Journal of Urban Economics 57(1), 7385.

O'Sullivan, Arthur (2009). "Schelling's model revisited: Residential sorting with competitive bidding for land". Journal of Urban Economics 39(4), 397-408.

Pancs, Romans and Nicolaas J. Vriend (2007). "Schelling's spatial proximity model of segregation revisited". Journal of Public Economics 91, 1-24.

Payne, Les (2010). "Is Harlem No Longer Black?" The Root. N.p., 8 Jan. http://www.theroot.com/articles/culture/2010/01/is harlem no longer black.html. 
Power, Anne, Jorg Ploger, and Astrid Winkler (2008). "Transforming Cities Across Europe: An Interim Report on Problems and Progress". CASEreport 49, Centre for Analysis of Social Exclusion, London School of Economics and Political Science.

Prasad, Prakash C. (1977). Foreign Trade and Commerce in Ancient India. New Delhi: Abhinav Publications, 90.

Quigley, John M. (1998). “Urban Density and Economic Growth”. Journal of Economic Perspectives 12(2), 127-138.

Quigley, John M. and Steven Raphael (2005). "Regulation and the High Cost of Housing in California". American Economic Review 95(2), 323-328.

Roback, Jennifer (1982). "Wages, Rents, and the Quality of Life". Journal of Political Economy $90(6), 1257-1278$.

Roberts, Sam (2010). "No Longer Majority Black, Harlem Is in Transition”. The New York Times, 5 Jan.

http://www.nytimes.com/2010/01/06/nyregion/06harlem.html?pagewanted=all\& $\mathrm{r}=0$

Rosenthal, Stuart S. (2008a). "Old Homes, Exernalities, and Poor Neighborhoods: A Model of Urban Decline and Renewal". Journal of Urban Economics 63(3), 816-840.

Rosenthal, Stuart S. (2008b). "Where Poor Renters Live in Our Cities: Dynamics and Determinants" in "Revisiting Rental Housing: A National Policy Summit," Nicolas Retsinas and Eric Belskey, eds., Brookings Press.

Rosenthal, Stuart S. (2014). "Are Private Markets and Filtering a Viable Source of Low-Income Housing? Estimates from a 'Repeat Income' Model'. American Economic Review 104(2), 687-706.

Rosenthal, Stuart S. and Robert Helsley (1994). "Redevelopment and the Urban Land Price Gradient”. Journal of Urban Economics 35(2), 182-200.

Rosenthal, Stuart S. and William C. Strange (2004), "Evidence on the Nature and Sources of Agglomeration Economies" in the Handbook of Urban and Regional Economics, Volume 4, pg. 2119-2172, Elsevier, eds. Vernon Henderson and Jacques Thisse.

Rosenthal, Stuart S. and William C. Strange (2008). "The Attenuation of Human Capital Spillovers". Journal of Urban Economics 64(2), 373-389.

Ross, Stephen (2011). “Chapter 9: Social Interactions within Cities: Neighborhood Environments and Peer Relationships" in Handbook of Urban Economics and Planning eds. N. Brooks, K. Donaghy, G. Knapp. Oxford University Press. 
Ross, Stephen and John Yinger (1999). "Chapter 47: Sorting and voting: A review of the literature on urban public finance" in Handbook of Regional and Urban Economics, eds. E.S. Mills and P. Cheshire, Volume 3, 2001-2060.

Ross, Stephen and John Yinger (2002). Color of Credit: Mortgage Discrimination, Research Methods, and Fair Lending Enforcement. Cambridge: MIT Press.

Saiz, Albert (2010). “The Geographic Determinants of Housing Supply”. Quarterly Journal of Economics 125(3), 1253-1296.

Saks, Raven E. (2008). "Job creation and housing construction: Constraints on metropolitan area employment growth”. Journal of Urban Economics 64(1), 178-195.

Sharma, Shalini (2003). "Persistence and Stability in City Growth". Journal of Urban Economics 53(2), 300-320.

Schelling, Thomas C. (1971). "Dynamic Models of Segregation”. Journal of Mathematical Sociology 1, 143-186.

Schelling, Thomas C. (1978), Micromotives and Macrobehavior, Norton Press.

Schmitt, Angie (2010). "Without a Plan, Sprawl Will Continue to Hollow Out Cleveland Region”. StreetsBlog USA, http://usa.streetsblog.org/2010/09/13/without-a-plan-sprawlwill-continue-to-hollow-out-cleveland-region/, Monday, September 13.

Snyder, Michael (2010). "The Mayor of Detroit's Radical Plan to Bulldoze One Quarter of the City”. Business Insider, March 10, http://www.businessinsider.com/the-mayor-of-detroitsradical-plan-to-bulldoze-one-quarter-of-the-city-2010-3.

Tabellini, Guido (2010). "Culture and Institutions: Economic Development in the Regions of Europe". Journal of the European Economic Association 8(4), 677-716.

Taylor, Paul and Richard Fry (2012). “The Rise of Residential Segregation by Income”. Pew Research Center Report, August 1.

Topa, Giorgio and Yves Zenou (this volume). "Neighborhood Versus Network Effects" in Handbook of Regional and Urban Economics, _Vol 5, Gilles Duranton, J. Vernon Henderson, and William C. Strange eds.

UN-Habitat (2013). "State of the World's Cities 2012/2013: Prosperity of Cities". Routledge Taylor \& Francis Group, 711 Third Avenue, New York, NY.

Vincent, Ted (2005). "Harlem". Continuum Encyclopedia of Popular Music of the World: Locations. N.p.: Continuum, Credo Reference. http://search.credoreference.com/content/entry/contpmwl/harlem/0 . 
Vigdor, Jacob L. (2010). "Is urban decay bad? Is urban revitalization bad too?" Journal of Urban Economics 68(3), 277-289.

Wahl, Fabian (2013). "Does medieval trade still matter? Historical trade centers, agglomeration and contemporary economic development". FZID Discussion Paper, No.82-2013, November.

Waldfogel, Joel (2003). "Preference Externalities: An Empirical Study of Who Benefits Whom in Differentiated-Product Markets”. RAND Journal of Economics 34(3), 557-568.

Waldfogel, Joel (2008). "The median voter and the median consumer: Local private goods and population composition”. Journal of Urban Economics 63(2), 567-582.

Waters, Clara E.C. (1895). Egypt, New York: Werner.

Watson, Tara (2009). "Inequality and the Measurement of Residential Segregation by Income in American Neighborhoods" Review of Income and Wealth, 55(3), 820-844.

Wheaton, William C. (1977). "Income and Urban Residence: An Analysis of Consumer Demand for Location”. American Economic Review 67, 620-631.

Wheeler, Christopher H. and Elizabeth A. La Jeunesse (2007). "Neighborhood Income Inequality" Federal Reserve Bank of St.Louis, Working Paper 2006-039B, February.

Williams, Timothy (2008). "Harlem Area Is Blighted, State Agency Declares". The New York Times. 18 July. http://www.nytimes.com/2008/07/18/nyregion/18columbia.html?_r=0.

Yoon, Chamna (2013). "The Decline of the Rust Belt: A Dynamic Spatial Equilibrium Analysis". Baruch College/CUNY Working Paper, New York, 4 Dec.

Zhang, Junfu (2004). "A Dynamic Model of Residential Segregation”. Journal of Mathematical Sociology 28, 147-170.

Zhang, Junfu (2011). “Tipping and Residential Segregation: A Unified Schelling Model”. Journal of Regional Science 51(1), 167-193. 
TABLES 1 THROUGH 6 
Table 1: Serial Correlation in Growth in Neighborhood Relative Income (t-ratios based on robust standard errors in parentheses)

\begin{tabular}{|c|c|c|c|c|}
\hline & $\begin{array}{c}\text { Philadelphia County } \\
\text { Ward Panel }^{a} \\
\log \left(\mathrm{y}_{2000} / \mathrm{y}_{1950}\right)\end{array}$ & $\begin{array}{c}\text { Philadelphia County } \\
\text { Ward Panel } \\
\log \left(\mathrm{y}_{1980} / \mathrm{y}_{1950}\right)\end{array}$ & $\begin{array}{c}\text { Philadelphia County } \\
\text { Census Tract } \\
\text { Balanced Panel }{ }^{b} \\
\log \left(\mathrm{y}_{\mathrm{t}} / \mathrm{y}_{\mathrm{t}-1}\right)\end{array}$ & $\begin{array}{c}35 \text { MSA } \\
\text { Census Tract } \\
\text { Balanced Panel }^{b} \\
\log \left(\mathrm{y}_{\mathrm{t}} / \mathrm{y}_{\mathrm{t}-1}\right)\end{array}$ \\
\hline $\log \left(\mathrm{y}_{1950} / \mathrm{y}_{1900}\right)$ & $\begin{array}{c}-0.9465 \\
(-6.17)\end{array}$ & - & - & - \\
\hline $\log \left(\mathrm{y}_{1950} / \mathrm{y}_{1920}\right)$ & - & $\begin{array}{c}-0.4538 \\
(-3.20)\end{array}$ & - & - \\
\hline $\log \left(\mathrm{y}_{\mathrm{t}-1} / \mathrm{y}_{\mathrm{t}-2}\right)$ & - & - & $\begin{array}{c}-0.0126 \\
(-0.24)\end{array}$ & $\begin{array}{l}-0.0564 \\
(-11.27)\end{array}$ \\
\hline Constant & $\begin{array}{c}-0.0617 \\
(-1.10)\end{array}$ & $\begin{array}{c}-0.0423 \\
(-0.82)\end{array}$ & $\begin{array}{c}-.0863 \\
(-10.66)\end{array}$ & - \\
\hline Period Length (Years) & 50 & 30 & 10 & 10 \\
\hline Time Span & 1900 to 2000 & 1920 to 2000 & 1950 to 2000 & 1950 to 2000 \\
\hline County Fixed Effects & - & - & - & 125 \\
\hline Observations & 39 & 39 & 1,304 & 37,676 \\
\hline R-square & 0.4329 & 0.1749 & 0.0002 & 0.0323 \\
\hline
\end{tabular}

${ }^{\mathrm{a}}$ All data were coded to year 1900 Ward boundaries. See Rosenthal (2008) for details.

${ }^{\mathrm{b}}$ All data were coded to year 2000 census tract boundaries. See Rosenthal (2008) for details.

Source: Rosenthal (2008a), based on Table 3, page 5. 
Table 2: Year 2000 Neighborhood Economic Status in Glaeser, Kahn and Rappaport (2008) and Brueckner and Rosenthal (2009)

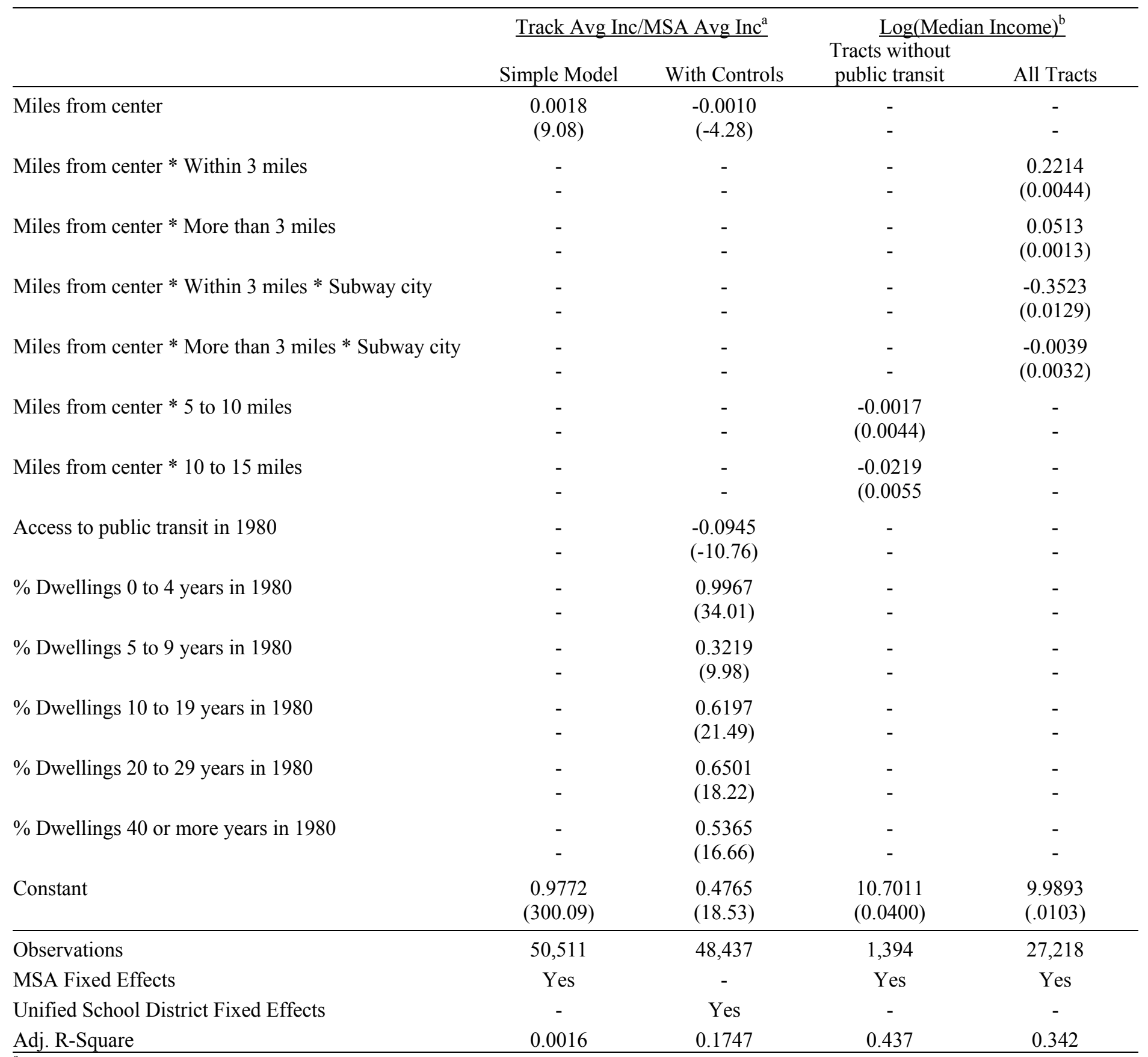

${ }^{\mathrm{a}}$ Source: Brueckner and Rosenthal (2009), Table 1, page 733.

${ }^{a}$ Source: Glaeser, Kahn, and Rappaport (2008), Table 6, page 17.

${ }^{\text {a} P u b l i c-t r a n s i t ~ a c c e s s ~ e q u a l s ~} 1$ if 10 percent or more of the tract's population in 1980 used public transit, and 0 otherwise.

${ }^{b}$ Dwelling ages are measured as of 1980 . The omitted category is age 30 to 39 years. 
Table 3: Investment in U.S. Residential Fixed Assets (Excludes Manufactured Housing) ${ }^{\mathrm{a}}$

\begin{tabular}{|c|c|c|c|c|c|c|c|}
\hline & 2000 & 2002 & 2004 & 2006 & 2008 & 2010 & 2012 \\
\hline New Construction (Millions \$) ${ }^{b}$ & 263,657 & 295,481 & 414,619 & 466,193 & 225,024 & 122,298 & 151,347 \\
\hline Percent of GDP & $2.56 \%$ & $2.69 \%$ & $3.38 \%$ & $3.36 \%$ & $1.53 \%$ & $0.82 \%$ & $0.93 \%$ \\
\hline Repairs/Improvements (Millions \$) & 116,725 & 133,974 & 159,134 & 183,626 & 170,218 & 159,609 & 159,505 \\
\hline Percent of GDP & $1.13 \%$ & $1.22 \%$ & $1.30 \%$ & $1.33 \%$ & $1.16 \%$ & $1.07 \%$ & $0.98 \%$ \\
\hline New Construction - Owner Occupied (Millions \$) & 238,055 & 266,519 & 376,838 & 418,887 & 192,574 & 109,545 & 132,891 \\
\hline Percent of Total New Construction ${ }^{\mathrm{d}}$ & $90.29 \%$ & $90.20 \%$ & $90.89 \%$ & $89.85 \%$ & $85.58 \%$ & $89.57 \%$ & $87.81 \%$ \\
\hline New Construction - Rental (Millions \$) & 25,602 & 28,962 & 37,781 & 47,306 & 32,450 & 12,753 & 18,456 \\
\hline Percent of Total New Construction $^{\mathrm{d}}$ & $9.71 \%$ & $9.80 \%$ & $9.11 \%$ & $10.15 \%$ & $14.42 \%$ & $10.43 \%$ & $12.19 \%$ \\
\hline Repairs/Improvements - Owner Occupied (Millions \$) & 81,050 & 98,759 & 117,782 & 146,459 & 132,094 & 124,218 & 123,576 \\
\hline Percent of Total Repairs and Improvements ${ }^{\mathrm{d}}$ & $69.44 \%$ & $73.72 \%$ & $74.01 \%$ & $79.76 \%$ & $77.60 \%$ & $77.83 \%$ & $77.47 \%$ \\
\hline Repairs/Improvements - Rental (Millions \$) & 35,675 & 35,215 & 41,352 & 37,167 & 38,124 & 35,391 & 35,929 \\
\hline Percent of Total Repairs and Improvements ${ }^{\mathrm{d}}$ & $30.56 \%$ & $26.28 \%$ & $25.99 \%$ & $20.24 \%$ & $22.40 \%$ & $22.17 \%$ & $22.53 \%$ \\
\hline Gross Domestic Product (Billion \$) ${ }^{\mathrm{e}}$ & 10,290 & 10,980 & 12,277 & 13,858 & 14,720 & 14,958 & 16,245 \\
\hline
\end{tabular}


Table 4: 8,000 Yeas of Zipf's Law in Japan ${ }^{a}$

\begin{tabular}{|c|c|c|c|}
\hline Period (year) & Zipf Coeff & Period (year) & Zipf Coeff \\
\hline-6000 to 300 & $\begin{array}{l}-0.809 \\
(0.217)\end{array}$ & 1600 & $\begin{array}{l}-1.192 \\
(0.068)\end{array}$ \\
\hline-300 to 300 & $\begin{array}{l}-1.028 \\
(0.134)\end{array}$ & 1721 & $\begin{array}{l}-1.582 \\
(0.113)\end{array}$ \\
\hline 725 & $\begin{array}{l}-1.207 \\
(0.133)\end{array}$ & 1798 & $\begin{array}{l}-1.697 \\
(0.120)\end{array}$ \\
\hline 800 & $\begin{array}{l}-1.184 \\
(0.152)\end{array}$ & 1872 & $\begin{array}{l}-1.877 \\
(0.140)\end{array}$ \\
\hline 900 & $\begin{array}{l}-1.230 \\
(0.166)\end{array}$ & 1920 & $\begin{array}{l}-1.476 \\
(0.043)\end{array}$ \\
\hline 1150 & $\begin{array}{l}-1.169 \\
(0.141)\end{array}$ & 1998 & $\begin{array}{l}-0.963 \\
(0.025)\end{array}$ \\
\hline
\end{tabular}


Table 5: Industry Movements Across Metropolitan Areas

\begin{tabular}{lcccc}
\hline Period (year) & Churn $_{c}$ & $\Delta E m p_{c}$ & Churn $_{c} / \Delta E m p_{c}$ & $\Delta$ SecEmp \\
\hline West Germany $^{a}$ & $4.98 \%$ & $2.29 \%$ & 2.17 & $2.62 \%$ \\
USA $^{b}$ & $8.26 \%$ & $4.10 \%$ & 2.01 & $\approx 5 \%$ \\
France $^{b}$ & $11.40 \%$ & $5.20 \%$ & 2.19 & $\approx 5 \%$ \\
\hline
\end{tabular}

${ }^{a}$ Source: Reproduced from Findeisen and Südekum (2008), Table 1, page 329. Values for West Germany were calculated by Findeisen and Südekum. Values for the USA and France were taken from Duranton (2007). 
Table 6: Change in MSA Income Rank Between 1980 and 2010

\begin{tabular}{lcccccc}
\hline & \multicolumn{1}{c}{ MSA Income Measured at Percentile $\ldots$} & MSA \\
& $10^{\text {th }}$ & $25^{\text {th }}$ & $50^{\text {th }}$ & $75^{\text {th }}$ & $90^{\text {th }}$ & Population \\
\hline $10^{\text {th }}$ pctl & -67 & -71 & -69 & -64 & -64 & -28 \\
$25^{\text {th }}$ pctl & -36 & -30 & -32 & -33 & -29 & -10 \\
Mean & 0 & 0 & 0 & 0 & 0 & 0 \\
Median & -3 & -1 & -4 & -5 & -1 & 1 \\
$75^{\text {th }}$ pctl & 34 & 31 & 30 & 25 & 26 & 14 \\
$90^{\text {th }}$ petl & 65 & 69 & 87 & 78 & 67 & 26 \\
\hline${ }^{\text {a }}$ Author calculations based on individual-level data from the 1980 and 2000 U.S. 5-percent Public Use \\
Micro Sample (PUMS) obtained from www.ipums.org. All calculations based on a balanced panel of \\
219 MSAs.
\end{tabular}


FIGURES 1 THROUGH 6 
Figure 1: Census Tract Median Income Relative to its MSA

by Distance (in miles) to the MSA Center (2005-2009 ACS Pooled Sample)
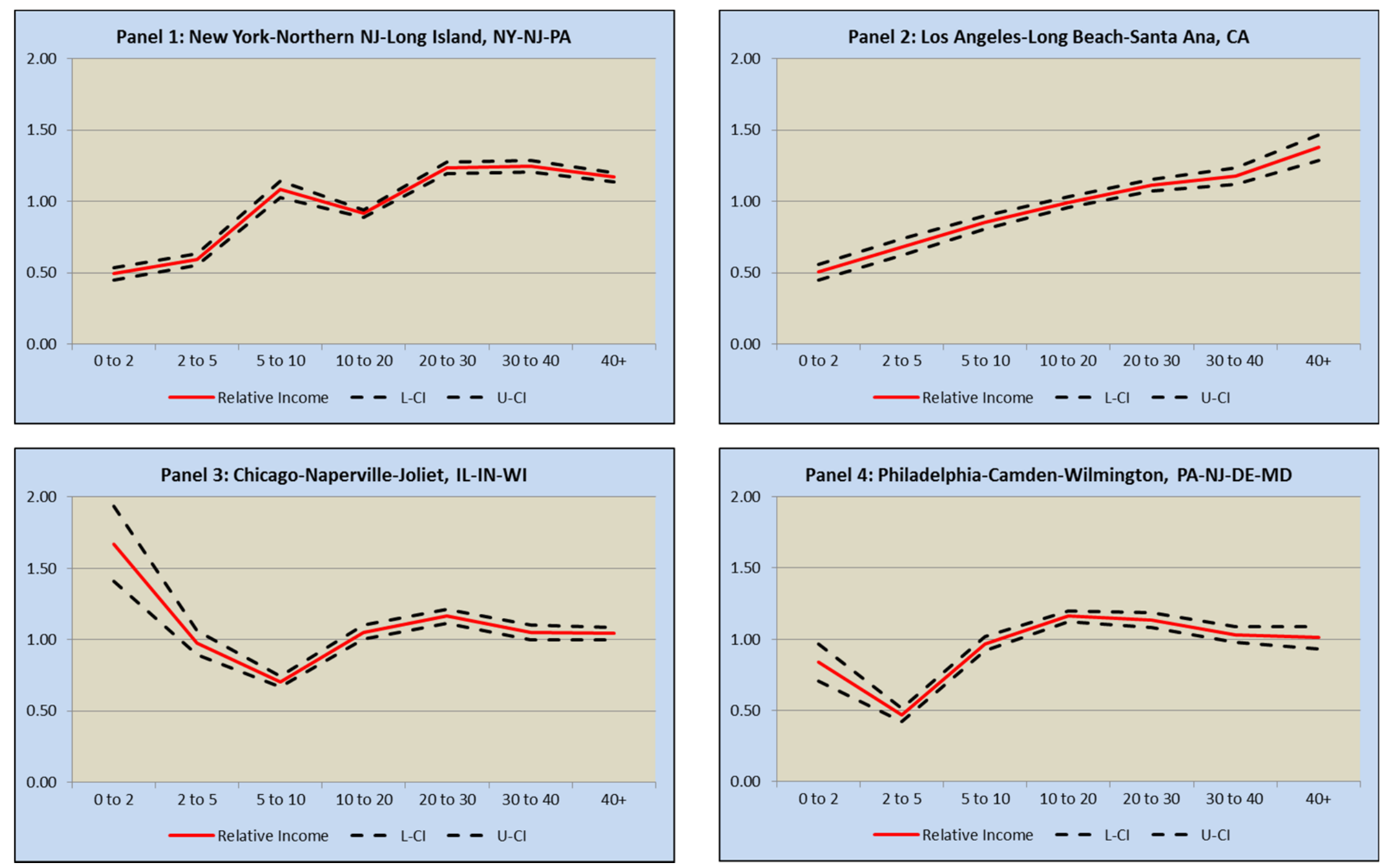
Figure 2: Transition rates of census tract relative income between 1950 and $2000^{a}$

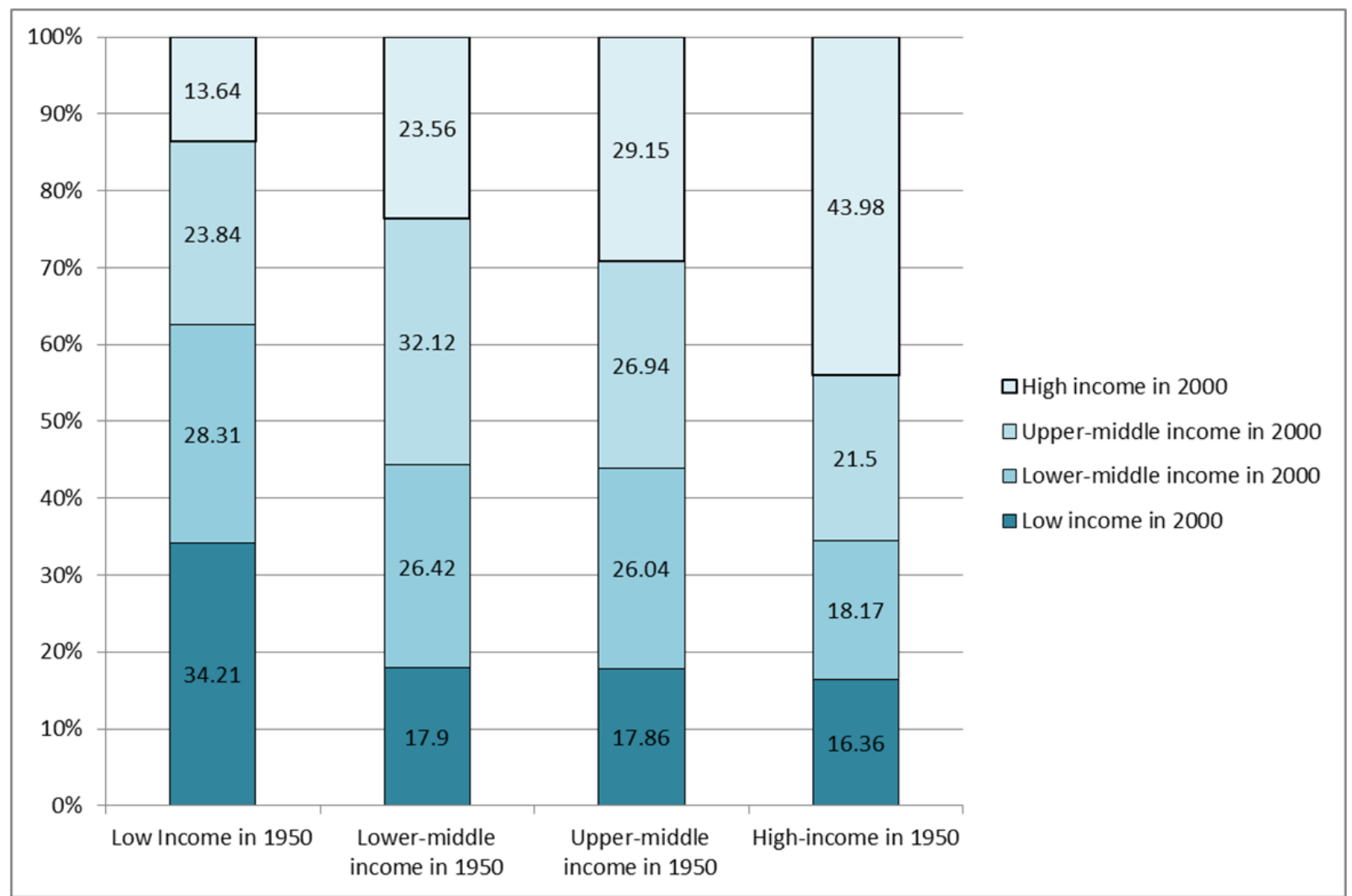

${ }^{a}$ Based on census tracts from 35 cities followed on a consistent geographic basis from 1950 to 2000 . Tract relative income is measured as census tract average income relative to the average income among tracts in the MSA in question and which are contained in the balanced panel.

Source: Rosenthal (2008a), Panel (a) of Table 1, page 2. 
Figure 3: AMM and Income Stratification with $\varepsilon_{h, y}>\varepsilon_{t, y}$

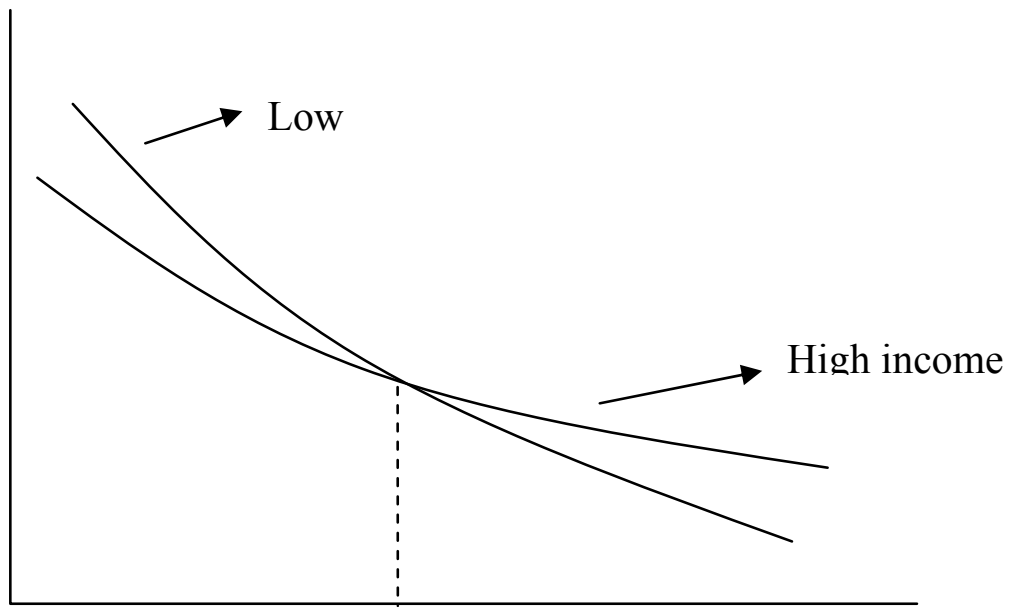

Poor occupy

Rich occupy

central city

suburbs 
Figure 4: Access to Public Transit and Age of the Housing Stock by Distance to the MSA Center (2005-2009 ACS Pooled Sample)
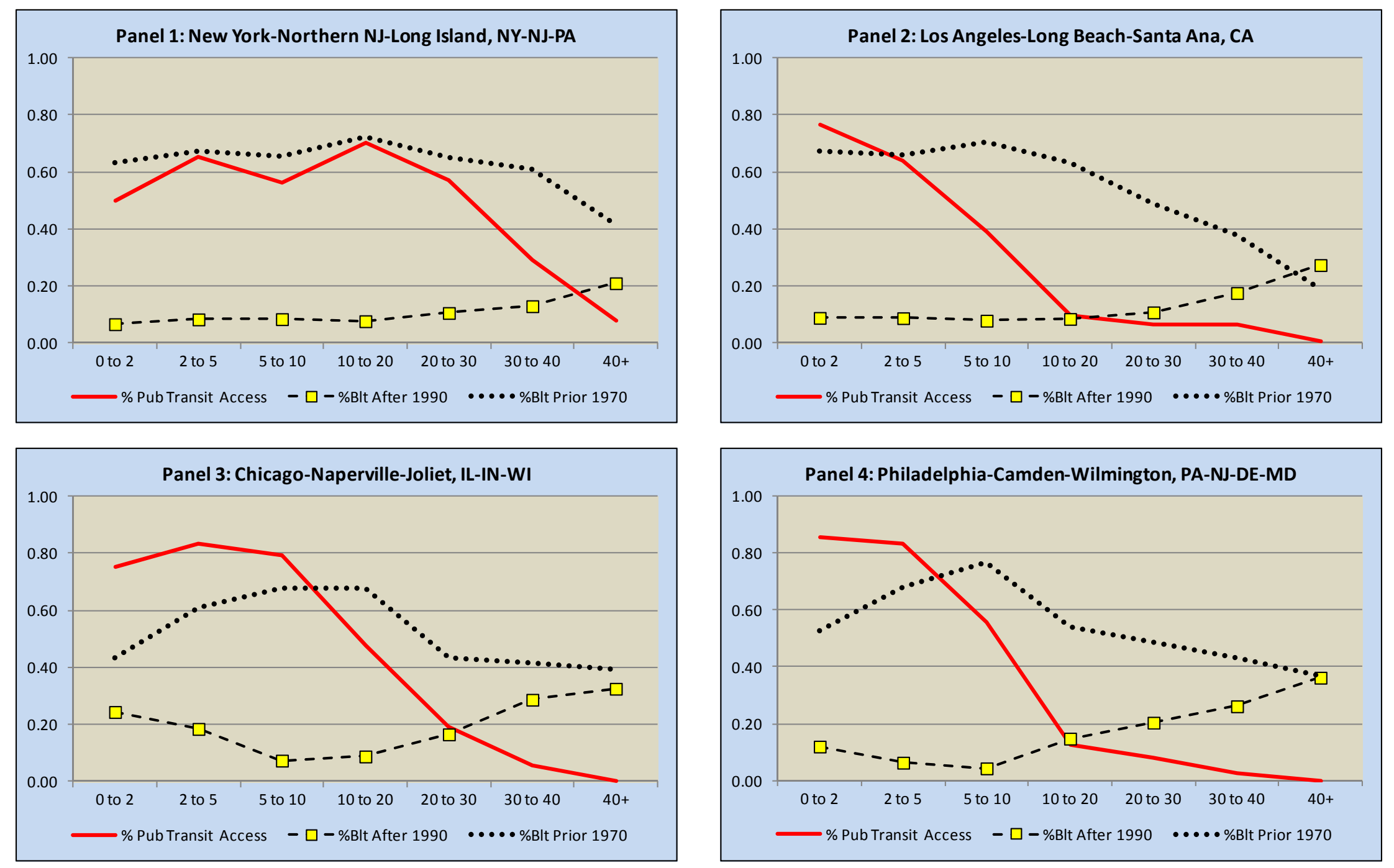
Figure 5: Aging Housing Stock and Income Stratification
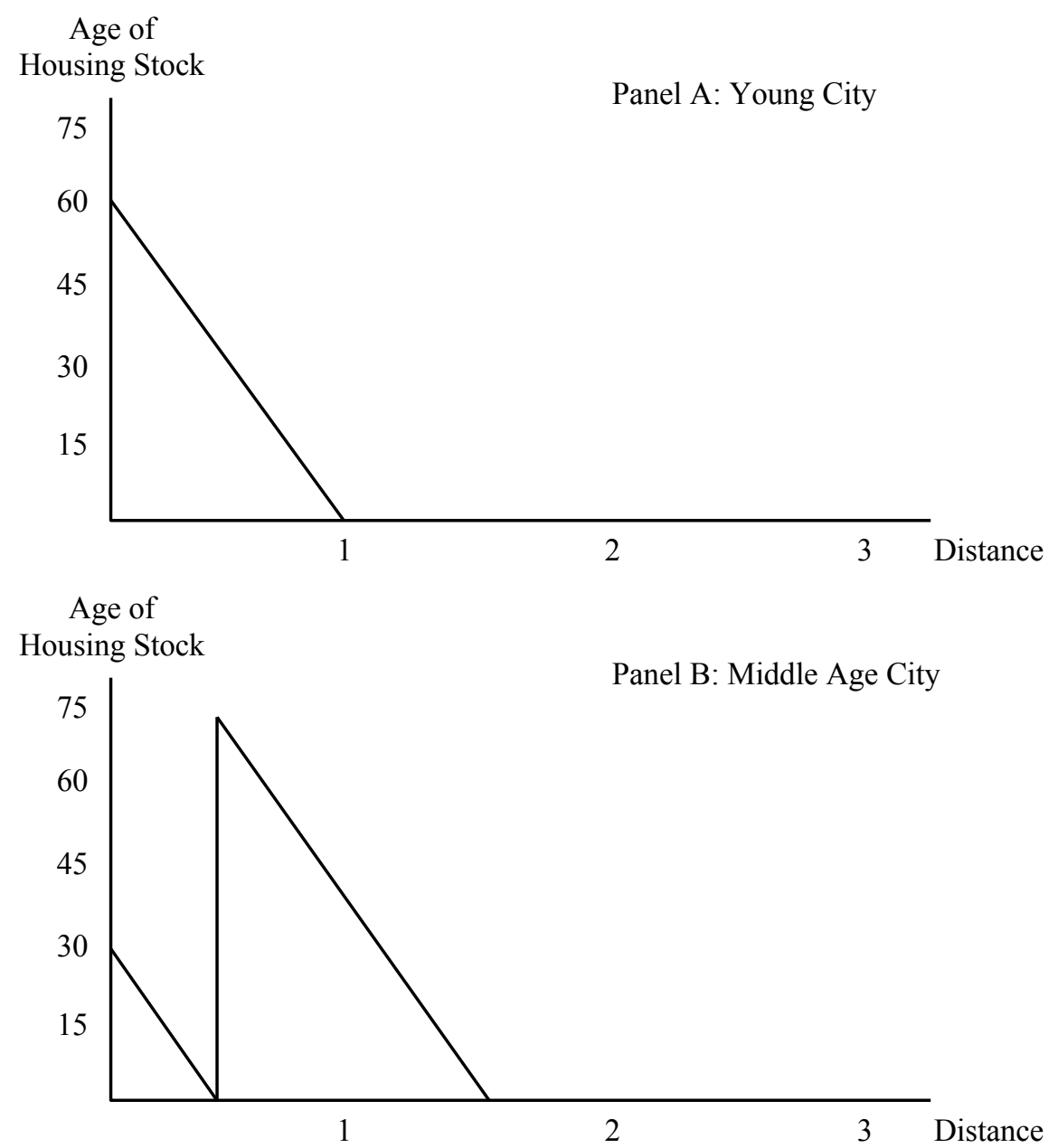

Age of

Housing Stock

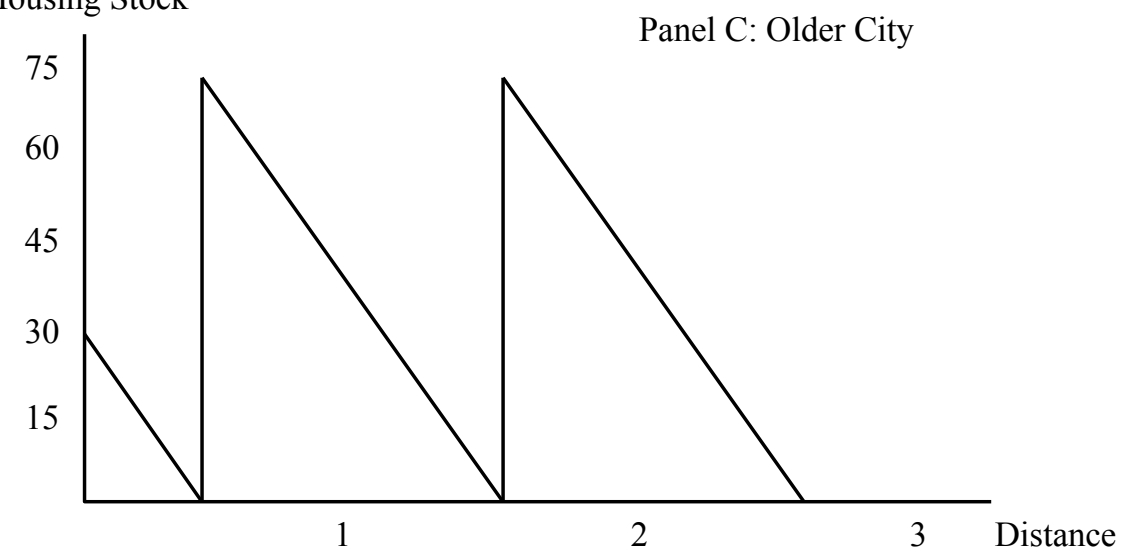


Figure 6: Lorenz Curve Measures of Inequality Across MSAs in Median Income and Populations

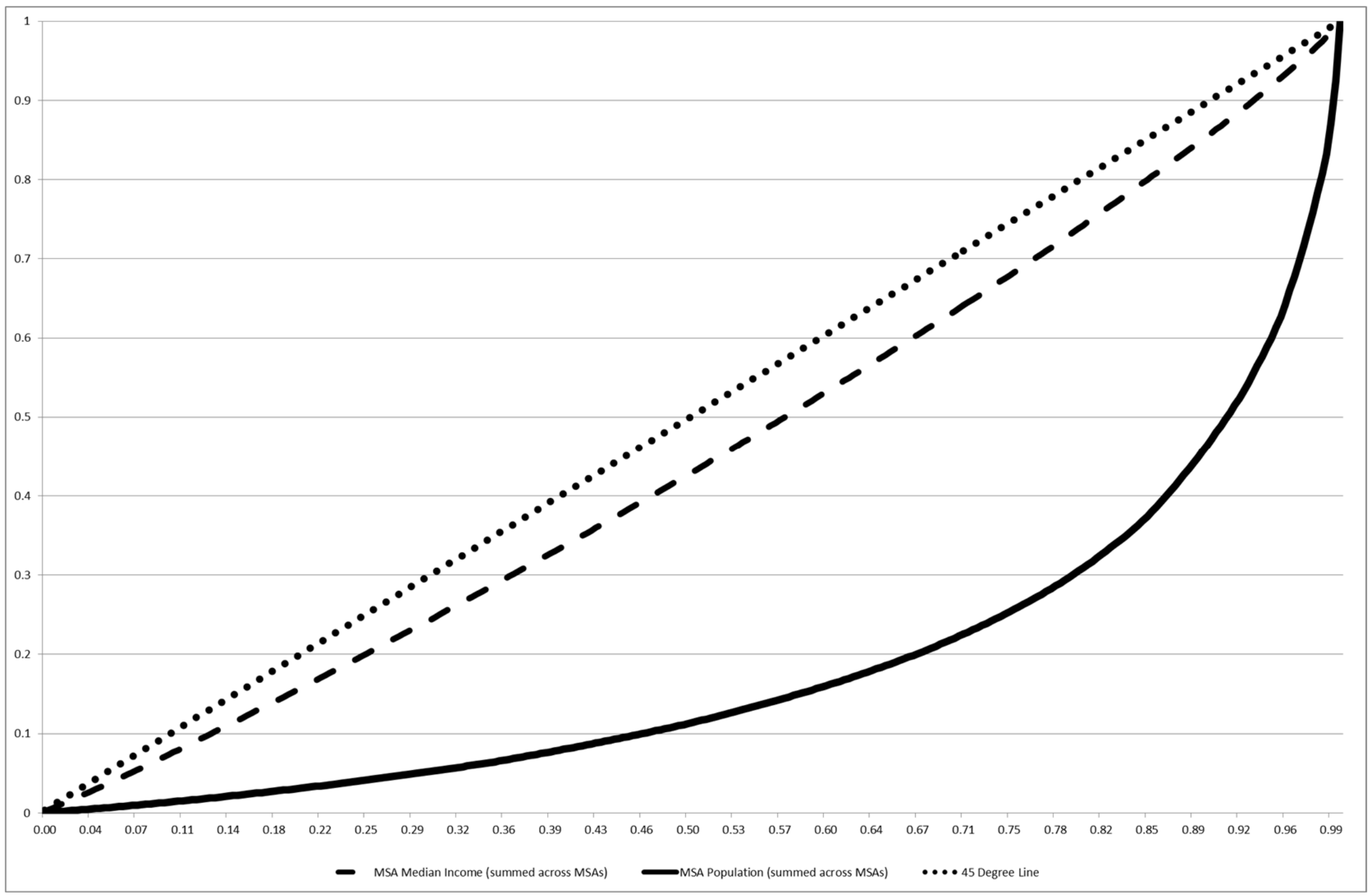

106 
APPENDIX: SUPPLEMENTAL FIGURES 
Figure A-1: Census Tract Income Relative to the MSA by Distance (in miles) to the MSA Center Using the 2005-2009 ACS Pooled Sample
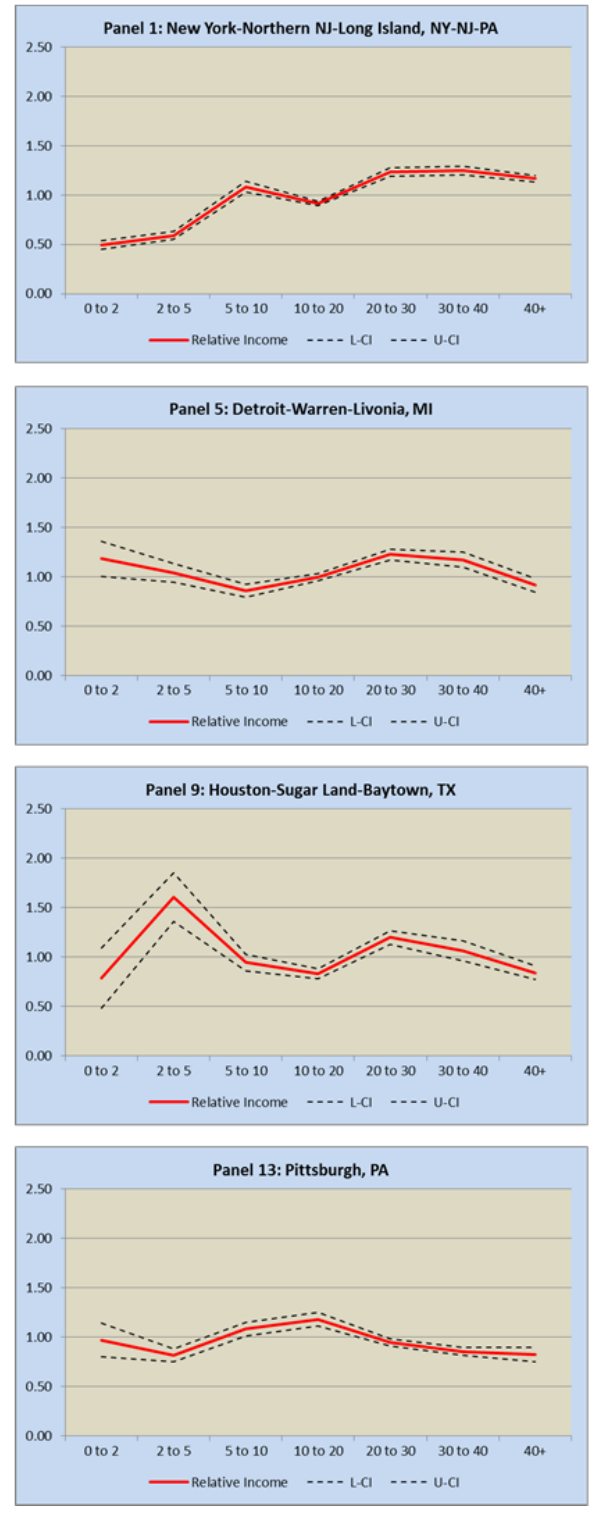
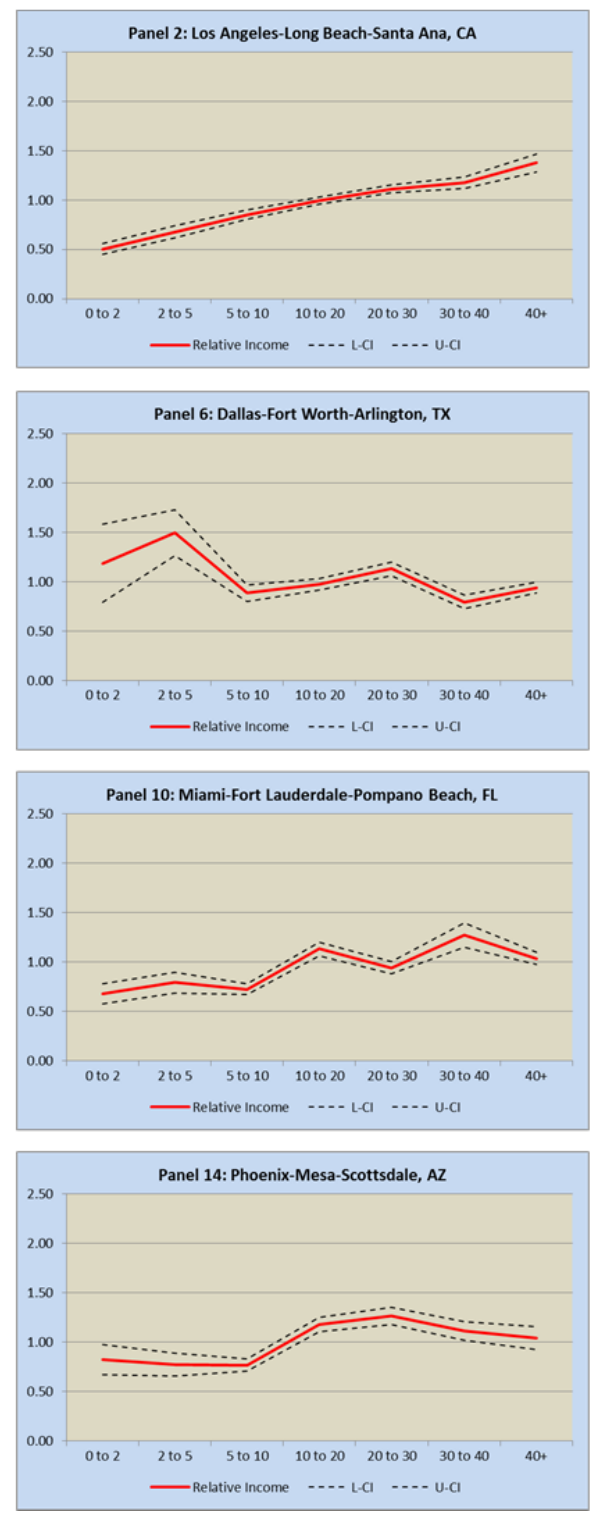
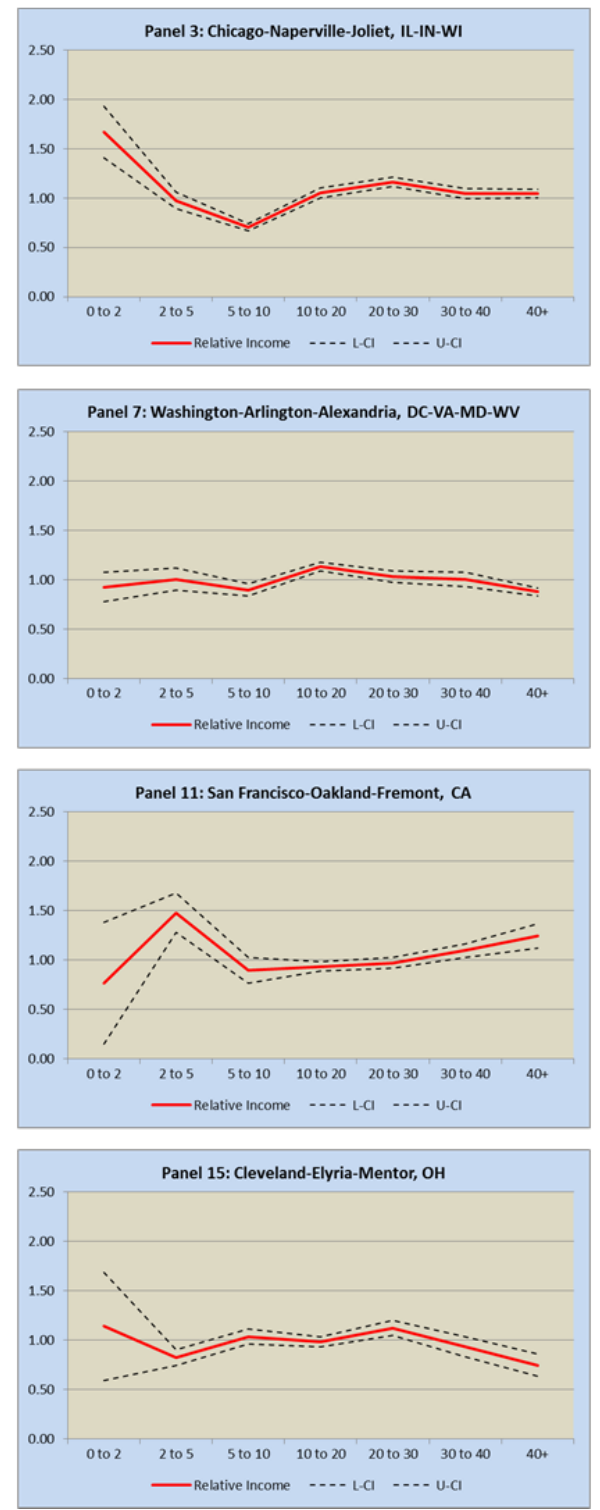
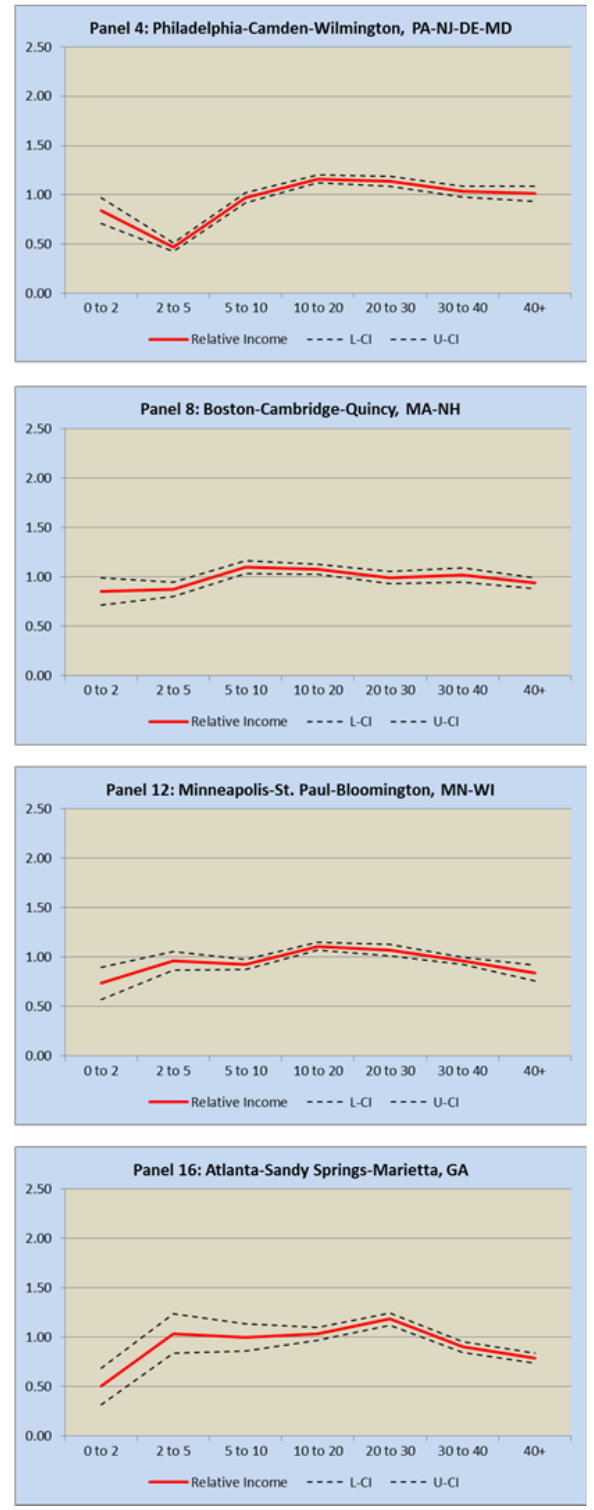
Figure A-1 cont.: Census Tract Income Relative to the MSA by Distance (in miles) to the MSA Center Using the 2005-2009 ACS Pooled Sample
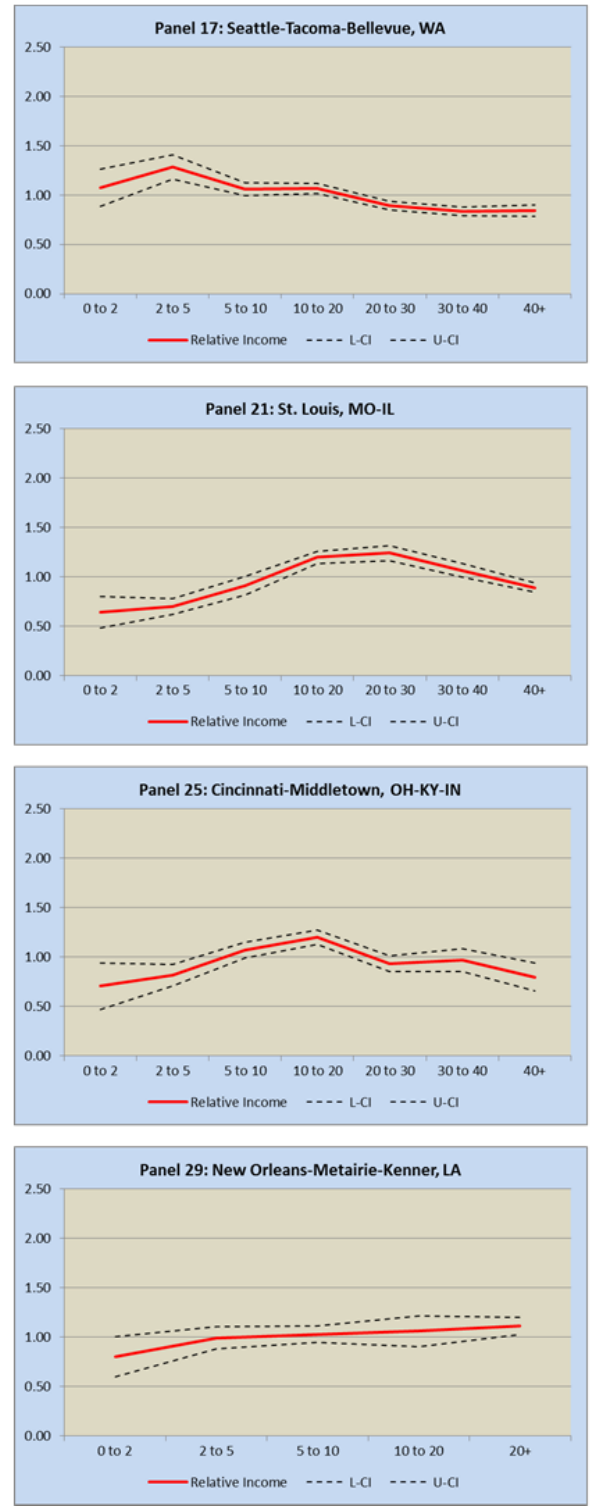
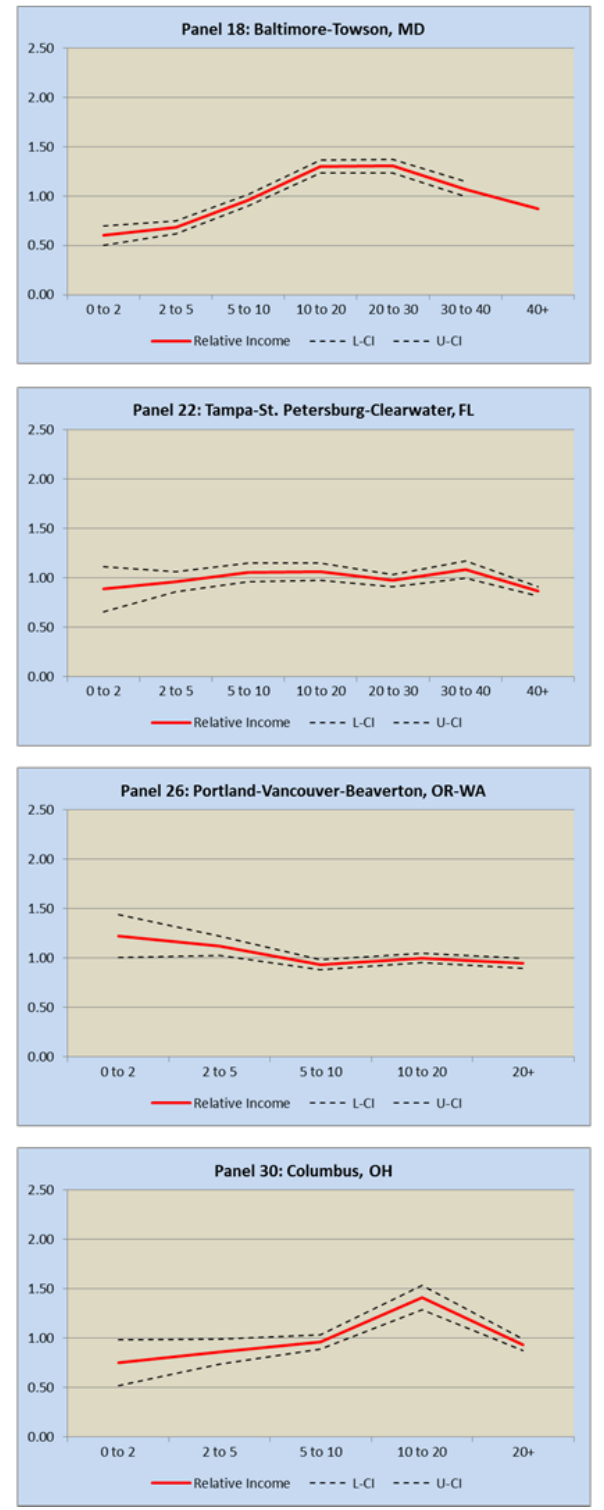
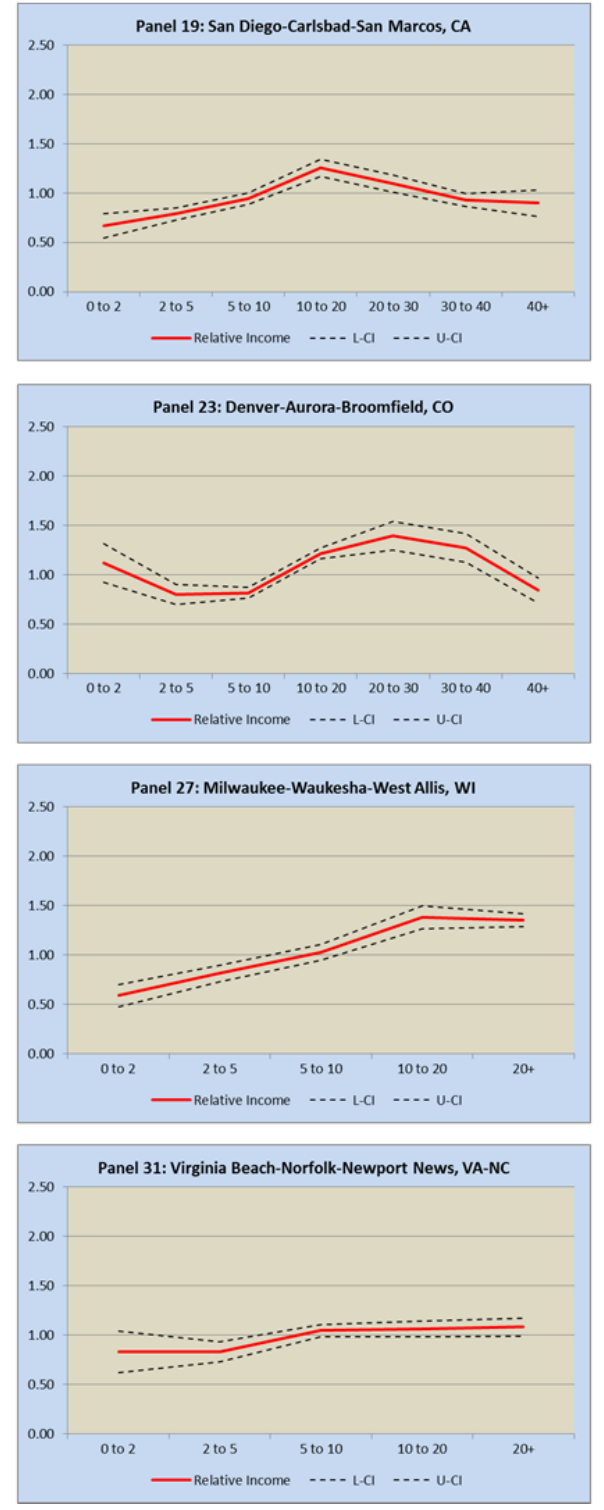
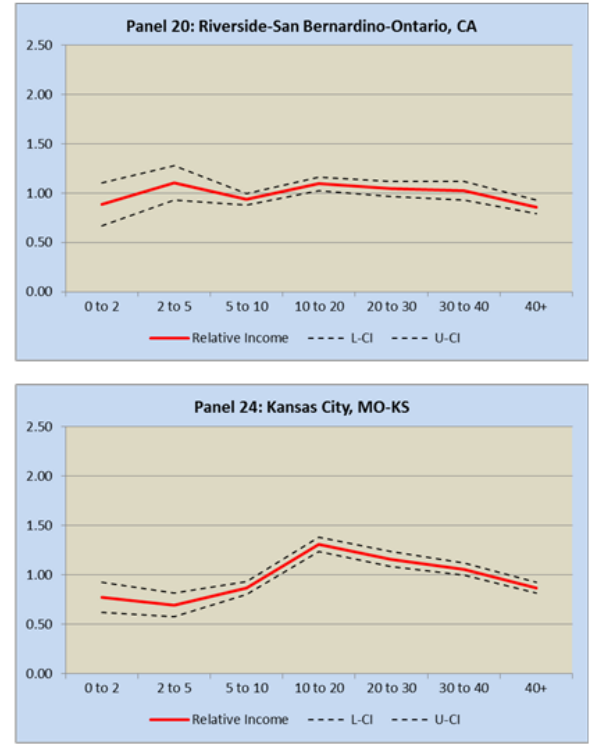

Panel 28: Sacramento-Arden-Arcade--Roseville, CA

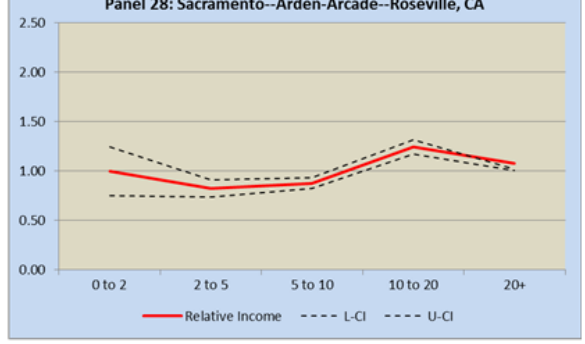

Panel 32: Providence-New Bedford-Fall River, R1-MA

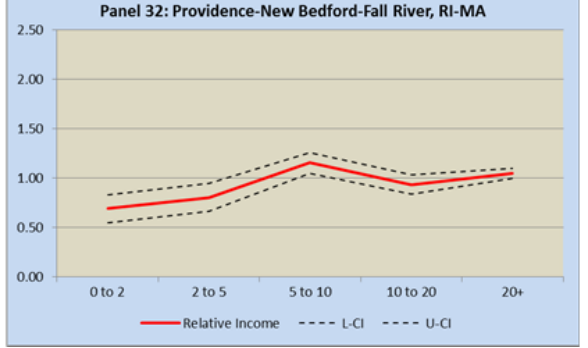


Figure A-1 cont.: Census Tract Income Relative to the MSA by Distance (in miles) to the MSA Center Using the 2005-2009 ACS Pooled Sample
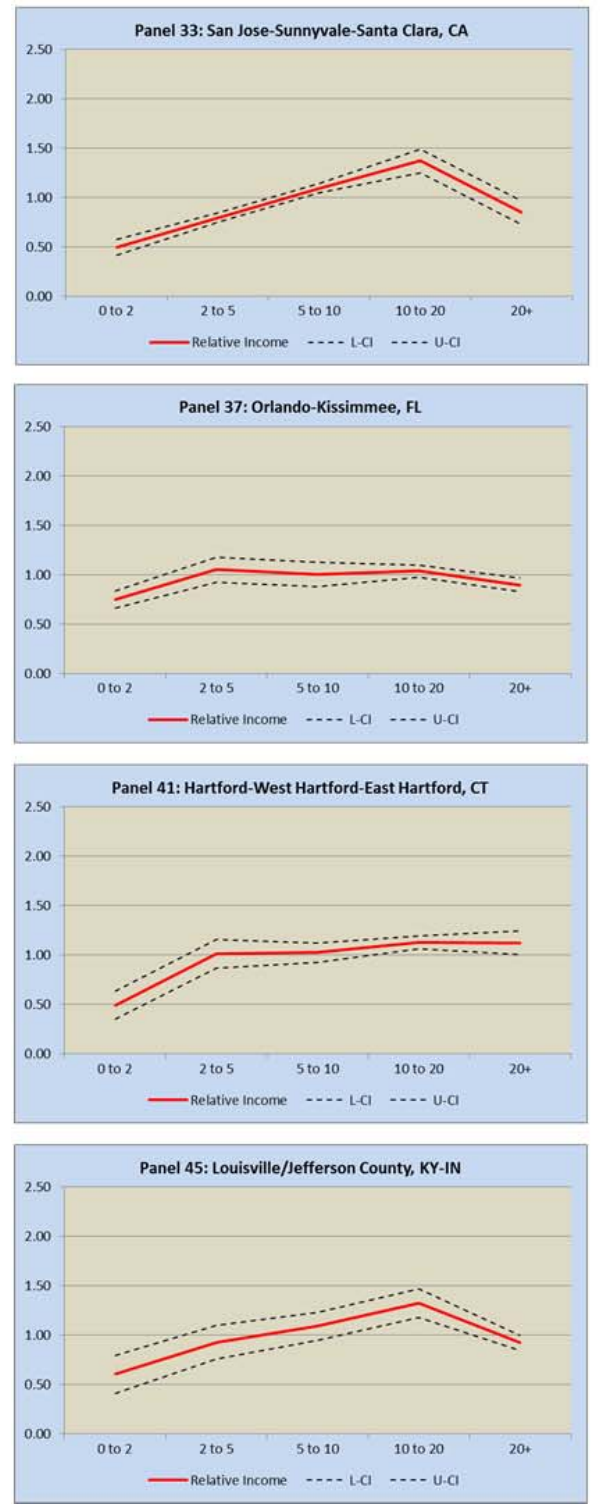
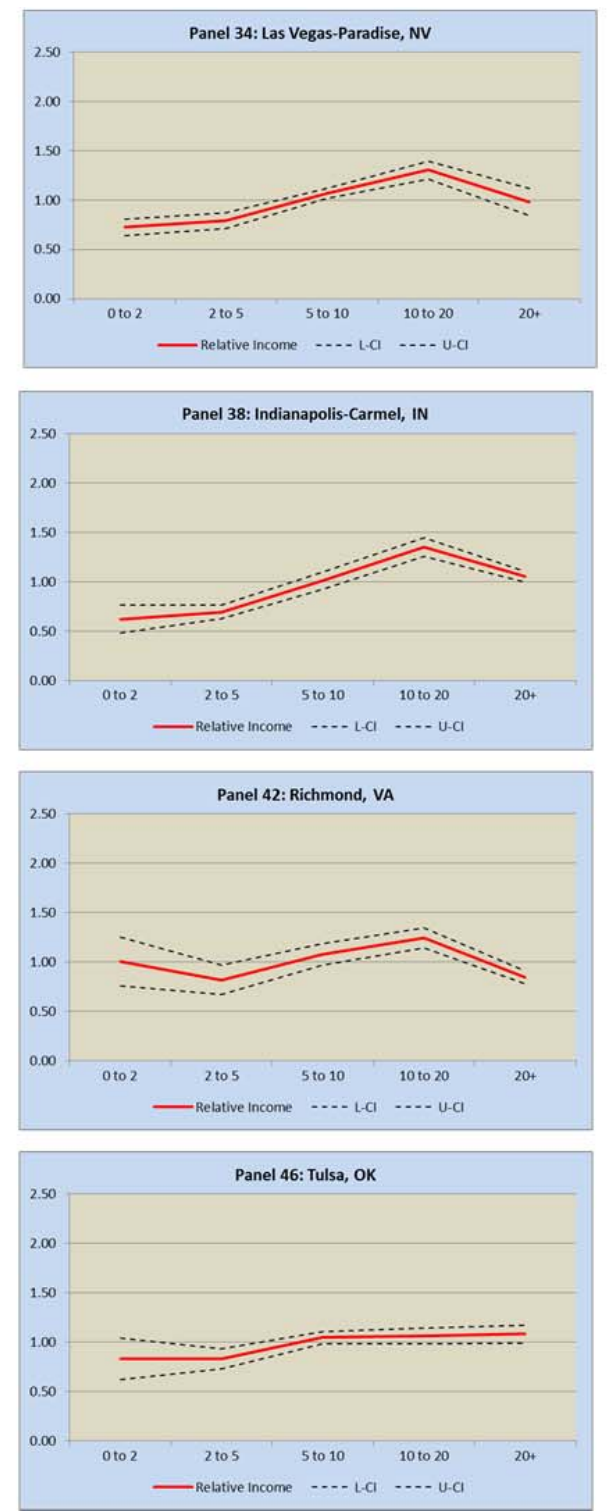
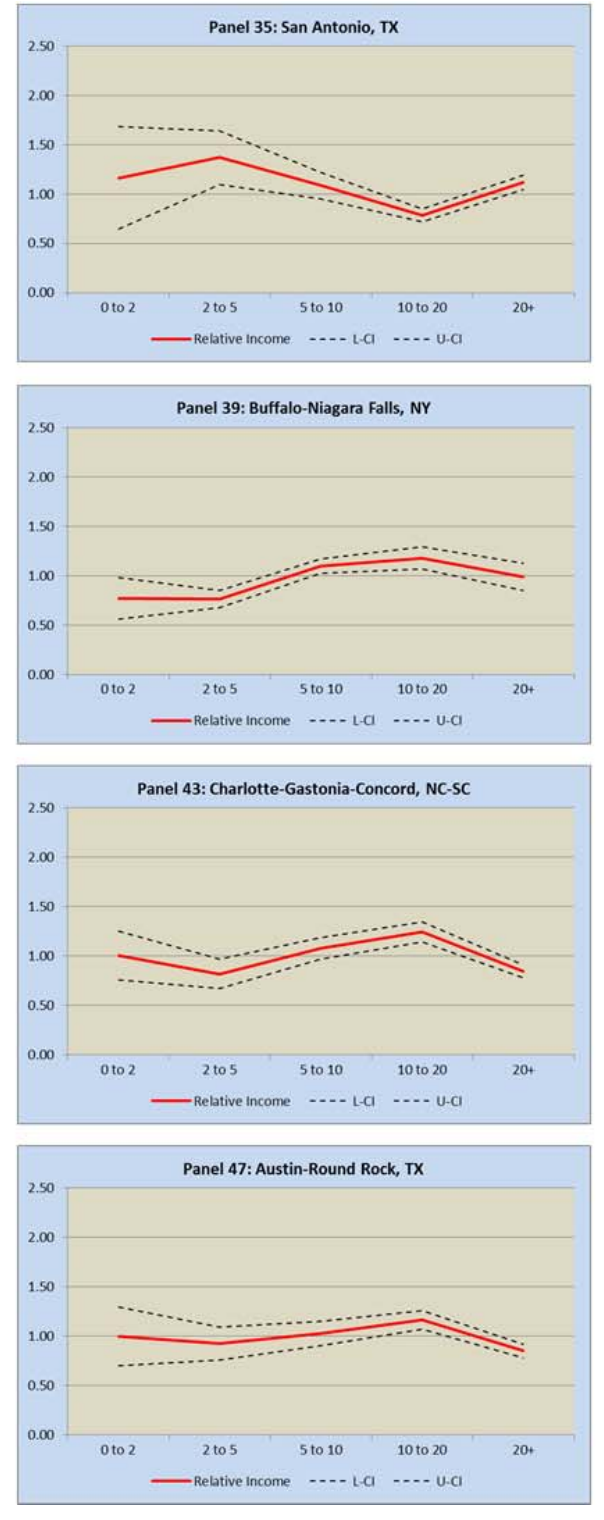
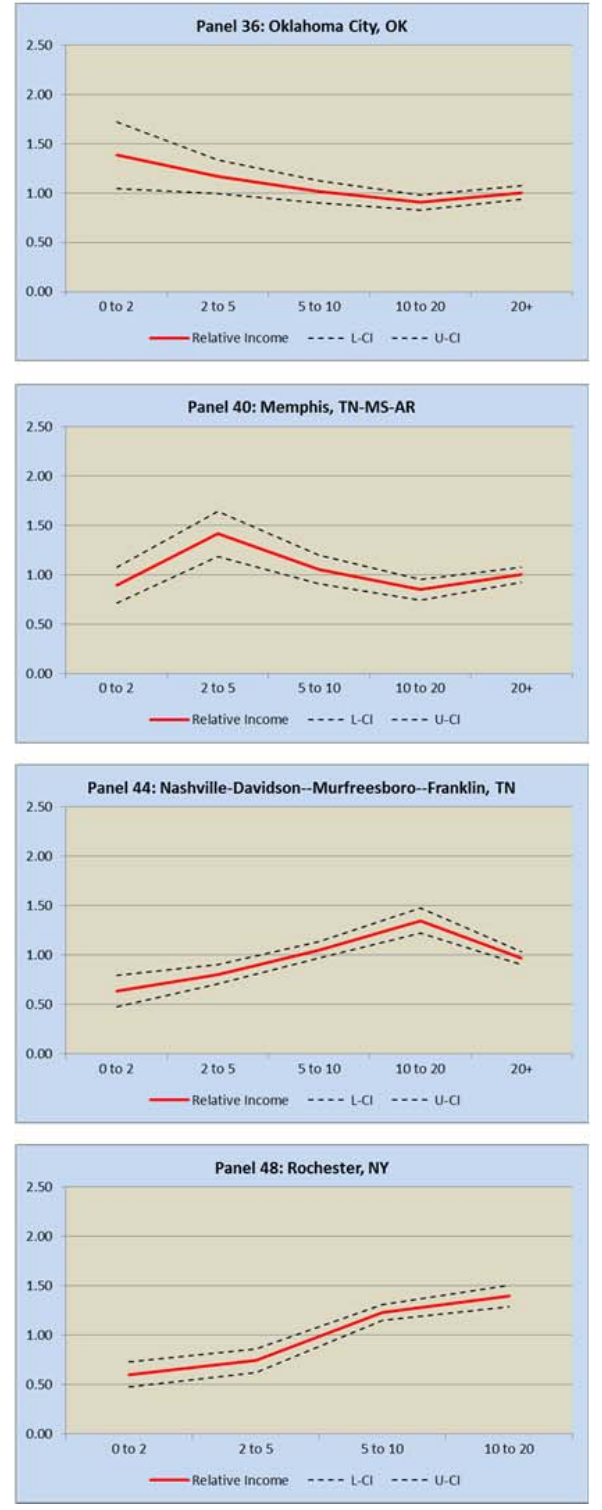
Figure A-2: Convenient Access to Public Transit for Work Trips and Age of Housing Stock by Census Tract Distance (in miles) to the MSA Center Using the 2005-2009 ACS Pooled Sample
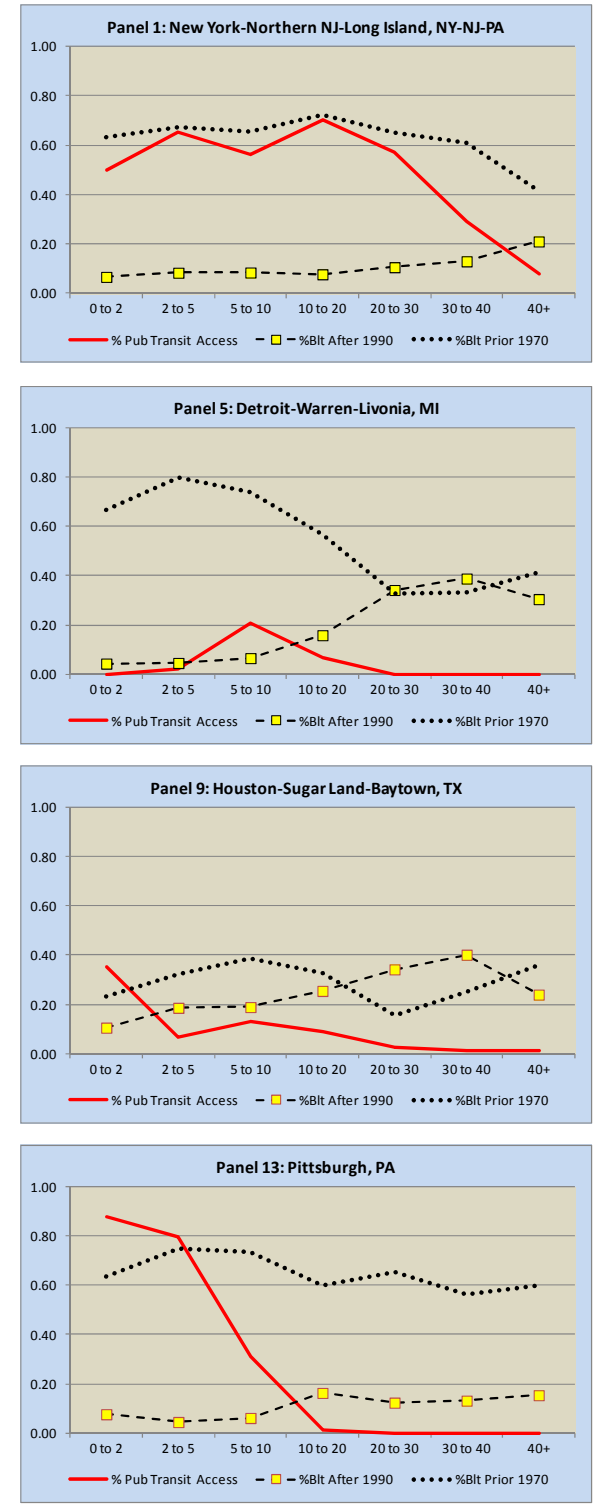
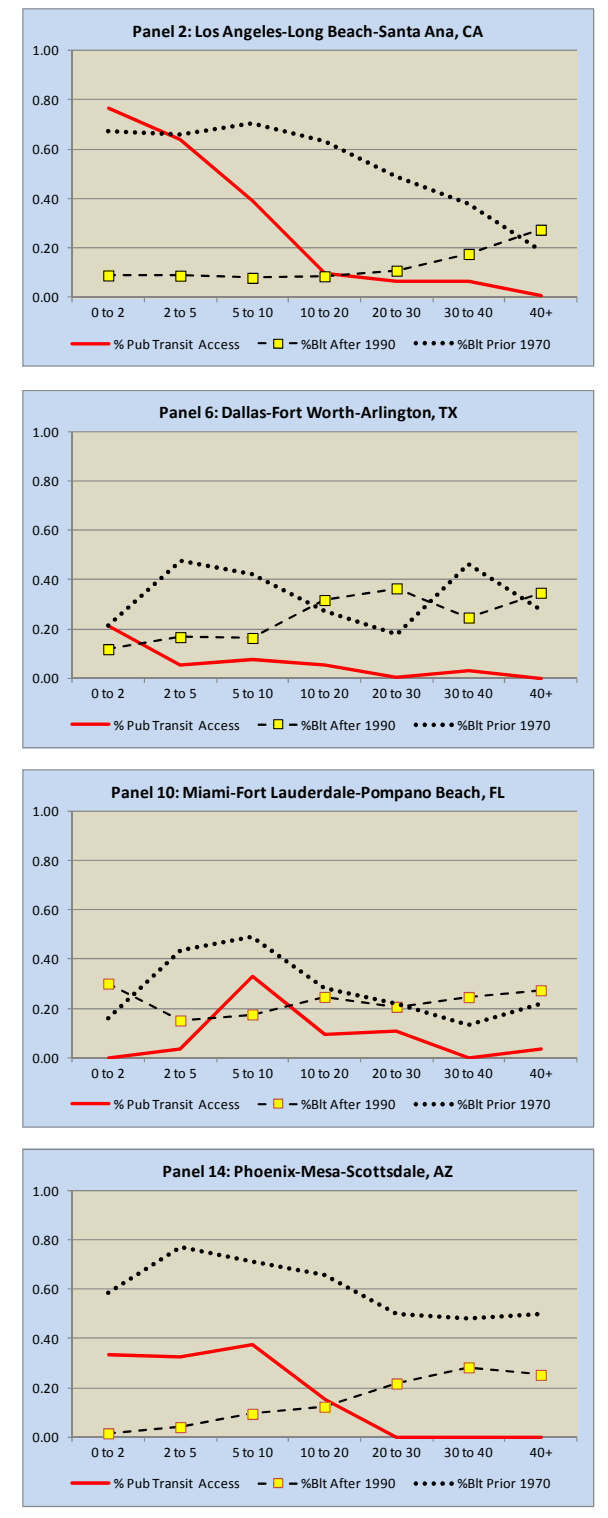
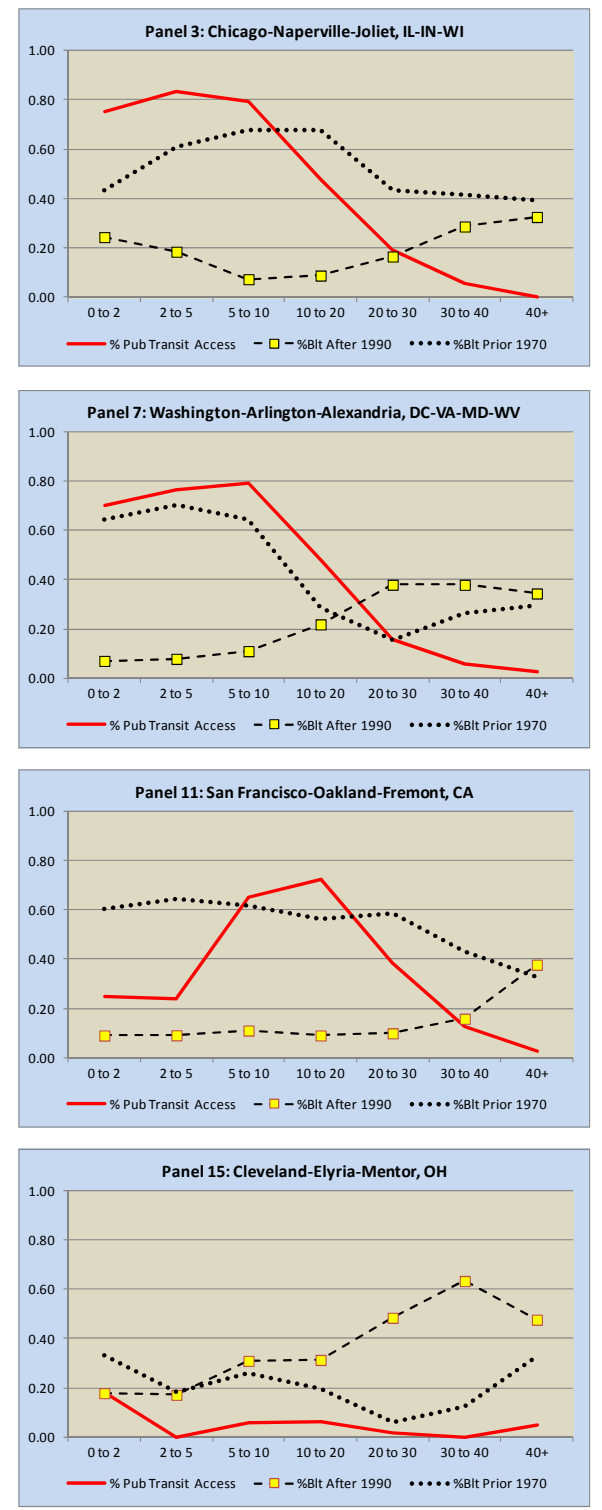
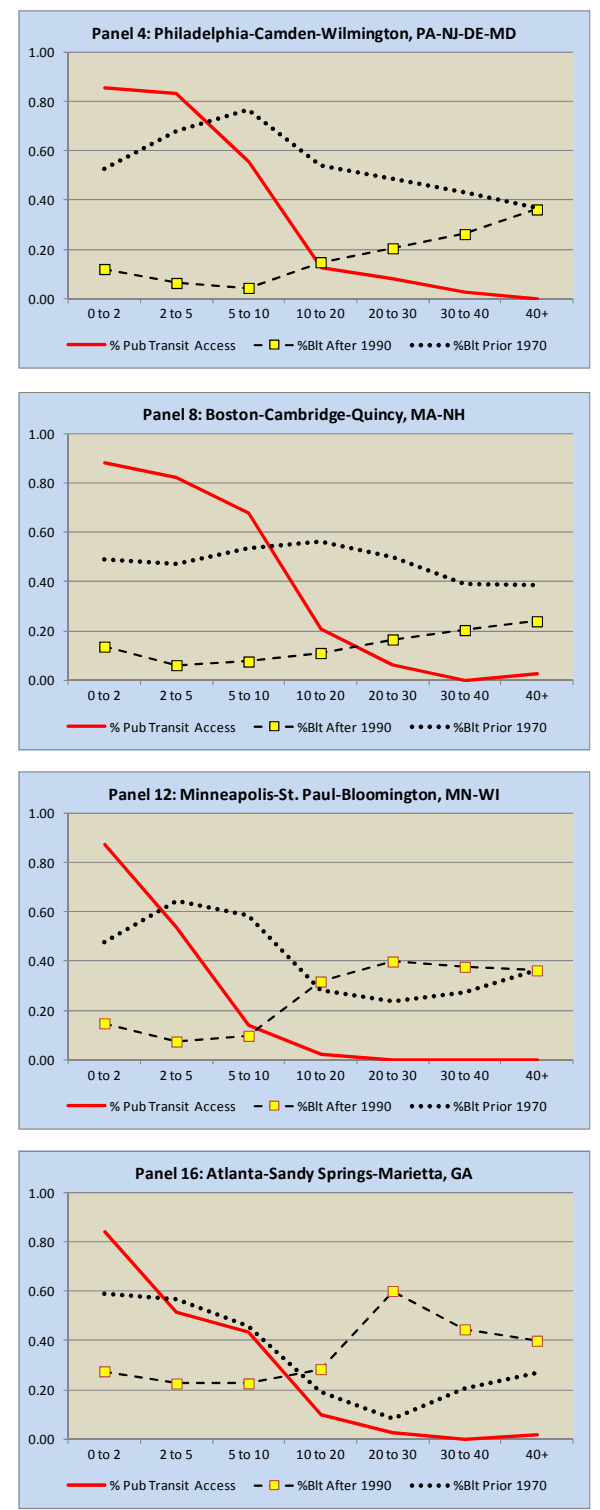
Figure A-2 cont.: Convenient Access to Public Transit for Work Trips and Age of Housing Stock by Census Tract Distance (in miles) to the MSA Center Using the 2005-2009 ACS Pooled Sample
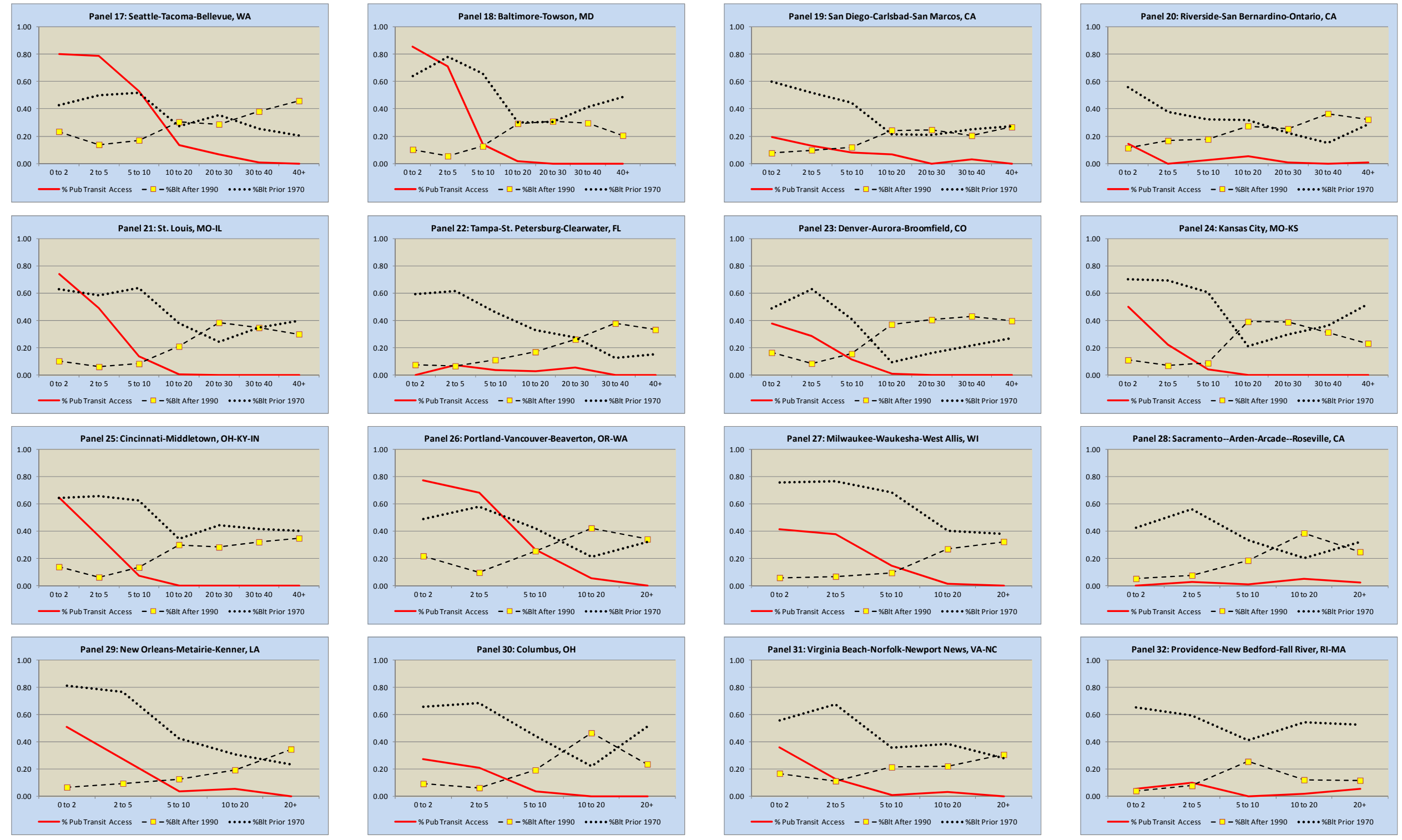
Figure A-2 cont.: Convenient Access to Public Transit for Work Trips and Age of Housing Stock by Census Tract Distance (in miles) to the MSA Center Using the 2005-2009 ACS Pooled Sample
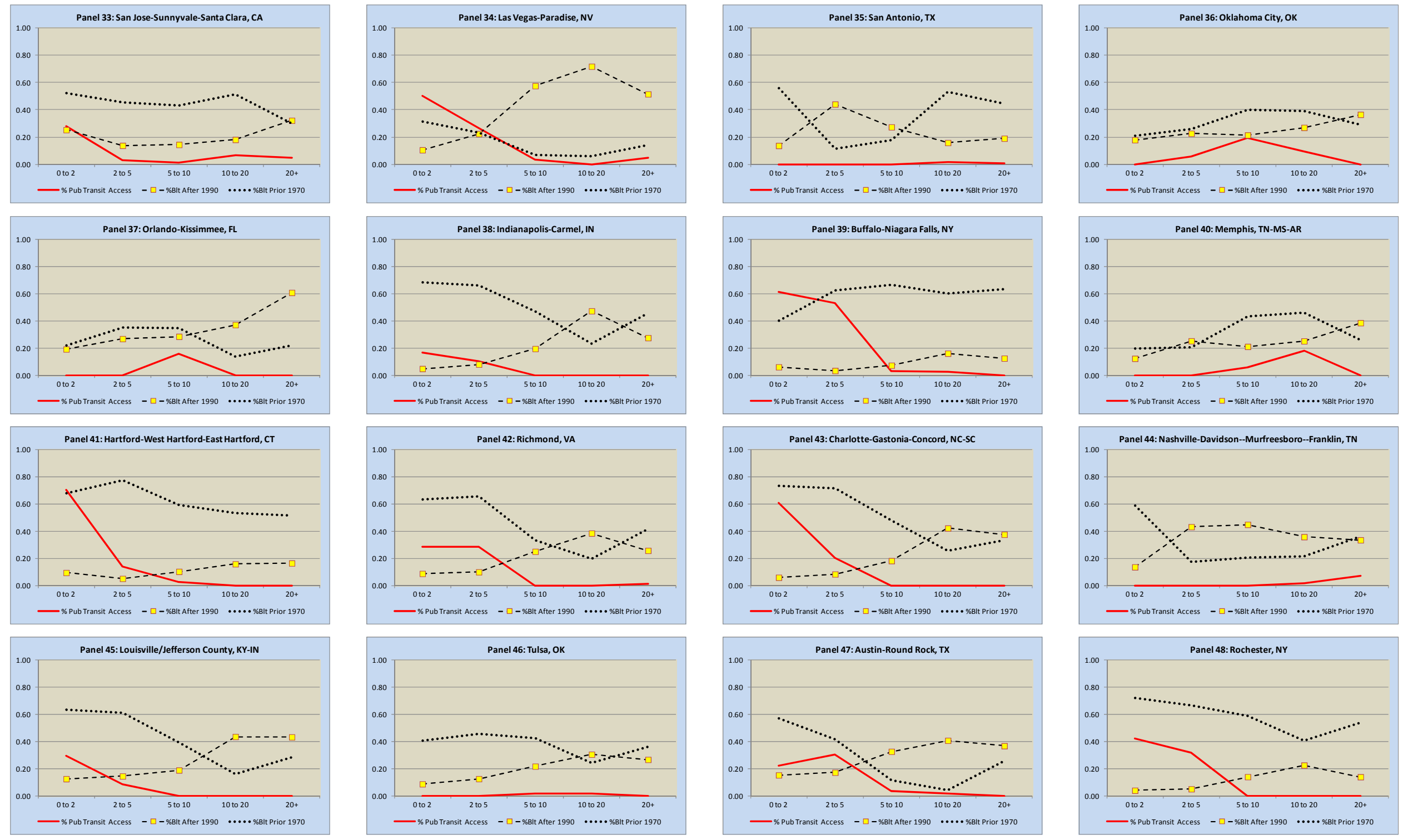